\title{
Economic Modeling of Electricity Production From Hot Dry Rock Geothermal Reservoirs: Methodology and Analyses
}

\author{
EA-630 \\ Research Project 1017 \\ LASL (LA-7888-HDR)
}

Final Report, September 1979

Prepared by

THE UNIVERSITY OF NEW MEXICO

Economics Department 191

1915 Roma, N.E.

Albuquerque, New Mexico 87131

Principal Investigators

Ronald G. Cummings, University of New Mexico

Glenn E. Morris, Los Alamos Scientific Laboratory

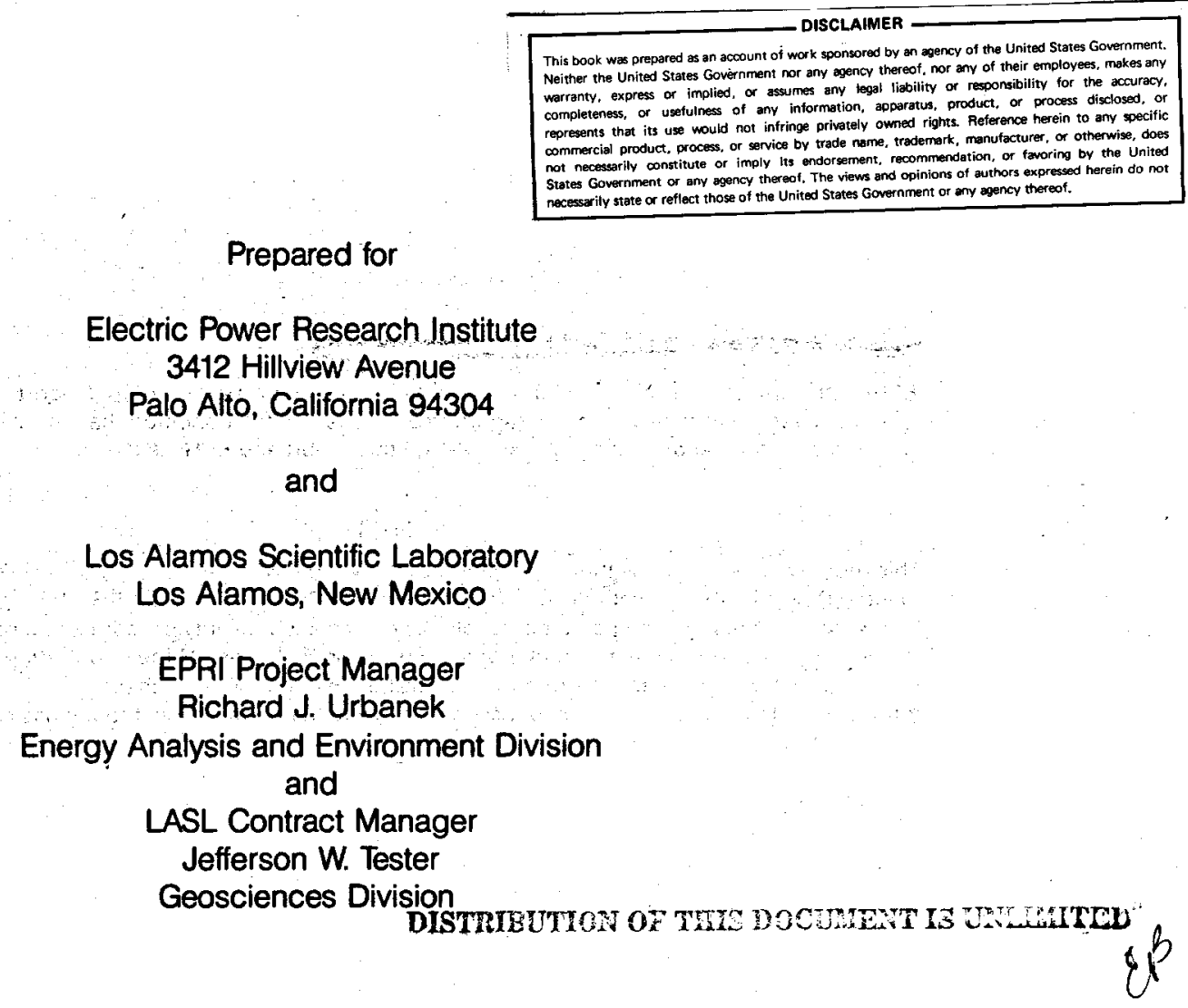




\section{DISCLAIMER}

This report was prepared as an account of work sponsored by an agency of the United States Government. Neither the United States Government nor any agency Thereof, nor any of their employees, makes any warranty, express or implied, or assumes any legal liability or responsibility for the accuracy, completeness, or usefulness of any information, apparatus, product, or process disclosed, or represents that its use would not infringe privately owned rights. Reference herein to any specific commercial product, process, or service by trade name, trademark, manufacturer, or otherwise does not necessarily constitute or imply its endorsement, recommendation, or favoring by the United States Government or any agency thereof. The views and opinions of authors expressed herein do not necessarily state or reflect those of the United States Government or any agency thereof. 


\section{DISCLAIMER}

Portions of this document may be illegible in electronic image products. Images are produced from the best available original document. 


\section{ORDERING INFORMATION}

Requests for copies of this report should be directed to Research Reports Center (RRC), Box 50490, Palo Alto, CA 94303, (415) 961-9043. There is no charge for reports requested by EPRI member utilities and affiliates, contributing nonmembers, U.S. utility associations, U.S. government agencies (federal, state, and local), media, and foreign organizations with which EPRI has an information exchange agreement. On request, RRC will send a catalog of EPRI reports.

\section{for Por}

EPRI authorizes the reproduction and distribution of all or any portion of this report and the preparation of any derivative work based on this report. in each case on the condition that any such reproduction. distribution. and preparation shall acknowledge this report and EPRI as the source.

\section{NOTICE}

This report was prepared by the organization(s) named below as an account of work sponsored by the Electric Power Research Institute. Inc (EPRI). Neither EPRI. members of EPRI. the organization(s) named below, nor any person acting on their behalf: (a) makes any warranty or representation. express or implied. with respect to the accuracy. completeness. or usefulness of the information contained in this report. or that the use of any information. apparatus, method. or process disclosed in this report may not infringe privately owned rights: or (b) assumes any liabilities with respect to the use of. or for damages resulting from the use of. any information, apparatus. method. or process disclosed in this report.

Prepared by

University of New Mexico

Albuquerque, New Mexico 
An analytical methodology is developed for assessing alternative modes of generating electricity from hot dry rock (HDR) geothermal energy sources. The methodology is used in sensitivity analyses to explore relative system economics. The methodology departs from more conventional approaches for evaluating geothermal electric energy systems because of the complexities introduced by the many critical, operatorcontrolled variables in the system. For example, drilling activities and reservoir fluid production rates are interdependent in their effect on system performance and are subject to management choices initially and over time.

The methodology used a computerized, intertemporal optimization model to determine the profit-maximizing design and management of a unified HDR electric power plant with a given set of geologic, engineering, and financial conditions. By iterating this model on price, a levelized busbar. cost of electricity is established. By varying the conditions of development, the sensitivity of both optimal management and busbar cost to these conditions are explored.

A plausible set of reference case parameters is established at the outset of the sensitivity analyses. This reference case links a multiple-fracture reservoir system to an organic, binary-fluid conversion cycle. A levelized busbar cost of $43.2 \mathrm{mills} / \mathrm{kWh}$ ( $\$ 1978$ ) was determined for the reference case, which had an assumed geothermal gradient of $40^{\circ} \mathrm{C} / \mathrm{km}$, a design well-flow rate of $75 \mathrm{~kg} / \mathrm{s}$, an effective heat transfer area per pair of wells of $1.7 \times 10^{6} \mathrm{~m}^{2}$, and a plant design temperature of $160^{\circ} \mathrm{C}$. Variations in the presumed geothermal gradient, size of the reservoir, drilling costs, real rates of return, and other system parameters yield minimum busbar costs between $-40 \%$ and $+76 \%$ of the reference case busbar cost. 

EPRI AND LASL PERSPECTIVE

\section{PROJECT DESCRIPTION}

This final report concludes a study of economic and technical relationships that will be important determinants of the commercial feasibility of producing electricity from hot dry rock (HDR) geothermal resources. Some portions were funded by EPRI and other portions were funded by the Los Alamos Scientific Laboratory (LASL).

Since HDR reservoirs are manmade, there is much greater flexibility in their development and management than with natural reservoirs. This fact also introduces complexity into attempts to model the process. For example, reservoir temperature and fluid production rate can be specified by design; consequently conversion plant design and cost must be determined conjunctively with optimum reservoir design and management strategies. These strategies also involve time-staging decisions.

This project was initiated to develop an analytic model with the capability of dealing with the above complexities while exploring the various economic and technical issues and tradeoffs inherent in alternative approaches to: (1) designing the HDR reservoir, (2) managing the time path of heat extraction from it, and (3) designing the conversion process to produce electricity. Since HDR technical feasibility has yet to be proven, the project is best regarded as an attempt to improve analytic techniques for long-range assessments and research planning.

\section{PROJECT OBJECTIVE}

The objective of the project was to develop and explore the use of a physicaleconomic model that could be used to optimize HDR investment and management strategies for alternative sets of geologic, economic, and engineering parameters.

\section{CONCLUSIONS AND RECOMMENDATIONS}

The contractor has developed a dynamic optimization model and used it to simulate the operation of an HDR electricity plant and reservoir under widely varying input 
assumptions. The analytic model has successfully highlighted economic trade-offs in different design and management strategies for the HDR reservoir and electric generation systems.

The model differs markedly in approach from previous geothermal analyses. The primary differences involve several key items related to reservoir and surface conversion plant design and operation that are treated as variables in this study. In previous studies of natural hydrothermal systems, these characteristics are usually specified or restricted by preexisting site conditions. There are, therefore, some departures in this work from the EPRI Technical Assessment Guide and from conventional electric utility "revenue requirements" methodology for economic comparison of generation alternatives.

Although the analyses are conducted in constant 1978 dollars, the real (inflationfree) rates of return assumed were in most cases higher than would be possible for a regulated utility. Attention of the reader is drawn to this conservative bias.

Results from using this model may be criticized on the grounds that they represent optimizations around large unknowns. Many questions concerning the dimensions of technical feasibility of HDR still remain. On the other hand, the issues raised in the analyses point out the desirability of interdisciplinary research as a vehicle for guiding hardware research into directions that will be most productive economically. The model as developed provides a powerful tool for analyzing drilling and management strategies in a consistent and systematic way. It undoubtediy will aid in HDR investment decisions when a viable data base is established.

The results of this study do not relate directly to current utility planning problems but may be of interest to those involved in longer-range research and technology assessments. In addition, the work may set an important precedent for increasing the efficiency of research and development by illustrating the role that an interdisciplinary approach may play at an early stage of technology development.

Richard J. Urbanek, Project Manager

Milton F. Searl, Program Manager

Energy Analysis and Environment Division

Jefferson W. Tester

Geosciences Division

Los Alamos Scientific Laboratory 


\section{CONTENTS}

Section

Page

1 INTRODUCTION AND OVERVIEW

2 TECHNICAL AND ECONOMIC ISSUES RELEVANT FOR THE EXPLOITATION OF HDR RESERVOIRS

2-1

The HDR Facility

$2-1$

Geothermal Gradients

Well-Flow Rates, Reservoir Surface Area, and Reservoir Lifetime

Surface Area of the Reservoir

$2-5$

The Well-Flow Rate

The Electric Generating Plant

Well Depths and Drilling Costs for HDR Reservoirs

Methodological Issues

3-1

Justification for an Optimization Approach

$3-1$

Taxes and Discounting

$3-4$

Time Horizons

$3-8$

Surface Plant costs

3-8

other Prices and Costs

$3-10$

The Optimization Model

3-10

Calculation of Period Revenues

3-11

Other Components of the Model

$3-12$

Use of the Model to Generate Busbar costs

3-14

Reservoir-Economic Parameters: A Sumary

3-15

Plan for Analyses and Major Caveats Relevant for the Analyses

4 ANALYSIS OF THE REFERENCE CASE

4-1

Optimal Management Characterizations

4-1

Analys is of Trade-offs in the Reference Case Solution

4-5 
5 ANALYSIS OF THE OPTIMAL PLANT DESIGN TEMPERATURE

Optimal Plant Design Temperature for the Reference Case

Optimal Plant Design Temperatures for Different Gradients

6 ANALYSIS OF RESOURCE, RESERVOIR, AND PLANT ENGINEERING PARAMETERS

$6-1$

Variation in the Geothermal Gradient

6-1

Variations in Capacity Factor

$6-2$

Varying Reservoir System Performance

$6-3$

Varying the Reservoir System Flow Rate

6-6

Simultaneous Variation in $\dot{m}_{d}$ and Reservoir Performance

6-6

7 ANALYSIS OF ECONOMIC PARAMETERS

$7-1$

Variations in Drilling Costs

$7-1$

The Effect of Variations in Plant Capacity and O\&M

Costs on $\mathrm{p}^{\star}$

$7-2$

Variations in Real Rates of Return

$7-4$

Changing the Production Lifetime of the Facility

$7-5$

8 SUMMARY AND CONCLUSIONS

8-1

Method for Evaluating the Use of HDR Technology for Electricity Production

8-1

Summary of Sensitivity Analyses

$8-3$

Potential for Commercial Feasibility

8-5

Interdiscipl inary Research

$8-6$

9 REFERENCES

$9-1$

APPENDIX A DESCRIPTION OF ASSUMED RESERVOIR PERFORMANCE

A-1

APPENDIX B METHODOLOGY FOR CALCULATING TEMPERATURE DRAWDOWN

B-1

APPENDIX C DEFINITION OF TERMS

C-1 


\section{ILLUSTRATIONS}

Figure

$\underline{\text { Page }}$

S-1 Summary of results from parametric analyses of an HDR S-7 electricity-generating system.

1-1 Schematic representation of an HDR electric generating facility. 1-2

2-1 Prel iminary geothermal gradient map showing three ranges of gradients.

2-2 Single- and multiple-fracture concepts applicable to low-permeability formations.

2-3 Schematic representation of triangular grid system for well siting.

3-1 Power decline as a function of the fractional fluid temperature drop from the design temperature $T_{d}$.

3-2 Design-flow rate requirements $\dot{M}_{d}$ per $M N(e)$ as a function of fluid temperature for different working fluids.

4-1 The present value of net benefits for various electricity busbar prices in the reference case.

4-2 Time path of reservoir temperatures for optimal management of the reference case.

4-3 Present value of net benefits with variation in the design well-flow rates.

4-4 Marginal well costs and marginal revenues associated with drilling in the first decision period of the reference case.

5-1 Present value of net benefits for alternative plant design temperatures in the reference case. $\nabla T=40^{\circ} \mathrm{C} / \mathrm{km}$ and $\dot{m}_{d}=75 \mathrm{~kg} / \mathrm{s}$.

5-2. Optimal drilling strategies for alternative plant design temperatures.

5-3 Marginal costs associated with varying the plant design temperature. Marginal plant costs were constant for all design temperatures at $-\$ 145,000 / \mathrm{m}$. 
5-4 Determination of the optimal plant design temperature in the reference case.

5-5 Time path of drilling and redrilling activities for varying geothermal gradients with optimal plant design tempertures used. 5-6

5-6 Optimal drilling strategies as a function of the number of fractures per reservoir with optimal plant design temperatures used.

6-1 Drilling strategies for variation of the geothermal gradient in the reference case.

6-2 Parametric power drawdown curves for a single fracture of radius $R$ with no thermal-stress cracking (2) .

6-3 Optimal drilling strategies for variations in the number of fractures in the reference case.

6-4 Optimal periodic well-flow rates with variations in the number of fractures for the reference case.

6-5 Optimal drilling strategies for variations in the design well-flow rate in the reference case.

7-1 Optimal drilling strategies for variations in the drilling cost algorithm in the reference case.

7-2 Optimal drilling strategies for variations in the real discount rates in the reference case.

7-3 Drilling strategies for different facility lifetimes.

A-1 Single- and multiple-fracture concepts applicable to low permeability formations. Symmetrical views of hydraulic fracture half-planes are shown.

A-2 Schematic representation of a conceptual Hot Dry Rock system in low-permeability rock.

A-3 Flow contours simulated by the McFarland-Murphy model (31) of heat transfer in an idealized plane circular crack of $500-\mathrm{m}$ radius and elliptical cross section. Streamlines shown contain $\sim 10 \%$ of the total $144 \mathrm{~kg} / \mathrm{s}$ flow. An initial mean rock temperature of $250^{\circ} \mathrm{C}$ was used with a gradient of $50^{\circ} \mathrm{C} / \mathrm{km}$. (a) With buoyancy affects suppressed. (b) With buoyancy affects active.

A-4 Parametric power drawdown curves for a single fracture of radius $R$ with no themal-stress cracking. 


\section{TABLES}

Table

S-1 Parameter Values for the Reference Case

2-1 Estimated Drilling Costs

3-1 Preoperational Costs

3-2 Sumary of Reservoir and Economic Parameters

3-3 Parameter Values and Assumptions for the Reference Case

3-4 Planned Parametric Analyses

4-1 Present Value of the Components of Surface Capital Costs: Reference Case

4-2 The Time Path of Drilling Costs in the Reference Case

4-3 Periodic Values for Average Annual Power Output and Revenues

4-4 Drilling Costs for Various Drilling Depths in the First Decision Period of the Reference Case

4-5 Revenues for Various Drilling Depths in the First Decision Period of the Reference Case

5-1 Optimal Design Temperatures Associated With Alternative Values for $\nabla T$

$5-5$

6-1 Percentage Changes in $p^{*}$ Associated With Alternative Values for $\nabla T$

6-2 Percentage Changes in $\mathrm{p}^{*}$ as the Capacity Factor Varies From $85 \%$

6-3 Percentage Changes in $p^{*}=43.2 \mathrm{mill} / \mathrm{k}$ Wh With Alternative Numbers of Fractures

6-4 Percentage Changes in $\mathrm{p}^{*}$ With Alternative Design Well-Flow Rates

6-5 Percentage Changes in $\mathrm{p}^{*}$ for Alternative Combinations of $m_{d}$ and Number of Fractures 
7-1 Percentage Changes in $\mathrm{p}^{*}$ Associated With Alternative Drilling Costs

7-2 Percentage Changes in $\mathrm{p}^{*}$ Associated With Variations in Plant Capacity

7-3 Percentage Change in $\mathrm{p}^{\star}$ With Alternative Values for $r$ and $i$

$7-5$

7-4 The Effect of Planning Horizon Variations on $p^{*}$

$7-7$

8-1 Summary of Sensitivity Analyses $\quad 8-4$

8-2 Sensitivity Analyses for Reservoir Performance 8-5

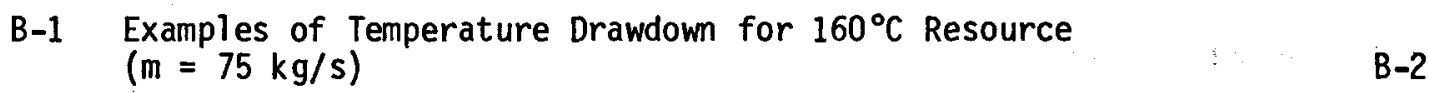




\section{SUMMARY}

This work develops and uses an analytical methodology for assessing alternative methods for generating electricity from hot dry rock (HDR) geothermal energy sources. The study had two major goals. The first was to develop a methodology for systematically examining economic tradeoffs from different HDR investment and management strategies. The second was to apply this methodology to analyze the sensitivity of HDR system economics to changes in key system parameters.

The study's first goal was achieved by building an intertemporal optimization model based on a dynamic programming algorithm. The traditional minimum revenue requirements method for comparing electric generation alternatives was not applied because capital costs and the time staging of capital outlays cannot be chosen a priori for HDR systems. The determination of the least cost drilling strategy for $H D R$ reservoirs and the power plant design require an analytical framework which is intertemporal in design.

The madel developed in this study treats as explicit variables well-flow rates for the HDR reservoirs, periodic drilling/redrilling activities, and reservoir temperatures. Key parameters in the model, which are subjected to sensitivity analyses, include design temperatures and installed capacity for the HDR power plant, the geothermal temperature gradient, the effective surface area of HDR reservoirs (based on the multiple fracture concept), maximum well-flow rates for each pair of wells, and drilling costs. Given values for these parameters, intertemporal strategies for drilling and reservoir management are chosen which maximize the present value of profits net of all taxes. Parametric techniques are used to determine the resulting busbar cost (in 1978 dollars) for each set of values for these parameters.

Since HDR technology is in its infancy, many of its physical and engineering characteristics and behavior had to be hypothesized for purposes of this study. A major assumption underlying the use of the model for sensitivity analyses was 
that a proven technology exists having the characteristics as posited. This has major implications for the sensitivity analyses. Any sensitivity analysis is both mode1 dependent and data base dependent.

\section{THE METHODOLOGY}

The study's first goal is achieved by an intertemporal optimization model. The logic of this model is one wherein at the beginning of each decision period the plant manager chooses: (a) whether or not to drill or redrill to create or restimulate an HDR reservoir, (b) the terminal depth of such drilling activity, and (c) well-flow or reservoir production rates. The criterion guiding these decisions is to maximize the present value of system profits, net of taxes. These decisions are based on beginning-of-period values for reservoir temperatures and established drilling depths.

The two basic interrelated components of the model are, first, the power plant and, second, the system of HDR reservoirs. These components are characterized as follows.

The plant consists of a binary fluid Rankine-cycle power system. For a given plant design temperature and installed capacity, power output in each period is determined by the capacity factor and two performance parameters: the difference between fracture reservoir temperature at the beginning of the period and plant design temperature; and the ratio of the actual reservoir production flow rate to the design rate.

Plant capital costs are also determined by design temperature and installed capacity. These costs, along with site-acquisition costs and explorationdevelopment costs, are staged over a nine-year construction period with cumulative interest charges included.

Gross periodic revenue for the plant is determined by applying a constant busbar selling price of electricity to actual power output. Periodic costs include operation and maintenance costs, a revenue $\operatorname{tax}(2.5 \%$ of gross revenues), property taxes, and any drilling costs for HDR reservoirs incurred during the period. Plant construction and setup costs (roughly one-half of total capital costs) are financed by bonds whose real rate of return on investment is varied between $3 \%$ and $12 \%$. The drilling and subsurface reservoir costs and the surface fluidgathering system (roughly one-half of total capital costs) are financed by a mix 
of preferred and common stock for which the average real rate of return on investment is varied between $6 \%$ and $21 \%$. Fifty-one percent of the present value of profits is charged to federal/state income taxes. Finally, the useful lifetime of the plant is varied between 20 and 50 years.

An HDR reservoir is modeled as a system of parallel multiple fractures that are connected to the surface by a pair of inclined boreholes. For this study, each fracture has an assumed radius of 300 meters, and the number of fractures, which determines the effective surface area of hot rock in the system, is varied to alter the nominal lifetime of the reservoir. An idealized cracked-plane model, developed at Los Alamos Scientific Laboratory (LASL), is used to calculate temperature drawdown from the system of fractures. A potentially critical assumption implicit to this treatment of reservoir perfomance is that fluids flow uniformly over the fracture surfaces; that is, preferential flow paths are not generated. The plant's design-flow rate divided by the design well-flow rate determines the number of HDR reservoirs required by the plant.

Initial rock or reservoir temperature at the bottom of the borehole is calculated as $T=15^{\circ} \mathrm{C}+\nabla T(D)$, where $15^{\circ} \mathrm{C}$ is the earth's crustal average temperature, $\nabla T$ is an average geothemal temperature gradient $\left({ }^{\circ} \mathrm{C}\right.$ per kilometer), and $\mathrm{D}$ is drilling depth (in kilometers). Values used for $\nabla T$ vary between $20-60^{\circ} \mathrm{C} / \mathrm{km}$. For a given reservair size (number of fractures), the well-flow rate then determines the rate of reservoir temperature drawdown. In any decision period, HDR reservoirs can be restimulated by entering the initial boreholes and redrilling to new areas of hot rock incurring whatever costs are associated with the operation. Redrilling produces the initial rock temperatures plus a modest increase because the reservoir is at a deeper, hotter depth. Costs for redrilling include rig mobilization costs, as well as drilling costs.

The optimization model, as outlined above, is used to achieve the second objective of this study: the parametric analysis of key variables in an HDR system used to generate electricity. To facilitate analysis, a "reference case", which represents an appropriate set of parameter values, is postulated for the HDR system. These values are listed in Table S-1. The model determines a level ized busbar cost $p^{*}$, which just covers the costs and normal profits of the system. In considering these busbar costs, it is important to recognize that the real, inflation-free values of debt and equity rates of return $(i=9 \%$ and $r=12 \%$ in Table S-1) are very high relative to those which characterize capital market 
Table S-1

PARAMETER VALUES FOR THE REFERENCE CASE

\section{Reference Case Conditions}

$\begin{array}{ll}\text { Real Rate of Return on Equity } & =12.0 \% \\ \text { Real Rate of Interest on Debt } & =9.0 \% \\ \text { Number of Fractures } & =6 \\ \text { Fracture Radius } & =300 \mathrm{~m} \\ \text { Geothermal Gradient } & =40^{\circ} \mathrm{C} / \mathrm{km} \\ \text { Plant Design Temperature } & =160^{\circ} \mathrm{C} \\ \text { Design Well-Flow Rate per } & \\ \text { Pair of Wells } & =75 \mathrm{~kg} / \mathrm{s} \\ \text { Capacity Factor } & =0.85 \\ \text { Plant Capacity } & =50 \mathrm{MW}(\mathrm{e}) \\ \text { System Life } & =30 \mathrm{gr} \\ \text { Operation and Maintenance } & =1.3 \mathrm{mill} / \mathrm{kWh} \\ \text { Contingency } & =13 \% \\ \text { Working Capital } & =10 \% \text { of surface plant cost } \\ \text { Taxes } & =51 \% \text { of taxable income }\end{array}$

conditions facing the power industry. These high values, admittedly arbitrary, are purposely used to reflect the assumptions that HDR facilities will initially be viewed in capital markets as involving higher levels of risk and uncertainty than those in commercial systems. In this comparative approach results for greater and lesser risk, as reflected in higher and lower $r$ and $i$, are shown in the results presented in Figure S-1 (\$1978). In the reference case, the levelized busbar cost was determined to be $43.2 \mathrm{mill} / \mathrm{s} / \mathrm{kWh}$. This value was then used as the basis for evaluating the effects of changes in other system parameters.

The results of the parametric analyses are summarized in Figure S-1. Some of these relate directly to prospects for future research and development and to the minimum conditions under wich HDR-produced electricity might be commercially feasible. For example, the results suggest the need for fairly precise estimates of drilling costs to obtain reliable feasibility studies. 
Because the technical feasibility of designing and operating a system of multiple fractures has yet to be proved, it is difficult to assess the practicality of a reference case using six, 300-m-radius fractures that result in a relatively low rate of temperature drawdown. The large increases in busbar costs that obtain as the number of fractures decline (Figure S-1) point to the potentially critical dependence of system feasibility on reservoir size as represented here by the number of fractures. Also, a commercially feasible HDR system will require average rates of temperature drawdown that do not exceed (all el se equal) some 5-8\% of initial temperatures over a five-year period. Thus, research focused on reservoir design for minimizing temperature drawdown is al so a prerequisite for a meaningful assessment. In practice, research should be directed at developing alternative designs that incorporate the effects of large single fractures; multiple, parallel systems; and thermal-stress cracking to produce sufficient reservoir heat transfer area.

Finally, it is interesting to speculate as to what minimum characteristics an HDR system must have to produce electricity at a competitive price. The first requirement is to establish future competitive prices for of the U.S. when HDR-produced electricity might be used. While numerous unanticipated difficulties attend comparisons of estimated busbar costs from differing sources, a conservative future competitive busbar price of $30 \mathrm{mills} / \mathrm{kWh}$ (in 1978 dollars) for nuclear-coal mixes was used. This price is an estimated average of busbar prices in $1985(\underline{s}-\underline{1})$.

The method of analysis varies each parameter individually while all others remain constant at their respective reference case values. Therefore, a busbar cost of $\leq 30 \mathrm{mills} / \mathrm{kWh}$ obtains in each of the following cases and indicates a set of minimum conditions for a cormercially competitive HDR facility, assuming a proven technology.

- Geothermal temperature gradients are at $50^{\circ} \mathrm{C} / \mathrm{km}$ and higher.

- The reduction in drilling costs is $30-40 \%$ of those used in the reference case.

- A large number of fractures per pair of wells ( 8 to 10) combined with higher well-flow rates $(125 \mathrm{~kg} / \mathrm{s})$.

- Real debt and equity rates are on the order of $3 \%$ and $6 \%$, respectively.

A higher competitive price would have a significant impact in relaxing the requirements listed above. 
Although the costs of well and surface plant components are not based on detailed engineering design estimates, they do include direct and indirect cost factors which account for contingencies, installation, auxiliary hardware, and associated services. At this stage of development, this method is considered to be acceptable engineering practice and is a necessary precursor to the refinements that will result from more detailed analysis.

In conclusion, it seems appropriate to comment on the close working relationships and intellectual interchange that have evolved over the last two years and more between LASL and University of New Mexico economists and the reservoir and chemical engineers at LASL. Throughout the project strengths and weaknesses of alternative choices for parameter values, functional representations for reservoir and/or economic processes, etc. were evaluated. There is little in either the model or resulting analyses that has not been the subject of joint, intensive scrutiny and discussion by economists and engineers. It is somewhat unusual for economists to be so involved in assessment studies for activities at such an early stage of technological development. We hope that the results of this work demonstrate the value of such early involvement, particularly as they relate to the provision of insights that assist in the selection of R\&D efforts which are particularly critical to the potential economic feasibility of HDR-produced electricity.

\section{REFERENCE}

S-1. R. G. Cummings, J. W. McFarland, S. C. Nunn. "An Economic Analysis of the HDR Geothermal Energy Resource." Resources and Energy, Fall 1978. 

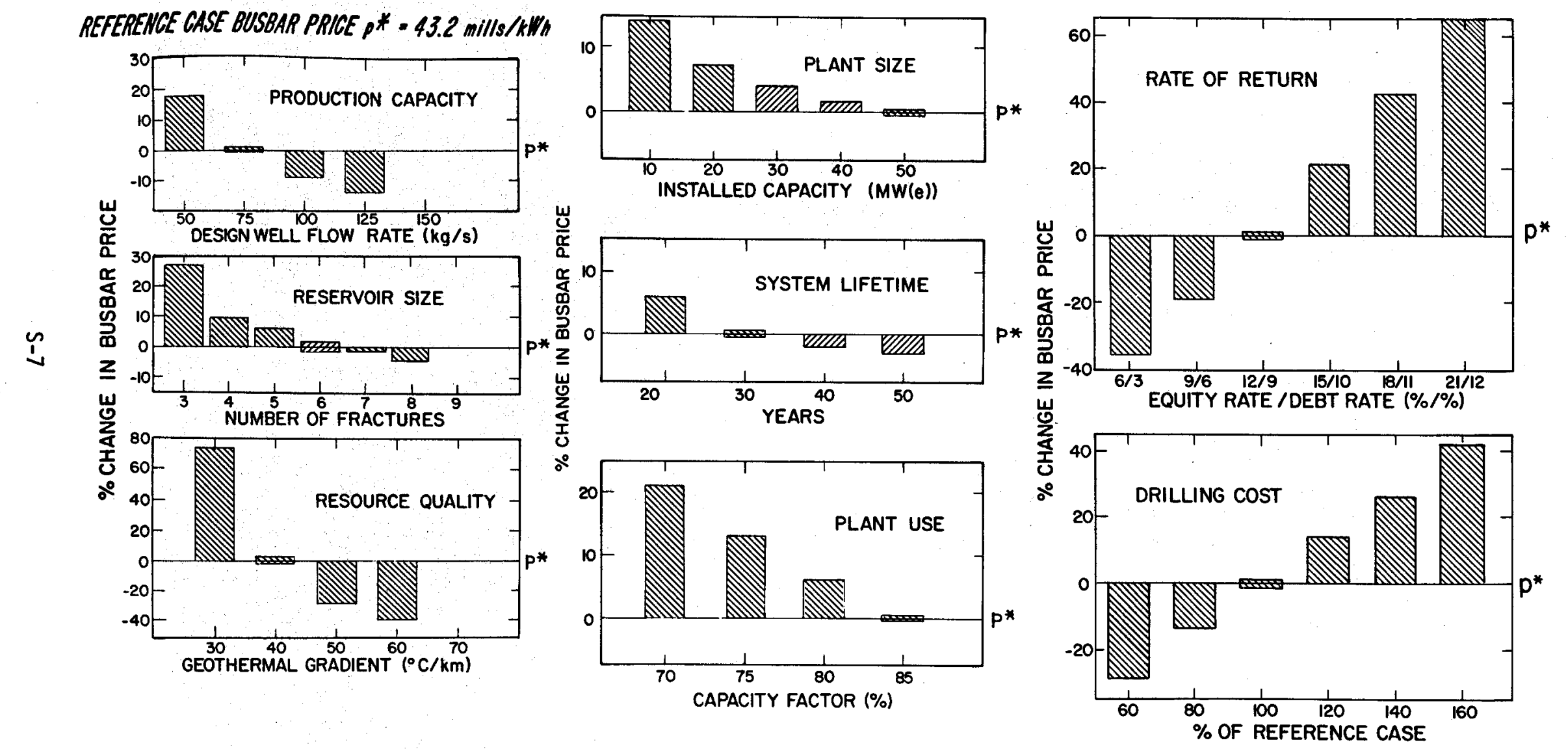

Figure S-1. Summary of results from parametric analyses of an HDR electricity-generating system. 
Section 1

INTRODUCTION AND OVERVIEW

This study is a final report for research concerning hot dry rock (HDR) geothermal resources conducted by the authors under contracts with the Electric Power Research Institute (EPRI) and the Los Alamos Scientific Laboratory (LASL) over the period May 15, 1976 to November 2, 1978. The goal of this research was essentially twofold. The first purpose was to develop a method for economic tradeoff analysis of HDR-produced electricity. The second was to use the developed method for analyzing the sensitivity of the HDR system to parametric changes in key economic and reservoir parameters. The parametric analyses are then used to focus on potential priority areas for future research and development, as well as on developing a set of conditions from which we might speculate as to the future commercial feasibility of HDR-produced electricity.

There have been several engineering-economic studies concerning electricity production from geothermal resources over the past few years (1 $-\underline{3})$, and the rationale for still another economic study of geothermal resources may serve to place the research reported here in perspective. These earlier studies focus on "wet", liquid or steam dominated, geothermal resources. Those systems typically involve a natural underground reservoir containing natural steam and/or hot water that is brought to the surface through a set of drilled wells. Indigenous geothermal fluid flows under artesian pressure or is pumped through a gathering system of pipes to a centrally located power plant, which may produce electricity, process heat, or both. The location of such geothermal resources, as well as system characteristics such as the size of the resource, geothermal temperature, and fluid-flow rates, are essentially fixed by natural conditions.

The HDR geothermal resource differs from the wet geothermal resource in several critical ways (4). To appreciate these differences, consider the schematic representation of an HDR system in Figure 1-1. The injection well is drilled some 3-10 km below the surface of the earth to geologic areas of hot, low-permeability crystalline rock. An artificial "reservoir" is then created in the hot region 
using hydraulic-fracturing techniques originally developed by the petroleum industry. The HDR reservoir then consists of single or multiple fractures having radii of 100-500 meters $(\mathrm{m})$ and widths of a few millimeters in cross section. A second well is directionally drilled to intersect the fracture(s) with sufficient separation from the other well to avoid flow short circuiting. Pressurized water is then circulated down the injection well to remove energy transferred as heat from the rock and is recovered from the production well for use in the generation of electricity $(\underline{2}, \underline{5}, \underline{6})$.

Thus, unlike liquid/vapor-dominated natural geothermal systems, the HDR systems are manmade, and their characteristics are, in large part, amenable to control and design. - For example, the location of exploitable HDR resources is not only a geologic/geographic issue, but also an economic issue. That is, although most areas will overlie hot, crystalline basement rock at some depth, a key consideration is the drilling costs required to reach the resource. Similarly, resource quality, that is reservoir temperature, is a design variable. Given the

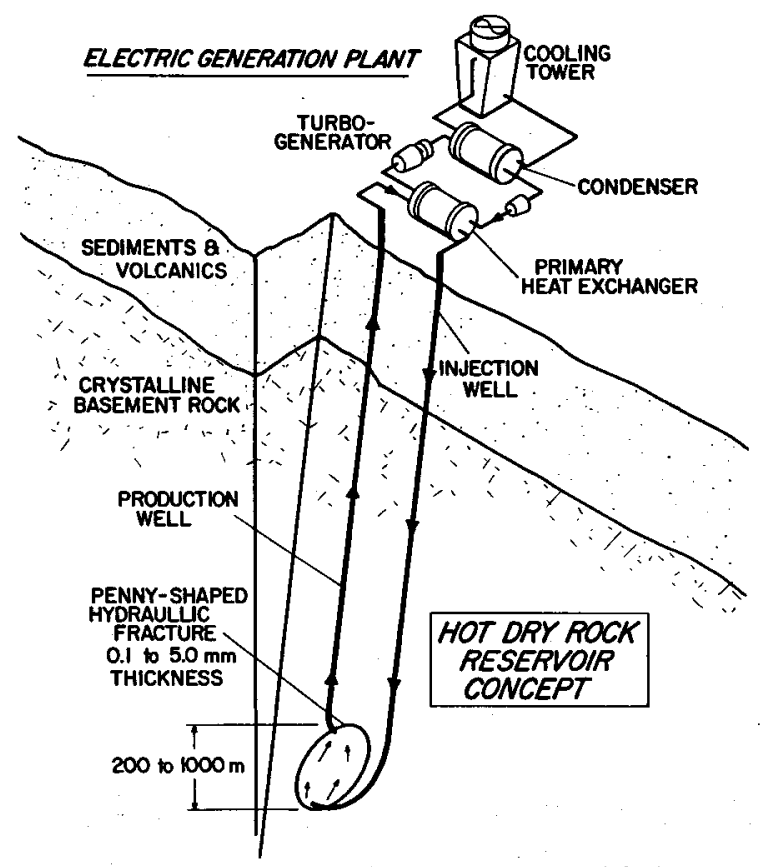

Figure 1-1. Schematic of a Hot Dry Rock electric generating facility. A singlefracture reservoir in low-permeability, basement rock is depicted. 
geothermal temperature gradient for an area, the deeper the drilling to establish the HDR reservoir, the higher are reservoir temperatures. Additionally, wellflow rates for HDR reservoirs may be set by design within limits determined by the success of the technology. Conditions determining the chemical composition of circulated fluids will certainly be site specific and may be important in designing power cycle and reservoir components (ㄱ).

The fact that the system for exploiting HDR geothermal energy is a manmade one, in contrast to the natural, wet geothermal system, requires making decisions concerning a wide range of interrelated reservoir, generating $\mathrm{pl}$ ant, and site characteristics. These include installed capacity and design temperatures for the electric generating plant, HDR reservoir design parameters (such as, heat transfer surface area of the fractures and well-flow rates), and geothermal temperature gradients that relate to plant siting considerations. Most of these are fixed by site location in studies of natural geothermal systems. As the technology for exploiting HDR geothermal resources differs from that appropriate for exploiting wet reserves, so the framework for economic analyses appropriate for analyzing HDR systems differs markedly from those appropriate for natural, wet systems. This notion is developed in considerable detail in Section 3.

The United States' first circulating system for extracting heat from hot granite below the surface of the earth was completed by scientists at LASL in June 1977 under the sponsorship of the US Department of Energy. The experimental HDR reservoir, located in the Jemez Mountains in central New Mexico, has a vertical depth of about three kilometers, with an initial downhole temperature of $\sim 185^{\circ} \mathrm{C}$. Since June 1977, an active program of experiments and tests aimed at understanding reservoir performance and characteristics has been ongoing ( $\underline{8}-\underline{10})$.

Because the technology for developing and exploiting HDR reservoirs is in its infancy, values for critical reservoir parameters can only be bounded within a broad range at this time. However, a method that allows for early economic trade-off analyses based on parameter values within these broad ranges may be worthwhile for a number of reasons. Experimental research on HDR reservoirs must compete with other research for funding, and a method that generates insight as to the necessary conditions for commercially feasible HDR-produced electricity may then be useful in considering the relative priority of HDR in new technology research. Further, physical scientists at LASL face a wide range of alternatives in terms 
of major directions for future phases of HDR research. These choices may be influenced by information as to the sensitivity of HDR system costs to changes in these reservoir parameters. Finally, economic analysis of HDR-produced electricity may be of value to the broader research community concerned with analyzing and forecasting future economic conditions as they reflect al ternative scenarios related to the nation's energy situation.

It is important that the results reported in this study be viewed with in the context described above. For the analytical method developed, a proven technology for HDR-produced electricity is assumed. The results from the models developed below are then of the form: given that reservoir parameters for this proven technology take on "these" values, "these" are the appropriate management choices and costs for the system. Different values for reservoir parameters will, however, yield different economic trade-offs and system costs. Analyses must then be (and are) conducted for a wide range of variations in values for key reservoir parameters.

The expositional structure of this study is as follows. In Section 2 a heuristic description of the technical and economic issues, which are relevant for the exploitation of HDR geothermal resources, is given. This section is purposefully nonrigorous and is intended to provide the nontechnical reader with an insight into the engineering-economic issues relevant to HDR systems. For more detailed engineering descriptions of LASL's HDR system, a number of publications are available $(\underline{6}, \underline{9}-\underline{11})$.

Section 3 is concerned with the first purpose of this study: the development of a method for evaluating the economic trade off of HDR-produced electricity. The rationale and need for a new methodology for evaluating an HDR system is discussed and the justification for using particular economic concepts is given. The method, an intertemporal optimization model based on a dynamic programming computational algorithm, is presented along with a description of data and parameter sets that are used for empirical applications of the model. Then a summary of parameters and variables is given, and the plan for analysis is described. Concluding remarks relate to the caveats that must be considered in interpreting the results from model solutions given in later sections.

Sections 4 through 7 deal with the second purpose of this study: parametric ana1yses. Results from the analytical model as they apply to a reference case are 
analyzed in Section 4; drilling and management strategies for an optimally designed and operated HDR system are described. Attention is focused on parametric variations in $\mathrm{plant}$ design temperature in Section 5 . Important resource, $\mathrm{plant}$ engineering, and reservoir design parameters, especially as the latter relates to temperature drawdown, are considered in Section 6. Parametric variations for economic parameters are analyzed in Section 7.

In the concluding Section 8, ramifications of the parametric analyses for future HDR research are suggested. Al so, an effort is made to use the multifarious analyses of the study to focus on the speculative question: What might be some of the minimum conditions for the commercial feasibility of HDR-produced electricity? 


\section{Section 2}

TECHNICAL AND ECONOMIC ISSUES RELEVANT

FOR THE EXPLOITATION OF HDR RESERVOIRS

\section{THE HDR FACILITY}

To provide the reader with some insight into the nature of an HDR facility, we begin with the following extremely simplified characterization of one process by which HDR reservoirs are created and used for electricity generation. For the following discussion, refer to the schematic representation of the HDR reservoir and the associated electricity-generating facility shown in Figure 1-1. A borehole, referred to here as a well, is drilled into the ground to a depth of between 3 and $10 \mathrm{kilometers}(\mathrm{km})$. Depending on the heat flow and geological characteristics of the intercepted region as the well extends deeper, the average temperature of the surrounding rock increases. At depths between 3 and $10 \mathrm{~km}$, low-permeability, crystalline basement rock at temperatures in excess of $150^{\circ} \mathrm{C}$ may be encountered, thus the description: "hot dry rock."

Once the well has been drilled into a region of hot dry rock, one or more large fractures are created in the hot granite by pumping water into the well at high pressure. Such hydraulic-fracturing techniques are commonly used to enhance recovery in $0 i 1 /$ gas reservoirs. Fractures in the HDR reservoir will have radii from 100 to $500 \mathrm{~m}$ or more with a maximum aperture of about 5 millimeters $(\mathrm{mm})$ or less. As discussed below, a very large single fracture (radius of $1000 \mathrm{~m}$ or more) may result in negligible temperature losses but will suffer from the consequence of averaging fluid outlet temperature between the injection and production well and may not have the stability of smaller fractures.

With the reservoir established, a second well is drilled to enter the fracture(s) some distance above the first well. With the second well completed, a system for circulating water is established. Water is injected into one well under pressures sufficient to avoid vaporization. Energy in the form of heat is transferred to the water as it flows across the rock surface, and the heated water then returns to the surface through the recovery well at temperatures above $100^{\circ} \mathrm{C}$ for use in generating electricity. 
It can be expected that as water circulates through the HDR reservoir, return flow will carry dissolved minerals and suspended solids. Poor water quality may cause scaling, fouling, or deposition problems as are often encountered in liquid-dominated systems. Although all dimensions of this problem for HDR reservoirs are not presently understood, there are no indications to date of water quality problems from LASL's brief experience with HDR experiments at their Fenton Hill site $(\underline{7}, \underline{10})$. These problems aside, however, an HDR system consists of a closed-loop circulation system, in which case the environmental impact may be extremely low. Furthermore, assuming minimal risk of induced seismicity from pressurized fractures, it is probable that HDR facilities can be located in or near urban centers.

The technical feasibility of many facets of HDR systems has been demonstrated in the first field experiments being conducted by LASL at Fenton Hill. At present, a reservoir has been created by hydraulic fracturing in low-permeability, crystall ine basement rock at $\sim 185^{\circ} \mathrm{C}$. The reservoir has been flow tested for 75 days at a maximum energy extraction rate of approximately five megawatts of thermal energy $[M W(t h)]$. Although the present reservoir has only $8000 \mathrm{~m}^{2}$ of heat transfer area (effective fracture radius of $\sim 50 \mathrm{~m}$ ) and is too small to be of commercial value, plans are under way to enlarge this to a $50 \mathrm{MW}(\mathrm{th})$ capacity with an extended lifetime (10).

Results from the experimental research and conceptual design studies are sufficient to provide a basis for selecting a range of values for HDR system characteristics and costs, which at this stage of development seem to be most important for assessment purposes. System characteristics are first, geothermal gradients; second, wel1-flow rates and reservoir sizes as they affect the rate of reservoir temperature decline and lifetime; and third, surface plant design as it relates to the choice of design temperatures and plant capacity. A critical cost involves the drilling of the boreholes for the subsurface system. Managementrelated issues associated with these sets of characteristics and costs will be discussed in detail.

\section{GEOTHERMAL GRADIENTS}

One determinant of the quality of a HDR resource is the geothermal temperature gradient, referred to here as simply "the gradient." It is a measure of the 
change in rock temperature encountered as depth changes, normally given in degrees centigrade per kilometer of depth $\left({ }^{\circ} \mathrm{C} / \mathrm{km}\right)$. Common values for this gradient in the US 1 ie between $20^{\circ} \mathrm{C} / \mathrm{km}$ in the eastern region and $30^{\circ} \mathrm{C} / \mathrm{km}$ in a large part of the western three-fourths of the U.S. Gradients for generalized regions in the continental U.S. are given in Figure 2-1 (12).* In very active hydrothermal regions, average gradients can be as high as $250^{\circ} \mathrm{C} / \mathrm{km}$. In conduction-dominated areas such as that found at LASL's Fenton Hill experimental site, regions with anomalous heat flow may have average gradients that range from 45 to $70^{\circ} \mathrm{C} / \mathrm{km}$ or more $(\underline{13-18})$.

Any effort to evaluate the magnitude of the HDR resource must identify the gradients that can be commercially exploited. This follows from the obvious ramifications of the gradient on drilling costs. For example, if we wish to reach rock temperatures of $250^{\circ} \mathrm{C}$ in an area with an average gradient of $50^{\circ} \mathrm{C} / \mathrm{km}$, the pair of wells required for the reservoir would be drilled to something less than $5 \mathrm{~km}$ at a cost of approximately $\$ 6.1$ million. To obtain the same rock. temperature in an area with an average gradient of $20^{\circ} \mathrm{C} / \mathrm{km}$, the wells would be drilled to a depth of $\sim 12 \mathrm{~km}$ at a cost of more than $\$ 226$ million.

\section{WELL-FLOW RATES, RESERVOIR SURFACE AREA, AND RESERVOIR LIFETIME}

Almost everyone has had the experience of walking barefooted on a cement driveway or sidewalk on a hot, sunny day. If one pours water on the cement, the temperature drops as heat is transferred to the water. How fast the cement cools depends on the rate at which water is applied relative to the surface area of the cement.

The cement example, however homey, illustrates a major technical problem in the exploitation of HDR reservoirs. Heat flows through the rock toward the fracture, but at a very slow rate because of the low thermal conductivity of the rock. As water passes over the surface of the fracture, local cooling of the rock will take place. Over time, the outlet fluid temperature will decrease. At issue, of course, is how fast will the temperature decline; that is, what will be the

*Data in Figure 2-1 are not meant to suggest that these average gradients are found "everywhere" in a given region. For any given region, a wide range of anomalous conditions would undoubtedly exist in "pockets" throughout the region--some yielding much higher gradients. 


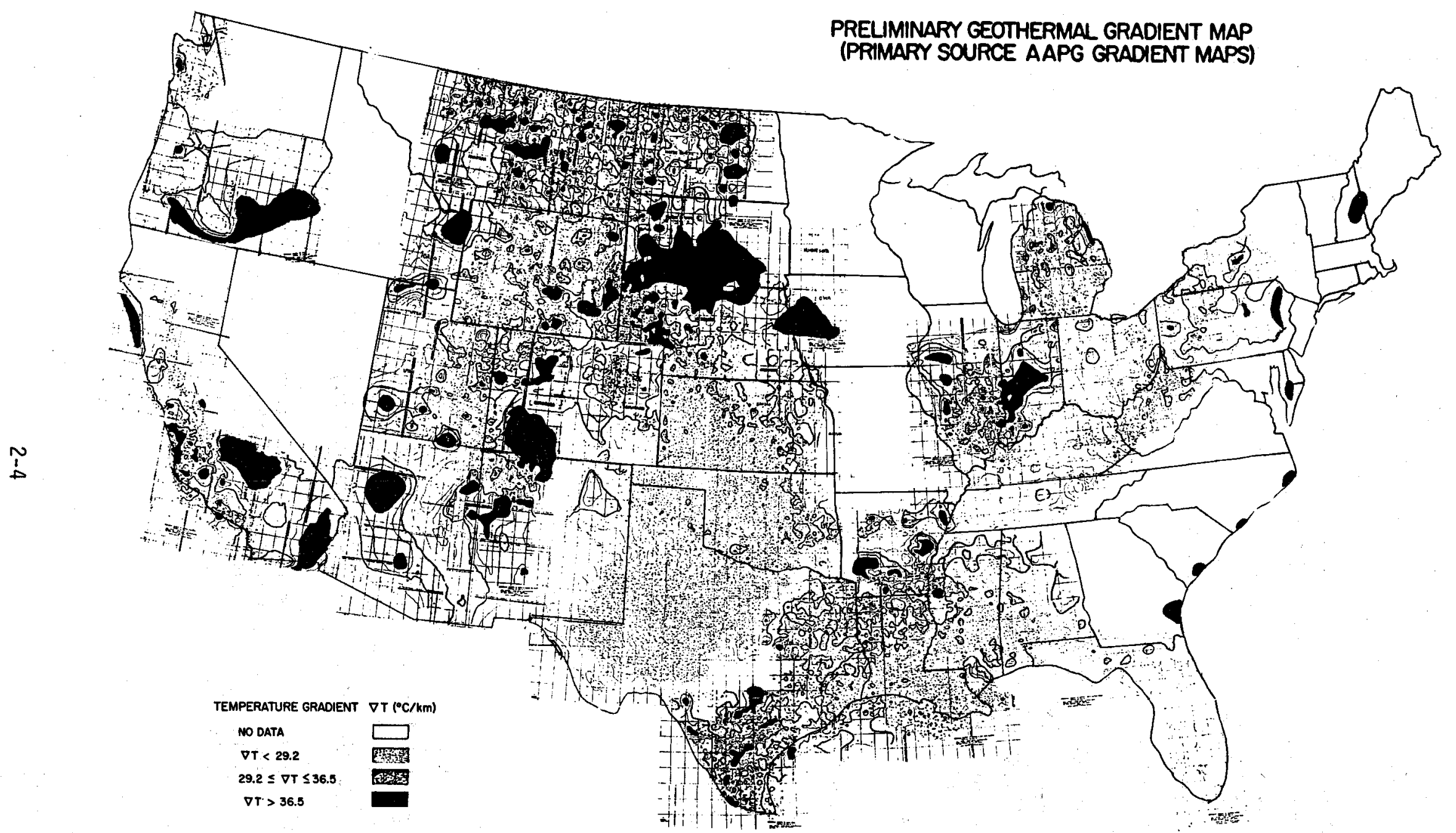

Figure 2-1. Preliminary geothermal gradient map showing three ranges of gradients. Map prepared by R. M. Potter $(12,13)$. (Source: American Association of Petroleum Geologists.) 
reservoir's useful "lifetime?" As in the cement example, this will depend on the rate at which water flows or is pumped through the reservoir (the "well-flow rate") relative to the surface area of the fractures. The greater the total effective surface area of the reservoir, the lower the rate of temperature drawdown.

\section{Surface Area of the Reservoir}

As mentioned previously there is an obvious economic incentive to create as large a fracture(s) as possible. There is however, a 1 imit to the surface area that one would create in an HDR reservoir. This limit is not imposed by costs, but by natural features of the rock formation and the surrounding earth-stress field. The fracture takes on an orientation and direction determined by in situ stress patterns of the formation. Furthermore, natural weak regions in the formation, such as sealed, old fractures, may significantly influence the initiation and propagation direction and extent of the hydraul ic fracture.

Ramifications of the direction, or orientation, of the fracture are also important in determining reservoir performance. The use of nonvertical slanted wellbores improves the probability of intersecting vertical, hydraulic fractures (see Figure 2-2A). In addition, to maximize the use of the fracture surface area, the injection wellbore should be located below the production wellbore and separated from it by as large a distance as possible. Although maintaining maximum separation distances has the disadvantage of averaging temperatures over a wider range, it may significantly reduce the probability of short circuiting.

Larger surface areas for HDR reservoirs may result from natural and/or manmade forces. One possibility is that as the surface area of the rock over which water flows becomes cooler, the crystalline rock will crack. Water then flows through these secondary cracks and crevices, and the total heat transfer surface area is expanded. This phenomenon is called thermal-stress cracking enhancement (19-23). See Figure 2-2B.

A second possibility for maintaining temperatures in the HDR reservoir with the limitations on radij described above is to simply redrill the reservoir when rock temperatures in the original reservoir fall beyond some limit. One may enter the original wellbores and vertically drill deeper to higher temperatures or directionally drill somewhat laterally to reach new rock areas at the original rock temperature and create a new reservoir. 
A third possibility for controlling temperature drawdown in an HDR reservoir is to periodically shut down the subsurface system. With pressure maintained in the reservoir during the shutdown period, new preferential water flow paths through hotter areas of the reservoir may result, and thermal redistribution over the face of the rock and/or thermal recuperation from the influx of energy from surrounding rock may result. These latter possibilities are referred to as a "heal ing" process in the HDR reservoir.

Finally, the surface area of an HDR reservoir may be expanded by the initial creation of a connected sequence of "small" fractures. The creation of multiple fractures (Figure 2-2C), the summed areas of which are sufficiently large, will minimize the rate of temperature drawdown $(\underline{6}, \underline{24}, \underline{25})$. Thus, rather than creating one fracture with a radius of $0.6 \mathrm{~km}$, six connected fractures with radii of $0.25 \mathrm{~km}$ may be created. Longer reservoir life (attributable to larger surface areas) is thus obtained while reducing the uncertainty as to the direction, orientation, and extent of the fracture.

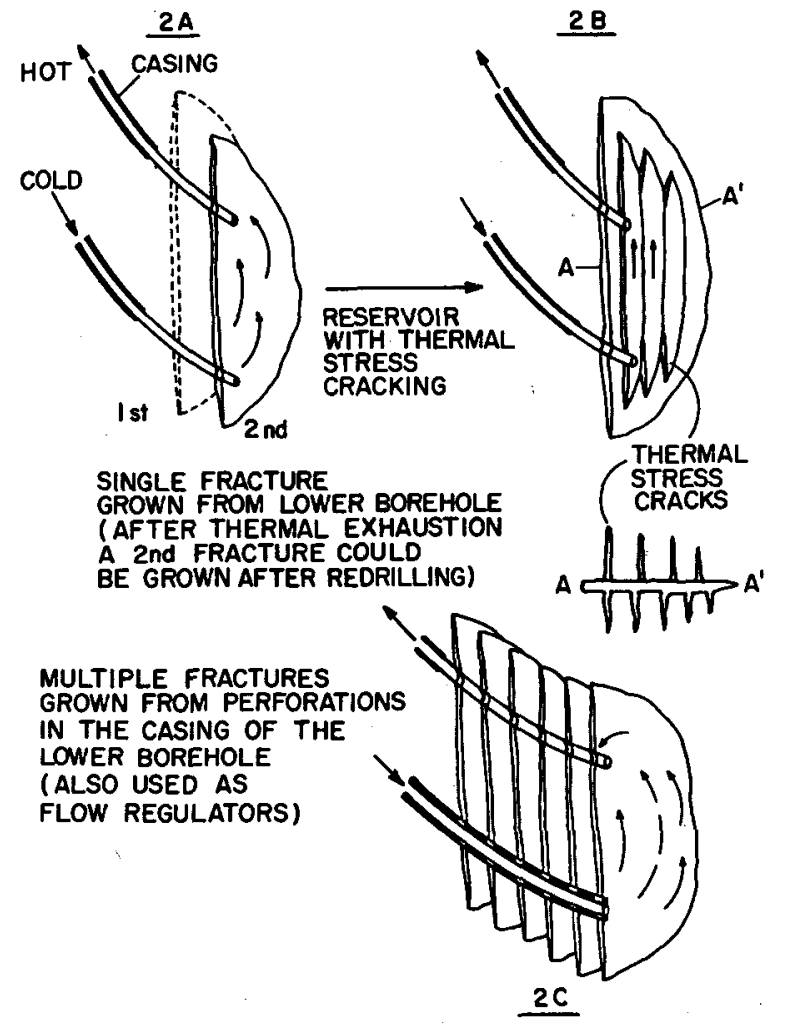

Figure 2-2. Single- and multiple-fracture concepts applicable to low-permeability formations (6). 
The multiple-fracture concept is used for numerical analyses generated in this study to introduce the dimension of a variable finite rate of drawdown. Each fracture is assumed to have a radius of $300 \mathrm{~m}$, and fractures are horizontally spaced at intervals of $50 \mathrm{~m}$ to avoid thermal interaction. As the number of fractures is increased, the effective surface area for the HDR reservoir is correspondingly increased and the rate of drawdown decreased.

\section{The Well-Flow Rate}

The impacts of various well-flow rates on temperature drawdown were mentioned above. Of course, the well-flow rate can be varied. During periods when low flow rates are used, conditions analogous to the healing process described above for well-shutdown periods may result, in which case the reservoir lifetime may be affected by periodic variations in well-flow rates. However, the electric generating plant will be designed for use of a particular flow rate (referred to as the "design well-flow rate"). Lowering the well-flow rate below the design rate in an effort to prolong reservoir lifetime will then result in decreased efficiency in the power plant and lower the initial levels of electrical output. Thus, during any period in which lowering the well-flow rate is under consideration, the relevant management issue is whether or not the benefits of a prolonged reservoir life exceed the value of losses in electrical output during initial periods.

An admittedly simplified method of treating reservoir life as it relates to reservoir size and well-flow rates is used in this study. Temperature drawdown in the HDR reservoirs is related to the effective area of the reservoir (denoted $S$, in square meters) and well-flow rates (denoted $\dot{m}$, in kilograms per second, $\mathrm{kg} / \mathrm{s}$ ) by a simplified "error function", erf $(\dot{m}, S)$, which is described in some detail in Appendices $A$ and $B$.

Denoting the design well-flow rate as $\dot{m}_{d}$, it is assumed that periodic power output from the electric generating $\mathrm{pl}$ ant varies proportionally to $\dot{\mathrm{m}} / \dot{\mathrm{m}}_{\mathrm{d}}$.

THE ELECTRIC GENERATING PLANT

The third set of HDR system characteristics of interest here is that which includes the design and scale of the HDR power plant. The thermodynamics of the power-generating cycle relevant for HDR-produced electricity involves a wide range of problems and issues of central importance ( $\underline{8}, \underline{26}, \underline{27})$. 
The analyses that follow are based upon the use of a binary cycle power plant with mechanical draft condenser/desuperheaters (dry cooling towers), where the cost of the power plant has been minimized for various fluid temperatures by varying the plant's design and operating conditions $(\underline{2}, \underline{26})$. Two characteristics of this plant are of particular interest for these analyses: the plant's installed capacity, [expressed in megawatts of electricity, MW(e)] and the temperature of working fluids for which the plant is designed (denoted $T_{d}$, in ${ }^{\circ} \mathrm{C}$ ). These two characteristics of the power plant are given particular attention because of their direct impact on revenues and costs for the HDR facility.

The relevance of installed capacity to revenue-cost valuations is perhaps the most obvious. First, the cost of the power plant increases proportionally to its installed capacity when its installed capacity is $\geq 50 \mathrm{HW}(\mathrm{e})$. In other words, because of the inherently low conversion efficiency of the plant and the equipment sizes, such as heat exchangers that tend to be very large with multiple units required, economics of scale are not important above $50 \mathrm{MW}(\mathrm{e})$. For installed capacities below $50 \mathrm{MW}(\mathrm{e})$, however, the cost per unit of installed capacity is inversely related to the size of the power plant. Second, increases in installed capacity imply the need for increasing numbers of reservoirs (pairs of wells) to supply the power plant. These result in proportionally higher increases in drilling costs.

The choice of the power plant's design temperature will also impact the HDR facility's revenues and costs. Recalling the discussions above concerning potential rate of temperature drawdown in the reservoir, as the temperature of fluids from the HDR reservoir fall below the design temperature, efficiency is lost in the power-generating cycle and electrical output and revenues decline. An especially difficult problem therefore involves the selection of a "best" design temperature for the particular physical characteristics of the HDR site and for the expected future time path of reservoir temperatures.

The plant's design temperature affects costs in two distinct manners. First, the higher the design temperature, the higher the temperature of geothermal fluids required to maintain efficiency in the power $\mathrm{plant}$, and therefore, all else equal, the greater the depths required for the HDR reservoirs. Of course, drilling costs increase very rapidly as one drills to greater depths, and higher design temperatures then imply higher drilling costs for the HDR facility. 
The second impact on costs related to the plant's design temperature involves the number of reservoirs required by the power plant (similar to the impacts of installed capacity). As the design temperature changes, the design flow rate of geothermal fluids through the plant changes; thus, the design temperature determines a plant design-flow rate $\left(\dot{M}_{d}\right.$ in $\mathrm{kg} / \mathrm{s}$ per megawatt of installed capacity). The plant design-flow rate is inversely related to the design temperature; that is, higher design temperatures imply lower design-flow rates. The number of HDR subsurface systems $N$ required by the power plant is determined by the Eq. 2-1, where $q$ is $p l$ ant capacity in $M W(e)$.

$$
N=\frac{Q \cdot \dot{M}_{d}}{\dot{m}_{d}}
$$

Therefore, for a given design well-flow rate and installed capacity, higher design temperatures imply lower plant design-flow rates $M_{d}$, thereby reducing the required number of subsurface systems. From this ratio the basis for the argument made above concerning installed capacity is clarified: higher installed capacities increase the number of required subsurface systems, and therefore, drilling costs. Thus, higher design temperatures may increase individual well drilling costs by requiring that reservoirs be drilled to greater depths but decrease both the costs of the electric generation plant, because of improved efficiency, and well costs by reducing the required number of subsurface systems.

\section{WELL DEPTHS AND DRILLING COSTS FOR HDR RESERVOIRS}

The critical role of well depths and the associated drilling costs has been alluded to in several instances in the discussions above. These expenditures are such an important cost component for HDR systems that they warrant particular attention. For example, in the 50-MW(e) reference case to be discussed in Section 4, the present value of drilling costs (exclusive of the fluid-gathering costs) account for $49 \%$ of the present value of total system costs ( $\$ 112 \mathrm{million}$ ).

Drilling costs for the HDR facility consist of four components: rig mobilization and demobilization, initial drilling, redrilling, and fluid gathering. One could argue for a fifth component, namely costs incurred for exploratory drilling, but for the purpose of this study these costs are included in startup costs discussed in Section 3. Rig mobilization and demobilization charges are flat fees charged for setting up and dismantling the drilling rig. As treated in this work, rig mobilization costs are estimated at $\$ 67,800$; $\$ 203,400 ; \$ 339,000$; and $\$ 474,600$ for 
drilling depths to 2025, 2025-4050, 4050-6075, and 6075-8100 m, respectively. Rig mobilization costs increase with drilling depths simply because larger rigs are required for deeper drilling. Rig mobilization costs are incurred for initial drilling activities and any redrilling activities undertaken in later periods.

The second drilling cost component is the cost of initial drilling required to establish the HDR reservoirs. The relation used here to calculate drilling costs is a modified form of the relation given on pages 80-82 and 128-131 in Ref. ( $\underline{9}$ ) and is based upon an extrapolation of oil- and gas-well costs scaled to observations on costs for several geothermal wells $(\underline{28})$. The calculation of 1976 costs of drilling one well as specified in Ref. $(26)$ is multiplied by a $13 \%$ contingency factor and a $20 \%$ inflation factor and then doubled to state costs in 1978 dollars for drilling two wells to a depth $D(\underline{29})$. Assuming that fractures are oriented strictly upward from the deepest well. The cost (in 1978 dollars) for drilling a pair of wells $\left(\hat{c}_{W}\right)$ to a depth of $D$ meters is

$$
\hat{c}_{w}=\$ 174.65 \text { (D) } \exp (0.00039 \text { D) }
$$

This statement of drilling costs is an overestimate in that the recovery well is actually drilled only to a depth of $D-2 R$, where $R$ is the fracture radius. To place this cost function in some perspective, average costs for drilling and equipping oil wells along the central California coastal region are given in Table 2-1 for average depths of 2449, 3376, and 3966 meters by the American Petroleum Institute. These costs multiplied by two and adjusted for price changes since 1974 (using the price index of 159.2 from the Report of the cost Study Committee, Independent Petroleum Association of America) are compared with the cost of drilling a pair of wells calculated by Eq. 2-2.

From the discussions above concerning design temperatures, recall that the HDR electricity-generating plant will require $N$ pairs of wells determined from Eq. 2.1. Recall also that each of these HDR subsurface systems has $F$ fractures, where each fracture has an assumed effective radius of $300 \mathrm{~m}$. The $F$ fractures are spaced horizontally at 50-m intervals (see Eigure 2-2C). The relation given in Eq. 2-2 is used to estimate drilling costs for two wellbores at an average depth of $D$ meters, and, by assumption, establishing the first of the $F$ fractures. Additional drilling is required to establish the remaining ( $F-1)$ fractures, 
ESTIMATED DRILLING COSTS

Drilling Depth
(m)

2449

3376

3966
Estimated Well-Pair

Cost Using Eq. 2-2

(thousand 1978 \$)

2219.6

3030.6

4097.5
Estimated cost

for drilling

2 oil wells

(thousand 1978 \$)

867.8

18.97

24.97

namely, the additional drilling of $(F-1) 50 / \sin \theta$ meters, where $\theta$ is the angle from the vertical used in this directional drilling. Because the specification of $\theta$ has not been fully established, an angle $\theta$ of $90^{\circ}$ was used in this report. This characterizes a horizontal step of length ( $F-1) 50$ meters out of the vertical section of the borehole and probably over-estimates the linear drilling distance required to establish the reservoir using a gradually curving wellbore. Costs incurred for each subsurface system with $F$ fractures are then given by

$$
\hat{C}_{w}=\$ 174.65 \exp \left\{0.00039\left[D+\frac{(F-1) 50}{\sin \theta}\right]\right\}\left[D+\frac{(F-1) 50}{\sin \theta}\right]
$$

Total drilling costs $C_{D}$ for the initial establishment of the $N$ HDR subsurface systems is thus

$$
\begin{aligned}
C_{D} & =N \cdot \hat{c}_{W} \\
& =\frac{Q \cdot \dot{M}_{d}}{\dot{m}_{d}}\left\{\$ 174.65 \text { exp }\left[0.00039\left(D+\frac{50 F-50}{\sin \theta}\right)\right]\right\} \\
& \times\left[D+\frac{(F-1) 50}{\sin \theta}\right]
\end{aligned}
$$


The third component, redrilling costs, is really little more than an extension of $C_{D}$ above. As depicted in Figure 2-2A, we allow here for the possibility of redrilling to establish new HDR reservoirs. The process involves reentering the original boreholes and directional drilling to new areas of the rock some distance from the original holes. After this process, the $F$ fractures are reestablished at rock temperatures equal to initial rock temperatures plus the increase in temperatures associated with the greater depth.

Costs of redrilling include rig mobilization costs $\left(C_{R M}\right)$ and drilling costs that are determined by calculating the increase in drilling costs associated with drilling 150 meters beyond the original drilling depths, plus the cost of reestablishing $F$ fractures. Thus, if $C_{D}$ is the cost of drilling to an original depth of $D$ meters, redrilling costs would be

$$
\begin{aligned}
C_{R D} & =\left(N \$ 174.65\left[D+150+\frac{50(F-1)}{\sin \theta}\right] \exp \{0.00039[D+150\right. \\
& \left.\left.\left.+\frac{50(F-1)}{\sin \theta}\right]\right\}\right)+C_{R M}-C_{D} .
\end{aligned}
$$

The final component of drilling costs is a onetime charge incurred with original drilling, which is the cost of constructing the fluid gathering system for the $N$ subsurface systems. The costs of pipe and equipment for the fluid gathering system is taken to be proportional to the linear footage required to make pipe connections among corners of an array of equilateral triangles as shown in Figure 2-3. Pipe costs are estimated at $\$ 4.92 /$ inch diameter/foot of length in 1978 dollars. A 12-inch pipe diameter is assumed for all pipes. This implies that fluid from outlying wells is piped directly to the plant's central gathering system. For the six wells in the inner hexagon in Figure 2-3, pipe length is 600 feet. For the 18 wells in the outer hexagon, pipe length is assumed to be 1200 feet. For wells lying beyond the outer hexagon, pipe lengths of 1800 feet are assumed. Thus, denoting piping costs as $C_{\text {pipe, }}$,

$$
\begin{aligned}
C_{\text {pipe }} & =(\$ 70,848) N, \quad N \leq 6 \\
& =(\$ 70,848)(2 N-6), \quad 6<N \leq 18 \\
& =(\$ 70,848)(3 N-24), \quad 18<N \leq 36
\end{aligned}
$$




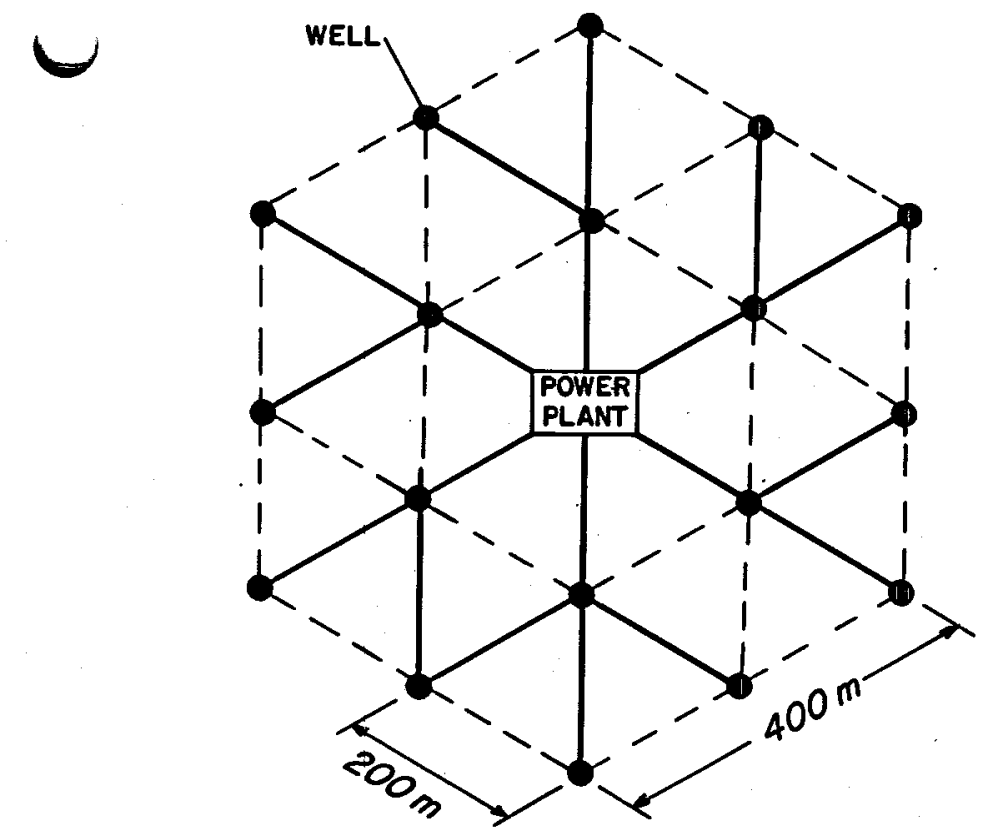

Figure 2-3. Schematic of the triangular grid system for well siting.

In summary, total drilling costs for the initial establishment of the HDR reservoirs is given by

$$
\mathrm{DC}_{1}=\mathrm{C}_{\mathrm{RM}}+\mathrm{C}_{\mathrm{D}}+\mathrm{C}_{\text {pipe }}
$$


Section 3

METHODOLOGY

The purpose of this section is to describe the general methodology used in this report to analyze HDR-produced electricity. To this end, we present the rationale for using an optimization framework and discuss a number of economic concepts as employed in this study. The optimization model is described, and ranges for the parametric values used for analyses are presented and discussed. The use of the model to generate busbar costs is described and followed by a sumary of reservoir and economic parameters. The section is concluded with a discussion of the plan for analyses, and major caveats, as they apply to the methodological approach used.

\section{METHODOLOGICAL ISSUES}

Justification for an Optimization Approach

There are a number of approaches commonly used in assessing the feasibility of power-generating systems, one of which is the Revenue Requirement approach. Revenue requirements are "the amounts that must be covered to compensate the utility for all expenditures made as a result of implementing an investment decision." As such, revenue requirements include "fixed costs, such as return on investment, depreciation, and taxes, that result from having made an investment; and operating costs, such as fuel costs and 0\&M costs, that result from the use of an investment." such costs may then be expressed as a "levelized" annual payment, and this levelized annual payment, divided by annual power output, may be interpreted as a busbar cost (30).

It would be desirable to use this well-established method if all else was equal. However, the problem, as one might anticipate, is that all else is not equal. The most basic requirement for using the Revenue Requirements approach for evaluating an HDR facility is that all costs can be estimated in advance. A moment's reflection concerning plant-reservoir interdependencies and trade-offs discussed 
in Section 2 is sufficient to suggest that such costs cannot be defined in advance for the HDR system. A given set of parameters, particularly the plant's optimal design temperature $T_{d}$, and therefore minimum plant costs, is determined conjunctively with optimal reservoir design and management strategies.

To illustrate the inability to specify system costs for an HDR facility beforehand, consider the economic trade-offs that must be incorporated into the determination of an optimally designed and managed HDR system. This determination must precede estimates for system costs. An appreciation for these trade-offs will be particularly useful in understanding the methodology used in this study as it contrasts with other approaches for evaluating electricity-generating facilities.

First consider the problem of selecting an optimal design temperature $T_{d}$. As noted above, as $T_{d}$ increases the following obtain:

- Costs in \$/installed capacity for the generating plant decline (see Eq. 3-8).

- The required number of HDR reservoirs (pairs of wells) decline by the resulting lower design-flow rate $\dot{M}_{d}$. Thus, total well costs decline (see Eq. 2-4, where : $2 \mathrm{~N} / \partial \mathrm{T}_{\mathrm{d}}<0$ ).

- Drilling costs per pair of wells increase. Higher values of $T_{d}$ imply higher required reservoir temperatures (for any given level of plant efficiency), and higher reservoir temperatures are obtained only by deeper drilling.

Thus, as $T_{d}$ increases, lower costs for the generating plant and total well costs (by reductions in the number of reservoirs) are traded off against higher drilling costs per well. An optimal value for $T_{d}$ is then one which in some sense balances these two opposing effects associated with changes in $T_{d}$. Note, then, that an optimal plant design is inextricably related to an optimal reservoir design. Furthermore, the decline in the required number of reservoirs, which attends increases in $T_{d}$, may also imply lower fluid gathering-pipe costs (see Eq. 2-6).

Second, given a design temperature $T_{d}$ and the resulting design well-flow rate $m_{d}$, the choice of well-flow rates $\dot{m}_{t}$ (for each reservoir) also involves a trade-off. As $\dot{m}_{t}$ falls below the design rate $\dot{m}_{d}$ in any period $t$ :

- The value of power output falls in the period $t$ as a result of decreased plant efficiency. 
- Temperature drawdown in the reservoir is diminished, which implies greater thermal efficiency and permits higher levels of power output in all later periods.

In any period $t$, then, an optimal level of the well-flow rate $\dot{m}_{t}$ is one wherein the loss in power output (as a result of an incremental variation in $\dot{m}_{t}$ ) is just balanced with the present value of increased power output in future periods that results from reduced temperature drawdown.

Third, as is obvious from Eq. 2-2 and 2-3, drilling costs for each pair of wells increase exponentially with drilling depths. Given a design temperature $T_{d}, a$ multidimensional trade-off is involved in choosing initial drilling depths, as well as for the intertemporal staging of redrilling activities. In terms of the choice of initial drilling depths:

- Higher drilling depths imply greater plant efficiency and greater values for periodic power output.

- Higher drilling depths, beyond that required to provide reservoir temperatures that equal $\mathrm{T}_{d}$, delay the need for redrilling for any given pattern of temperature drawdowns.*

- Higher drilling depths imply higher (exponentially increasing) drilling costs.

In terms of the periodic question as to whether or not redrilling should occur:-

- Redrilling results in the reestablishment of initial reservoir temperatures, in which case current and future efficiencies and therefore power output are increased.

- Redrilling requires higher costs per meter drilled plus rig mobilization costs.

An optimal drilling strategy, one which is inextricably tied to an optimal plant design, balances the temperature-related benefits with the associated cost.

From these discussions it is obvious that the determination of minimum costs for an HDR facility, within the context of an optimally designed and managed system,

\footnotetext{
* Future redrilling requires the fixed rig mobilization costs. Thus, it may be optimal to incur the higher marginal drilling costs initially, which does not increase revenues, but does provide excess temperatures to postpone the rig mobilization costs for redrilling.
} 
is not a trivial effort. Such costs must be determined within a framework that deals with all the trade-offs described above.

This discussion was not meant to preclude the use of the Revenue Requirements method, especially given a proven HDR technology and considerable experience with such systems. For example, through experience with these systems, it may eventually be known that, for areas with a particular temperature gradient, certain values for $T_{d}$, drilling depths, and well-flow rates; will be most economic and a particular pattern of temperature drawdown will occur and will require a specific manner of redrilling. Under such circumstances, costs may be estimated in advance, and the Revenue Requirements approach may be used to estimate level ized busbar costs. The need for more complex analytical methods to evaluate HDR facilities is then simply a reflection of the preliminary stage of development for this potential energy resource.

In sumary then, the objective of this study is to evaluate HDR-produced electricity with the wide range of management issues and physical/economic trade-offs outlined above, examined as to their impacts on fim profits and revenues. For this purpose a profit maximization framework is used. An alternative would be a cost minimization approach. However, optimal management is also a function of revenues (prices) as discussed above.

\section{Taxes and Discounting}

For any process that involves a flow of revenues, or costs, or both over time, these flows must be adjusted to add revenues and costs, that is, revenues and costs are measured in terms of their value at a specific time. Let $t_{1}, t_{2}$, and $t^{\star}$ denote, respectively, the time at which initial costs for exploration, development activities, etc. begin; the first year of operation of the HDR plant; and the end of the planning horizon. If the base or accounting year is $t_{1}, a l l$ values for periods $t_{1}<t \leq t^{\star}$ must be discounted. If the base year is $t_{2}$, values incurred during periods $t_{1} \leq t<t_{2}$ are compounded whereas values incurred during periods $t_{2}<t \leq t^{\star}$, are discounted. If $t^{*}$ is the base year, all values incurred during periods $t_{1} \leq t<t^{\star}$ are compounded to period $t^{\star}$.

In this work, $t_{2}$ is used as the accounting base period. Thus, all explorationdevelopment costs, as well as plant construction costs, are compounded to year 
$t_{2:}$ The interest, included in such costs and resulting from compounding, corresponds to the well-known "interest during construction". (IDC) cost component. All costs incurred and revenues received after year one $\left(t_{2}\right)$ are discounted to year $t_{2}$. Thus, postoperational values are expressed in terms of their present value, and year $t_{2}$ becomes $t=1$ for accounting purposes.

In this work we, assume that all preoperational costs are met from the sale of bonds that must earn $1 \%$ per year. The staging of preoperational costs is given in Table 3-1. Denoting $\mathrm{C}_{01}, \mathrm{C}_{02}, \ldots \mathrm{C}_{09}$ as preoperational costs incurred in years $1,2, \ldots 9$, these costs plus accumulated compound interest, denoted $C_{0}^{\prime}$ and evaluated at the first year of operation, are given by

$$
c_{0}^{\prime}=\sum_{\pi=1}^{9} c_{\text {ot }}^{\prime}(1+i)^{9-\pi} .
$$

Table 3-1

PREOPERATIONAL COSTS

Estimated Exploration, Leasing, and Development Costs For a Hot Dry Rock Power Plant

Years to Start of Production

9

9

8

7

7

6

\section{Type of Activity}

Power Plant Site Purchase

Leased Well Site (Per Pair of Wells)

Geophysical Surveys for Site Reconnaissance

Geophysical Surveys for Site Selection

Shal low Exploratory Drilling ( 5 holes)

Deep Evaluation Drilling

(1-3 holes)
Cost $(\$ 1978)$

125,000

293

131,000

131,000

262,000

$2,360,000$ 
Suppose, for this case, that $C_{0}^{\prime}$ is not paid to bondholders until the end of the $\mathrm{planning}$ horizon $\mathrm{t}^{*}$. $C_{0}^{\prime}$ plus accumulated compound interest at the end of $t^{*}$ is given by

$$
c_{0}^{*}=C_{0}^{\prime}(1+i)^{t^{*}},
$$

where $i$ is the rate of interest. Interest paid on bonds is tax deductible, however. Assuming an average income tax rate of $51 \%$, the value of preoperational costs plus accumulated interest at the end of year $t^{*}$, net of the tax deduction, would be

$$
C_{0}^{*}=C_{0}^{\prime}(1+i)^{t *}-\left[C_{0}^{\prime}(1+i)^{t *}-C_{0}^{\prime}\right] 0.51
$$

In evaluating Eq. $3-3$ at the beginning of the planning horizon $t=1$, it is assumed that these costs, which are primarily associated with the generating $p l a n t$, are discounted at the rate $i$. Using $i$ as the discount rate, the present value of Eq. 3-3 at $t=1$ is given by

$$
c_{0}=c_{0}^{1}\left\{1-0.51\left[1-(1+i)^{-t^{*}}\right]\right\} \text {. }
$$

All drilling and fluid-gathering costs are assumed to be financed from stocks, which would undoubtedly require a different and higher rate of return. Denote this rate of return by $R \%$ and let the "appropriate" discount rate be $\hat{r}$. Denote periodic revenues, net of $0 \& \mathrm{M}$ costs and revenue taxes as $R_{t}$, and denote periodic drilling costs as $D C_{t}$. The value over $t^{*}$ years at $t^{*}$ of $R_{t}$ minus $D C_{t}$ is given by

$$
\sum_{t=1}^{t^{*}}\left[R_{t}(1+\hat{r})^{t^{*}-t}-D C_{t}(1+r)^{t^{*}-t}\right] \text {. }
$$

The rate of return paid on $D C_{t}$-type debts must be from profits and is thus subject to state and federal income taxes. An average income tax rate of $51 \%$ is used here. $D C_{t}$-type debt, adjusted for income taxes, is then given by

$$
\sum_{t=1}^{t^{*}} D C_{t}(1+r)^{t^{*}-t}+\sum_{t=1}^{t^{*}}\left[D C_{t}(1+r)^{t^{*}-t}-D C_{t}\right](0.51) \text {. }
$$


The present value of revenues minus the present value of $D C_{t}$-type costs, including income taxes, is denoted $G_{t *}(0,0)$ and is given by the following (assuming $r=\hat{r}$ ).

$$
\begin{gathered}
G_{t^{*}}(0,0)=\sum_{t=1}^{t^{*}} R_{t}(1+r)^{-t}-\left[\sum_{t=1}^{t^{*}} D C_{t}(1+r)^{-t}(1.51)-\right. \\
\left.D C_{t}(1+r)^{-t^{*}}(0.51)\right] .
\end{gathered}
$$

This admittedly cumbersome method of discounting is necessitated by the difficulties associated with accounting for income taxes, and it would be desirable to compute income taxes on an annual or periodic basis. We have no mechanism for assuring that revenues will be available for payment of taxes in any specific period, given the structure of the dynamic programming algorithm. Thus, taxes are paid at the end of the planning horizon in this model, and the effect of periodic payment of taxes is preserved inasmuch as accumulated compound interest on tax liabilities is included as a cost.

The choice of interest on bonds $i$, interest on stocks $r$, and the discount rate $\hat{r}$, is a matter of judgement. Nominal debt and equity rates of return will reflect, among other things, risk and inflation. Since all values used in this study are in constant 1978 dollars, debt and equity rates used here must be "real"--inflation-free--rates of return. Based on rates currently paid by utility companies, real debt and equity rates of $3 \%$ and $6 \%$, respectively, might be appropriate, a11 else equal. The use of these rates, however, would imply that HDR facilities would involve the same degree of risk and uncertainty as existing electric generating facilities. Should HDR evolve into an "off-the-shelf" technology, there would be not real basis for arguing that HDR would involve more or less risk than one faces in current commercial technologies. At. this stage of technology development, however, a conservative approach to this issue would require that we assume a high degree of risk and uncertainty for HDR systems. Thus, in the reference case developed below, real debt and equity rates of $i=9 \%$ and $r=12 \%$ are used. These high, admittedly arbitrary, real rates are used in the reference case purposely to impose risk premiums on the HDR facilities because of an assumed risk and uncertainty associated with early commercializations of the technology. Of course, lower and higher combinations of $i$ and $r$ are used in parametric analysis. In general, preoperational costs (Eq. 3-4) are discounted at the rate $i$ and $D C_{t}$-type costs are discounted at the rate $r$, that is, two 
different real discount rates are used. Thus, the generating plant and the power-producing activities are treated as separate entities for the purpose of accounting, reflecting to some extent, the differences in risk between the two operations. For all other purposes, however, the two operations are viewed as a single management entity.

\section{Time Horizons}

The planning horizon of $t^{\star}$ years, relates directly to the assumed useful lifetime of the HDR system. Useful lifetime of the HDR reservoir is mainly determined by reservoir temperatures (see Section 2), however, new reservoirs may be established at any point by redrilling. Other system properties that al so affect the useful lifetime of the power plant include the level of maintenance expenditures and the quality of the geothermal fluids as it relates to the scaling and fouling of plant equipment (pipes, heat exchangers, condensers, etc.). Although results from limited experiments at LASL suggest that water quality may not be a substantial problem in HDR systems, particularly relative to these problems experienced with some liquid-dominated systems, system lifetime for HDR systems is currently an open question.

For the reference case a 30-year life is used, but parametric analyses are conducted using time horizons of 20,40 , and 50 years. The intent is to simply present results that would obtain for a system with a $20,30,40$, or 50 year 1 ifetime.

\section{Surface Plant Costs}

The cost of the generating $p l$ ant $C_{p}$ was estimated using

$$
C_{p}=Q\left[\$ 976,910-\$ 2,146\left(T_{d}\right)\right],
$$

where $100^{\circ} \mathrm{C} \leq \mathrm{T}_{\mathrm{d}} \leq 300^{\circ} \mathrm{C}$, and $50 \mathrm{MW}(\mathrm{e}) \leq \mathrm{Q} \leq 100 \mathrm{MW}(\mathrm{e})$. This equation for surface plant construction costs was adapted from results presented by Milora and Tester (26). These costs are estimated to be a decreasing linear function of design temperature between 100 and $300^{\circ} \mathrm{C}$ and directly proportional to capacity above $50 \mathrm{MW}(\mathrm{e})$. Milora and Tester's original estimation equation was then scaled up by $10 \%$ to allow for inflation to 1978 prices.

Although the derivation of Eq. 3-8 is not presented here, several important features should be noted. First, to calculate an estimate of the fixed capital 
investment, a factored estimate was used for direct and indirect cost factors combined with the total purchased cost of major equipment associated with power conversion. For the binary fluid cycle, this equipment included a primary heat exchanger, desuperheater/condenser, wet or dry cooling towers, turbine, generator, and feed pump. The direct cost factor covers the costs of plant piping, buildings and structures, instrumentation, and equipment installation. The indirect factor covers engineering fees, contingency, escalation during construction, and environmental impact. The application of these cost factors resulted in an installed, surface plant cost of 2.8 times the purchased cost of the major equipment. Plant capacities in the 50 to $100 \mathrm{MW}(\mathrm{e})$ range were used. Heat exchange equipment costs were estimated using empirical correlations, which gave component costs per unit surface area as a function of construction material and shell- and tube-side pressures. Turbine and pump costs were also generated empirically, based on such things as number of stages, exhaust-end pitch diameter, casing pressure, bladetip speed, and construction materials.

The cost equation for the $\mathrm{pl}$ ant was obtained by averaging a number of binary fluid cycle case studies, with geothermal fluid source temperatures varying from 100 to $300^{\circ} \mathrm{C}$. For each fluid a number of heat rejection temperatures $(27,37$, and $49^{\circ} \mathrm{C}$ ) and designs were also pursued. Optimal operating conditions minimized the surface $\mathrm{plant}$ costs. Parameters that were varied included primary heat exchanger and condenser approach temperatures and cycle operating pressure from subcritical to supercritical operation.

Equation 3-8 was constructed as a guide to show the effects of temperature on surface plant costs. In general, it should be used cautiously, keeping in mind that surface $p l a n t$ costs can easily vary by $\pm 30 \%$ using any number of design possibilities. Once a specific site has been selected, more specific plant designs can be considered.

The power plant costs were then distributed over an estimated five-year construction period: $10 \%$ cash outlay in the first year, $17 \%$ in the second year, and $24.33 \%$ in the third, fourth, and fifth years of construction. In keeping with the feasibility criterion, these staggered construction costs were all compounded by the appropriate real discount rate ( $9 \%$ in the reference case) to the beginning of plant operations. 


\section{Other Prices and Costs}

In addition to the method used for estimating costs for drilling activities described in Section 2 and exploration/development costs given in Table 3-1, other cost-related items used in this work are as follows.

- Revenue Tax: $2.5 \%$ of gross revenue.

- 0\&M Costs: $1.3 \mathrm{mills} / \mathrm{kWh}$.

- Property Taxes: paid annually on $1 / 3$ of undepreciated value of $C_{p}$. A straight-line depreciation schedule is used, and a tad rate of 0.026421 is assumed.

- Working Capital: $10 \%$ of $C_{p}$ is maintained.

THE OPTIMIZATION MODEL

The optimization model used for this study employs a dynamic programming algorithm. The model, as implemented, is structured so as to minimize its computational requirements. The state variables of the model are the reservoir temperature $\left(T_{t}\right.$, in $\left.{ }^{\circ} \mathrm{C}\right)$ at the beginning of stage (time period) $t$ and the established drilling depths $\left(D_{t}\right.$, in meters) at the beginning of stage $t$. Choice or decision variables are well-flow rates $\left(\dot{m}_{t}\right.$, in $\mathrm{kg} / \mathrm{s}$ ) for the HDR reservoirs and the depth of drilling or redrilling ( $d_{t}$, in meters) during stage $t$. Terms used in summarizing the model are defined in Appendix $C$.

The model is formulated as follows.

Maximize

$$
\begin{aligned}
G_{t}\left(T_{t}, D_{t}\right) & =\left[\left(\operatorname{REV}_{t}-0 \& N\right)-D C_{t}\left(\operatorname{TAX}_{t}\right)\right. \\
& \left.+(1+r)^{-1} G_{t+1}\left(T_{t+1}, D_{t+1}\right)\right]-C_{0}
\end{aligned}
$$

subject to

$$
\begin{aligned}
T_{t+1} & =T_{t} \cdot \operatorname{erf}\left(\dot{m}_{t}, S\right), \text { if } d_{t}=0 \\
& =\left[15^{\circ} \mathrm{C}+\left(D_{t}+d_{t}-R\right) \nabla T\right] \operatorname{erf}\left(m_{t}, s\right), \text { if } d_{t}>0, \\
D_{t+1} & =D_{t}+d_{t} .
\end{aligned}
$$

The operation of this model can be described as follows. $G_{t}\left(T_{t}, D_{t}\right)$ is a measure of the present net value of profits from the sale of electricity for an 
$\mathrm{N}$-stage planning horizon; $t=1, \mathrm{~N}$; given that the system begins stage $\mathrm{t}$ with reservoir temperatures $T_{t}$ and established drilling depths $D_{t}$. This measure has four principle components, three of which are described in considerably more detajl below, and preoperational costs $C_{0}$ which were described above (see Eq. 3-4 and Table 3-1). The first component is revenues (net of gross revenue taxes) from the sale of electricity during stage $t\left(R E V_{t}\right)$ less $0 \& M$ costs. The second component is the drilling cost, incurred during stage $t\left(D C_{t}\right)$ adjusted for income taxes $\left(\operatorname{TAX}_{t}\right)$. The remaining component is the maximum present value of profits from the next stage of operation $(t+1)$ when reservoir temperatures and established drilling depths have values $T_{t+1}$ and $D_{t+1}$, respectively.

The values for $T_{t+1}$ and $D_{t+1}$ depend, of course, on decisions made during stage $t$. By Eq. 3-10A, if there is no drilling of redrilling during stage $t$, temperature drawdown in the HDR reservoir occurs, and the percentage decline in temperature is derived by the error function $\operatorname{erf}\left(\dot{m}_{t}, S\right)$--higher well-flow rates $\dot{m}_{t}$ during $t$ increase the rate of temperature drawdown for a given reservoir size (S). By Eq. 3-10B, if drilling or redrilling takes place during $t$, initial reservoir temperatures are enhanced and are at values slightly higher than initial reservoir temperatures (see Section 2). The Eq. 3-1 simply adjusts established drilling depths at the end of stage $t$ or the beginning of stage $t+1$ to reflect drilling during stage $t$.

By finding the maximum of $G_{1}\left(T_{1}, D_{1}\right)$, where $T_{1}=15^{\circ} \mathrm{C}$ (the reservoirs have not been established) and $D_{1}=0$ (no drilling has occurred), we can establish both the maximum value of system profits net of taxes over the lifetime of the system and the time path of drilling and flow rates that achieve this maximum value. Thus, the system is evaluated at its economic opt imum, given the system parameters (including initial conditions) and performance characterization.

Attention is now turned to a detailed description of the methods used in calculating the components of Eqs. 3-9 through 3-11.

\section{Calculation of Gross Period Revenues}

The calculation of periodic revenues involves the solution of

$$
R E V_{t}=p(1-E) \cdot f\left(\overline{T_{t}}, T_{d}\right) \cdot Q \cdot 8760 \cdot C F \cdot Z_{t} \cdot \dot{m}_{t} / \dot{m}_{d}
$$


In Eq. 3-12, $p$ is the selling price/kWh of electricity at the busbar, and $E$ is the gross revenue tax rate. The remaining six terms determine power output in kWh during stage t. $Q$ is the installed capacity in $M W(e) ; 8760$ is the number of hours in a year; and CF is the capacity factor, the average output of the plant as a proportion of rated capacity given anticipated downtime for repair and maintenance (varied in this work between $70-85 \%$ ). The ratio $\dot{m}_{t} / \dot{m}_{d}$ is the ratio of the well-flow rate (determined endogenously) to the design well-flow rate. This ratio is restricted to be no less than $80 \%$ of the design-flow rate; thus, the value of power output declines linearly with reductions in $\dot{m}_{t}$ below the design rate $\dot{m}_{d}$. $z_{t}$ equals unity unless drilling or redrilling takes place If drilling takes $p l a c e$ in period $t$, we essentially assume that the plant is closed $(100-z) \%$ of the period, and the value of power output during period $t$ is accordingly $Z \%$ of design output. The value for $Z$ used in this work is $96.7 \%$.

Finally, the function $f\left(T_{t}, T_{d}\right)$ is used to reduce the efficiency of the power plant in periods wherein reservoir temperatures are less than the design temperature of the plant $\left(T_{d}\right)$. The variable $W=\left(T_{d}-\bar{T}_{t}\right) / T_{d}$ is the ratio of the difference between $T_{d}$ and average fluid temperatures $\left(\bar{T}_{t}\right)$ and $T_{d}$. The relationship is used here to determine periodic output as a function of installed capacity, as is given in Figure 3-1. A discrete approximation of this relationship is used in the model as given by the following.

$$
\begin{array}{rlrl}
W & \leq 0.075, \text { then } f(W) & =1 .-3.47 W \\
0.075<W \leq 0.125, & =0.75-3(W-0.075) ; \\
0.125<W \leq 0.250, & =0.6-2(W-0.125) ; \\
0.250<W \leq 0.4, & =0.35-1.33(W-0.25) ; \\
0.4<W<0.6, & =0.15-0.75(W-0.4) ; \text { and } \\
0.6 \leq W, & =0 .
\end{array}
$$

Thus, as $\bar{T}_{t}$ declines below $T_{d}$, power output declines at a rapid rate. If $\bar{T}_{t}$ is less than $40 \%$ of $T_{d}$, power output is zero.

Other Components of the Model

Other components of the system of Eqs. 3-9 through 3-11 are the following. Values for design flow rates, as a function of $T_{d}$, applicable for a binary fluid Rankine cycle are based on the relation given in Figure 3-2. The equation given in Figure $3-2$ is the result of a regression of flow rates on $T_{d}$ using points along the curve given in Figure 3-2. 
The structure used for calculating drilling costs was described in Section 2 and the same holds for the terms that adjust costs for income taxes (see Eqs. 3-3 and 3-6). Values used for the geothermal temperature gradient $T$ are $30,40,50$, and $60^{\circ} \mathrm{C} / \mathrm{km}$.

The final component of interest here is in the error function erf $\left(\dot{m}_{t}, S\right)$ used in the transition Eqs. 3-10a and 3-10b to calculate temperature drawdown in the HDR reservoirs. The error function is taken from the estimates of temperature drawdown for an ideal fracture with uniform flow by McFarland and Murphy. (31) The development of this relationship between $m_{t}$ and drawdowns, for a given reservoir size (see Section 2) is complex, and to preserve the continuity of the arguments developed here, the exposition of the error function is given in Appendix $A$. In addition, the nature of temperature drawdowns that result from the use of the error function are developed in Appendix $B$ for various reservoir sizes with a $160^{\circ} \mathrm{C}$ resource and a constant flow rate of $75 \mathrm{~kg} / \mathrm{s}$.

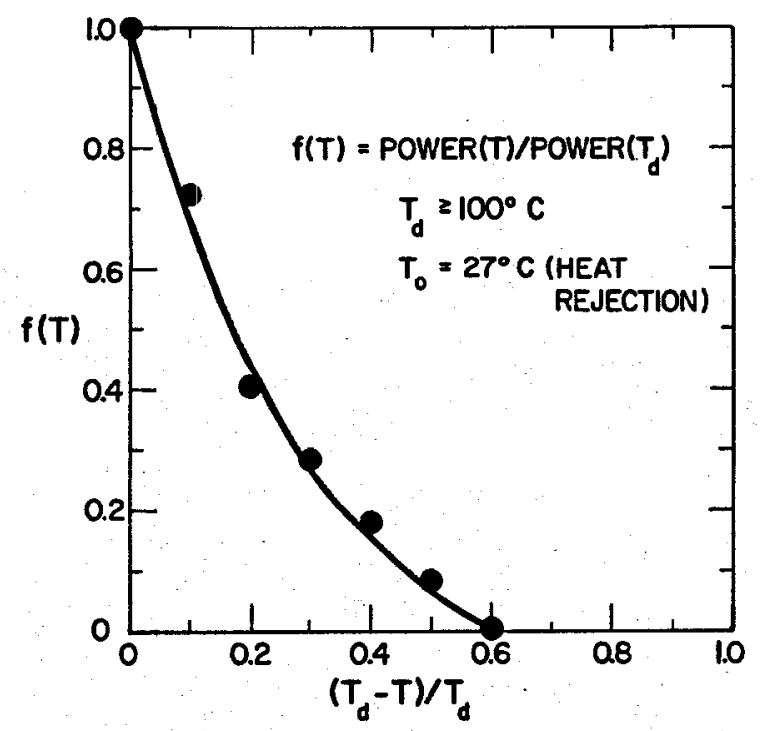

Figure 3-1. Power decline as a function of the fractional fluid temperature drop from the design temperature $T_{d}$. 
USE OF THE MODEL TO GENERATE BUSBAR COSTS

As described above, the solution of the dynamic programming model yields a value, denoted $G_{1}(0,0)$, which is the maximum present value of system profits at the initial period where $T_{1}=15^{\circ} \mathrm{C}$ and $D_{1}=0 . G_{1}(0,0)$ measures profits after all costs including interest changes, taxes, and payments to bond and stockholders have been accounted for. As such, $G_{1}(0,0)$ measures excess profits, those that exist after normal profits have been achieved.

The calculation of $G_{1}(0,0)$ requires the use of a price/kWh (denoted $p$ ). In this work $p$ is chosen arbitrarily and then varied until the solution $G_{1}(0,0)=0$

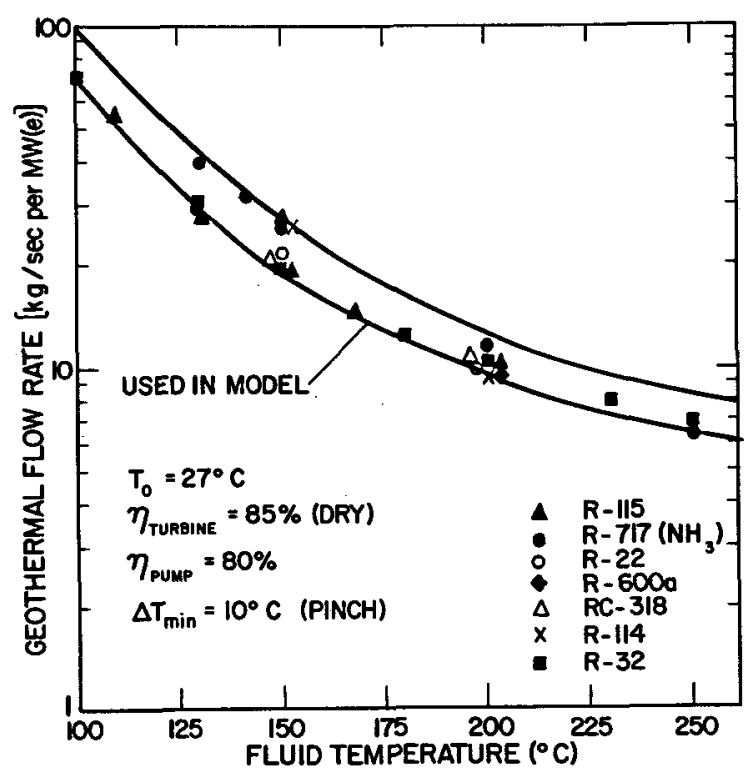

Figure 3-2. Binary fluid Rankine-cycles optimum thermodynamics conditions. Designflow rate requirements $\dot{M}_{d} \operatorname{per} M W(e)$ as a function of fluid temperature for different working fluids. Model calculation correlated as

$$
\begin{aligned}
& \dot{M}\left(T_{d}\right)=8.369 \times 10^{2}-1.631 \times 10^{1} \mathrm{~T}_{d} \\
&+1.224 \times 10^{-1} \mathrm{~T}_{d}^{2}-4.115 \times 10^{-3} \mathrm{~T}_{d}^{3} \\
&+5.179 \times 10^{-7} \mathrm{~T}_{d}^{4} . \\
& T_{d}={ }^{0} \mathrm{C} ; \dot{M}\left(\mathrm{~T}_{d}\right)=\mathrm{kg} / \mathrm{s} \operatorname{per} \operatorname{MW}(\mathrm{e}) .
\end{aligned}
$$


is obtained. The price $p^{\star}$ that results in this condition may then be viewed as the minimum selling price of electricity at the busbar that just covers all required costs. As such, this derived $p^{*}$ provides the measure described as the levelized busbar cost or, more simply, the busbar cost.

\section{RESERVOIR-ECONOMIC PARAMETERS: A SUMMARY}

Now that the reader has been exposed to numerous parameter and functional relations, a surmary of the characterization of the HDR electric generating process will provide an overview of the study. This summary is given in Table 3-2.

\section{PLAN FOR ANALYSES AND MAJOR CAVEATS RELEVANT FOR THE ANALYSES}

As stressed throughout the preceding sections, the purpose of this work is to analyze an electricity-producing system whose structure, in terms of engineering and economic parameters and characteristics, is in all cases speculative. Therefore, we can analyze, or assess only a hypothesized structure for this system and calculate the busbar price associated with the hypothesized structure. Such an analytical approach is commonly described as parametric analyses.

A study of sensitivity based on parametric analyses, requires a point of departure, that is, a reference case. For this purpose a set of parametric values that appear to be reasonable according to available information are chosen and used to calculate the reference case conditions, or simply the reference case. Parametric values and assumptions for the reference case are given in Table 3-3.

The analyses continue from the reference case with examination of the ramifications of parameter changes on values for $p^{*}$ (the level ized busbar cost), as well as on optimal drilling and other management strategies. Parameters and relations that will (and will not) be analyzed parametrically in this work are described in Table 3-4. Thus, the remaining sections of this report focus on analyses concerning the HDR system under the reference case assumptions (Section 4) and with the parametric changes described in Table 3-4 (Sections 5-7).

Before beginning these analyses, however, it is important that the results discussed in the upcoming sections be viewed within an appropriate perspective. The optimization model provides optimal values for endogenously determined variables for a world that is precisely described by the model's structure. But this model is not intended to perfectly or completely describe the socio-institutional, 
Table 3-2

SUMMARY OF RESERVOIR AND ECONOMIC PARAMETERS

Reservoir Parameters

Geothermal Temperature Gradient $(\nabla T)$ :

Capacity Factor (CF):

System Life:

Fluid Cycle:

Well-Flow Rates:

Design-Flow Rate:

Design Temperature:

Installed Capacity:

Reservoir Size:

Shutdown Time for Redrilling

Temperature Drawdown:

Plant Efficiency

\section{Economic Parameters}

Taxes:

Real Rates of Return:

Exploration, Development, and

Plant Costs:

O\&M Costs:

Drilling Costs:

Investment Tax Credits, Depletiontype allowances:
Functional Relations

Varied between $20-60^{\circ} \mathrm{C} / \mathrm{km}$.

$70-85 \%$.

20-50 years.

Binary fluid Rankine cycle.

Varied between $80-100 \%$ of design-flow rate.

Determined by design temperature as given in Figure 3-2.

$$
150-235^{\circ} \mathrm{C} \text {. }
$$

$$
\text { 10-50 MW(e). }
$$

Individual fractures have radii of 300 meters. Number of fractures varies between 3 and 12 .

Two months.

Determined by the error function detailed in Appendix A.

Varies proportionally with the ratio of well-flow rate to design-flow rate, and with geothermal fluid temperatures (see Figure 3-1).

\section{Functional Relations}

$51 \%$ income tax; $2.5 \%$ revenue tax; using straight-line depreciation; $2.6421 \%$ property taxes are charged on one-third of the undepreciated value of plant costs.

On debt, $i=3,6,9-12 \%$

On equity, $r=6,9,12,15,18$, and $21 \%$.

See Table 3-1 and Eq. 3-8.

$1.3 \mathrm{mills} / \mathrm{kWh}$ and varied.

See Eqs. 2-2 through 2-7.

\section{None.}


Table 3-3

PARAMETER VALUES AND ASSUMPTIONS FOR THE REFERENCE CASE

\section{Reference Case Conditions}

$\begin{array}{ll}\text { Real Rate of Return on Equity } & =12.0 \% \\ \text { Real Rate of Interest on Debt } & =9.0 \% \\ \text { Number of Fractures } & =6 \\ \text { Fracture Radius } & =300 \mathrm{~m} \\ \text { Geothermal Gradient } & =40^{\circ} \mathrm{C} / \mathrm{km} \\ \text { Plant Design Temperature } & =160^{\circ} \mathrm{C} \\ \text { Maximum Well-Flow Rate per Pair of Wells } & =75 \mathrm{~kg} / \mathrm{s} \\ \text { Capacity Factor } & =0.85 \\ \text { System Life } & =30 \text { years } \\ \text { Plant Capacity } & =50 \mathrm{MW}(\mathrm{e}) \\ \text { Operation and Maintenance (1978 } \$) & =1.3 \mathrm{mills} / \mathrm{kWh} \\ \text { Contingency } & =13 \% \\ \text { Working Capital } & =10 \% \text { of surface plant } \\ \text { Number of Decision Periods } & =6 \\ \text { Taxes cost } & =51 \% \text { of taxable }\end{array}$

political, economic, or engineering environment in which an HDR system might one day operate. The model (1ike all other models) abstracts from many characteristics of the real world but hopefully includes those that are of primary importance for the intended purposes of the work.

Assumptions used in this model, which were related to real interest rates, taxes, drilling and 0\&M costs, power production, etc., have been discussed in detail. However, there are a few subtle problems of a conceptual and/or computational nature that should be pointed out. These problens are as follows.

For computational and expositional simplicity, we allow the required number of HDR reservoirs $N$ to be a real number. Thus, a particular set of results might be based on the use of 2.3 or 4.7 reservoirs (pairs of wells), but only integer values of $2,3,4$, or 5 reservoirs could actually be drilled. To avoid this, $N$ must be a whole number. Therefore if $4.5 \leq N \leq 5.499$, set $N=5$; or if $5.5 \leq N \leq$ 6.499 , set $N=6$, etc. A problem with this method is that a system requiring 4.5 
Table 3-4

PLANNED PARAMETRIC ANALYSES

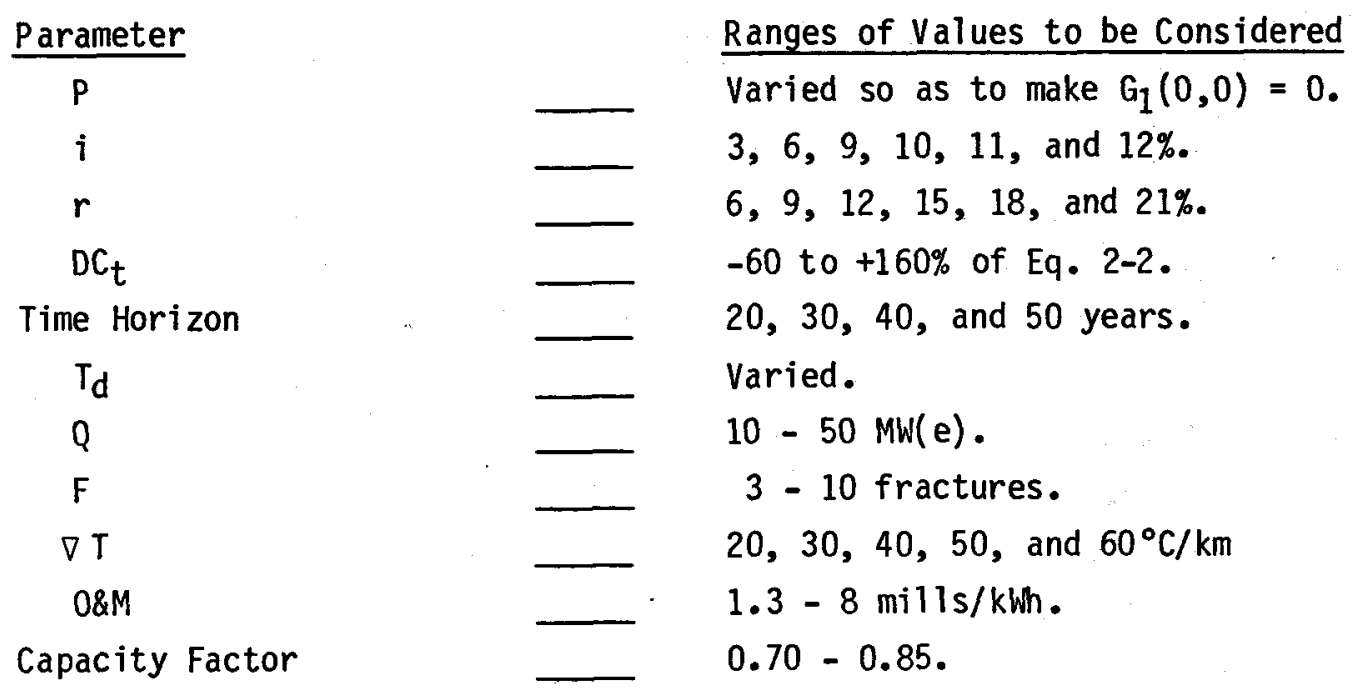

Values/Relations Not Changed Under Current Plans

Plant/Setup Costs

Tax Rates: Rev. $\operatorname{Tax}=2.5 \%$ of gross revenues.

$f\left(T_{t}\right)$

Inc. Tax $=0.51 \%$ of payments to stockholders.

$M_{d}$

Use of Binary Fluid Rankine-Cycle Power Conversion System.

reservoirs would cost the same as one requiring 5.4 reservoirs. Of course, in the actual situation minor adjustments in plant capacity and/or $T_{d}$ and/or $\dot{m}_{d}$ would be made so as to make 4 or 5 reservoirs (in this example) a rational choice. Including these adjustments in the computation would create complexities that cannot be handled at this stage of our work, and therefore we will use fractions of reservoirs. In doing so, we may necessarily be over- or under-estimating well costs.

As explained above, variables in this model ( $\dot{m}_{t}, T_{t}, d_{t}$, and $D_{t}$, see Table 3-3) are given discrete values; further, discrete time periods of five years are used. Although we have tried to minimize problems associated with the use of discrete values for variables by setting up a relatively fine grid (100-m drilling increments or $2.5^{\circ} \mathrm{C}$ temperature increments), the deviations from the true optimum may be significant if the errors compound themselves. The choice of a five-year decision period was made to minimize the computation time required by the code. 
Significant reduction of the decision period would require not only more iterations within the code but also a much more elaborate characterization of the rate of the reservoir temperature decline and another state variable in the model.

The time frame for these analyses should be reemphasized. As the model is structured, costs and revenues are evaluated once--at the first year of operation. Thus, payments are not required in any single period, and the cash flow problem is ignored. For a feasible system, the present value of revenues over a $t^{*}$-year period must only be sufficient to cover the present value of all costs incurred over the $t^{*}$-year period (plus 9 years before operation during which exploration-development, land acquisition, and plant construction costs are incurred. 
Section 4

ANALYSIS OF THE REFERENCE CASE

This section of the report is devoted to an analysis of the reference case described in the preceding section. The choice of reference case conditions is not meant to imply that these conditions are regarded by the authors as either the best charaterization or the most likely outcome for HDR-produced electricity. They were selected simply to initiate parametric analyses.

OPTIMAL MANAGEMENT CHARACTERIZATIONS

In searching for a levelized busbar cost for the reference case, the selling price of electricity is varied until the price $p^{*}$ is found such that the present value of revenues just equals the present value of all costs. The results of this iteration are given in Figure 4-1. The price at wich these conditions obtain is $43.2 \mathrm{mils} / \mathrm{KWh}$, which is the levelized busbar cost for the reference case.

The present value of surface plant equipment costs for the reference case at the start of production is $\$ 43.2$ million. Other surface costs, including site development and exploration (including exploratory drilling), property taxes, and working capital charges, are $\$ 12.2$ million, where present values are measured at the start of production. These items are presented in greater detail in Table 4-1. Together they yield an aggregate value, called total surface costs, of $\$ 55.4$ million.

Table 4-2 gives the present values of periodic drilling costs. The total of these costs is $\$ 56.6$ million. Given the treatment of debt and equity capital described in Section 3 , this results in a debt/equity ratio for the reference case of 0.98 . This figure differs slightly from usual debt/equity ratios in that it is derived from the present value of a time path of equity expenditures. It is presented here as an indication that the model solution does not reflect a heavily leveraged investment. From Tables 4-1 and 4-2, the sum of surface costs and drilling costs for the reference case is $\$ 55.4$ million plus $\$ 56.6$ million, or $\$ 112$ million. 


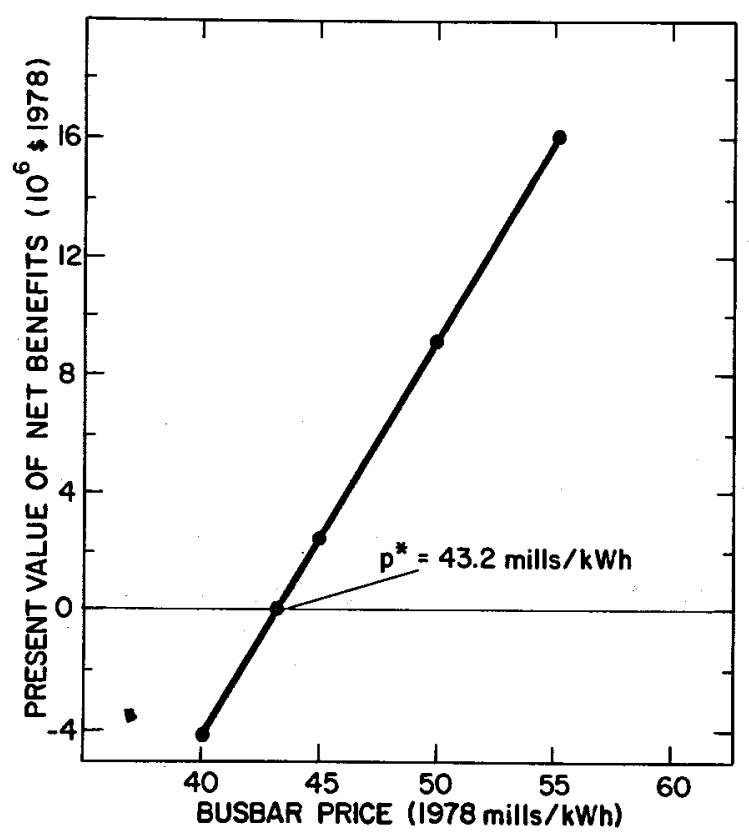

Figure 4-1. The present value of net benefits for various electricity selling prices in the reference case.

\section{Table 4-1}

PRESENT VALUE OF THE COMPONENTS OF

SURFACE CAPITAL COSTS: REFERENCE CASE

Million Dollars

Plant Construction Costs

43.2

Land Acquisition Costs

Purchasing

0.3

Leasing

0.1

Siting (Geophysical Costs)

0.6

Exploratory Wells

Shallow

0.6

Deep

4.7

Property Tax Over Plant Lifetime

1.6

Working Capital

4.3

TOTAL SURFACE COSTS

55.4 
Table 4-2

THE TIME PATH OF DRILLING COSTS IN THE REFERENCE CASE

\begin{tabular}{|c|c|c|}
\hline $\begin{array}{l}\text { Time } \\
\text { Period }\end{array}$ & $\begin{array}{l}\text { Time Period Value } \\
\text { of Drilling Costs } \\
(\$ \text { million, 1978) } \\
\end{array}$ & $\begin{array}{c}\text { Present Value at Start of } \\
\text { Production for Drilling Costs } \\
(\$ \text { million, 1978) }\end{array}$ \\
\hline 1 & 44.9 & 44.9 \\
\hline 2 & 9.5 & 5.4 \\
\hline 3 & 10.0 & 3.2 \\
\hline 4 & 10.6 & 1.9 \\
\hline 5 & 11.1 & 1.2 \\
\hline \multirow[t]{2}{*}{6} & 0.0 & $\underline{0.0}$ \\
\hline & & 56.6 \\
\hline
\end{tabular}

The time path of production and revenues, on the other hand, is given in Table 4-3. As this table shows, production and revenues vary over time as a result of changing operating conditions. During the first decision period of the reference case solution, the average annual production rate is $n 329 \mathrm{mill}$ ion $\mathrm{kWh}$, or about $88 \%$ of the maximum possible production rate after correcting for the capacity factor. The difference between this average annual production rate and the maximum rate reflects the decline in reservoir temperatures below plant design temperature over the course of the first decision period and the downtime associated with drilling activity.

The drilling strategy called for by the solution to the model begins with the initial drilling of approximately eleven pairs of wells (11.188 pairs of wells; see related discussion in Section 3 ) to a vertical depth of $4000 \mathrm{~m}$. For each pair of wells, a system of six vertical fractures with radij of $300 \mathrm{~m}$ are created so as to intersect a lateral extension of the two wells (see Figure 2-2C). This initial drilling activity is estimated to cost $\$ 44.9$ million: $\$ 43.6$ million for drilling services and equipment, $\$ 0.203$ million for rig mobilization, and $\$ 1.1$ million for a pipe system to gather and redistribute the geothermal fluid.

The solution calls for periodic redrilling of all well-pairs in the system during each of the four subsequent decision periods. Each redrilling increases the vertical depth of the wells by $100 \mathrm{~m}$ and, again, includes lateral drilling associated with the creation of a fracture system. The costs associated with these redrilling activities were presented in Table $4-2$ and are considerably less than 
$\$ 27.4$ million. The other item, despite its incorporation into the cost side of the analysis, is a credit associated with the tax deductions afforded by interest payments on the debt portion of the investment. The approach was also described in Section 3. In the reference case, the present discounted value of this credit is $\$ 26.1$ million. The present value of the net tax obligation is then $\$ 27.4$ million less $\$ 26.1$ million, or $\$ 1.3$ million.

The present value of revenues, net of $0 \& \mathrm{M}$ charges and revenue taxes, ( $\$ 113.3 \mathrm{mil}-$ lion) less the sum of surface and drilling costs ( $\$ 112$ million), and adjusted for the net tax bill of $\$ 1.3$ million, is zero, which is the condition requisite for $\mathrm{p}^{*}$ as a levelized busbar cost. Finally, the optimal solution for reference case assumptions involves well-flow rates $\left(\dot{m}_{t}\right)$ that are always at the design rate of $75 \mathrm{~kg} / \mathrm{s}$.

In summary, over the course of each of the five-year decision periods in the reference case, the temperature of the reservoir drops significantly. It is then reestablished at progressively higher levels as redrilling and refracturing occur at the beginning of periods 2-5 (see Figure 4-2). As noted above, redrilling does not occur at the beginning of the sixth period (twenty-sixth year), and reservoir temperature drops dramatically below the design temperature by the thirtieth year.

\section{ANALYSIS OF TRADE-OFFS IN THE REFERENCE CASE SOLUTION}

The optimal management strategy for the reference case described above is based upon various trade-offs between costs and revenues. One potential trade-off concerns the choice of well-flow rates $\dot{m}_{t}$, which are at their maximum value of 75 $\mathrm{kg} / \mathrm{s}$. The rationale for this strategy is taken from the data given in Figure 4-3. As $\dot{m}_{t}$ moves from the imposed lower bound of $60 \mathrm{~kg} / \mathrm{s}$ towards the upper bound of $75 \mathrm{~kg} / \mathrm{s}$, the value of power output continually increases. Under these conditions, this value is maximized at $75 \mathrm{~kg} / \mathrm{s}$. As detailed in section 2 , higher values for $\dot{m}_{t}$ increase flow efficiencies (and therefore the value of power output) as indiated by the ratio $\dot{\mathrm{m}}_{t} / \dot{\mathrm{m}}_{\mathrm{d}}$. Higher values for $\dot{\mathrm{m}}_{t}$, however, reduce thermal efficiencies by increasing the rate at which reservoir temperatures decline. Thus, flow efficiencies dominate the related thermal inefficiencies attending higher well-flow rates, and the optimal value of $\dot{m}_{t}$ is the maximum value. 


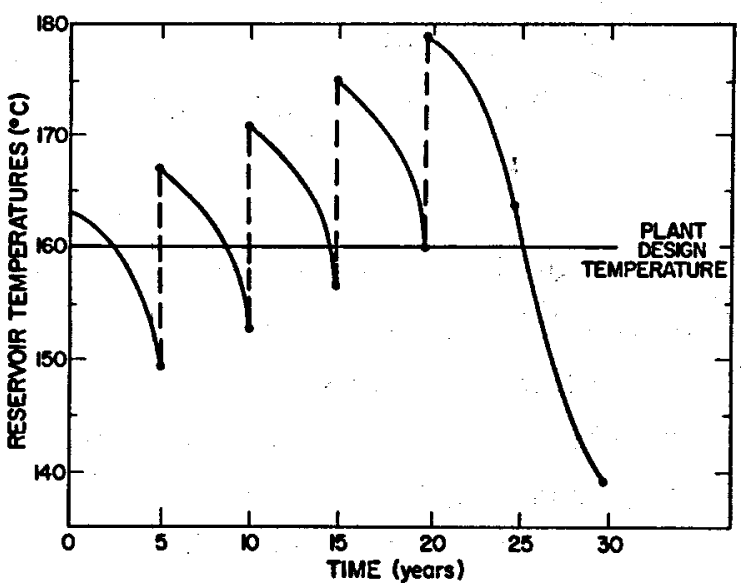

Figure 4-2. Time path of reservoir temperatures for the optimal management of the reference case.

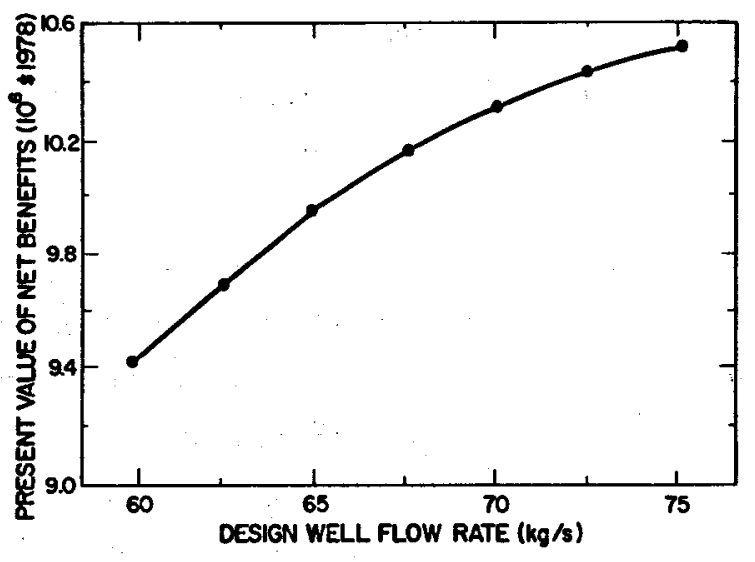

Figure 4-3. Present value of net benefits with variation in the design well-flow rate.

A particularly interesting trade- off in the reference case solution is that associated with drilling costs. In the first decision period, the model trades off the costs associated with deeper drilling against the increased revenues that might be achieved from higher reservoir temperatures at the greater depths. To appreciate the quantitative nature of this trade-off, consider Table 4-4, which shows the total and marginal drilling costs as they vary with drilling depth. As expected, the exponential costs of drilling yield increased marginal drilling costs. This marginal relationship is plotted in Figure 4-4.

Table 4-5 presents first period revenues, which would be generated by differing initial drilling depths, and the marginal revenues per meter drilled. Seen from these data, the marginal revenues rise rapidly over drilling increments from 3000 to $4000 \mathrm{~m}$. Beyond $4000 \mathrm{~m}$, however, marginal revenues decline because fluids from reservoirs below $4000 \mathrm{~m}$ in depth will be above the surface plant design temperature. This relationship is al so plotted in Figure 4-4.

The optimal management strategy is one which maximizes net benefits. This occurs when marginal costs are equated with marginal revenues. As demonstrated in Figure 4-4, marginal revenues equal marginal costs associated with initial drilling activities at a depth of about $4000 \mathrm{~m}$, which is in fact the first period drilling depth for the reference case solution. Again, the model yields results that are consistent with the dictums of net-benefit maximization. of course, a 
different set of engineering and economic conditions might yield an optimal solution with a different initial drilling depth, and these issues are treated in later parametric analyses.

A similar analysis can be performed for the drilling decision during the last period. The decision would be whether or not to redrill another $100 \mathrm{~m}$ vertically and $250 \mathrm{~m}$ horizontally to establish a new reservoir with higher temperatures. This would allow the HDR system to operate at its maximum capacity and would increase the revenues in the period by $\$ 9.5$ million, from $\$ 45.7$ million to $\$ 55.2$ million. Redrilling costs, however, would be $\$ 11.7$ million. Marginal costs ( $\$ 11.7$ million) would exceed marginal benefits $(\$ 9.5 \mathrm{million})$, and a decision to redrill would yield a net loss.

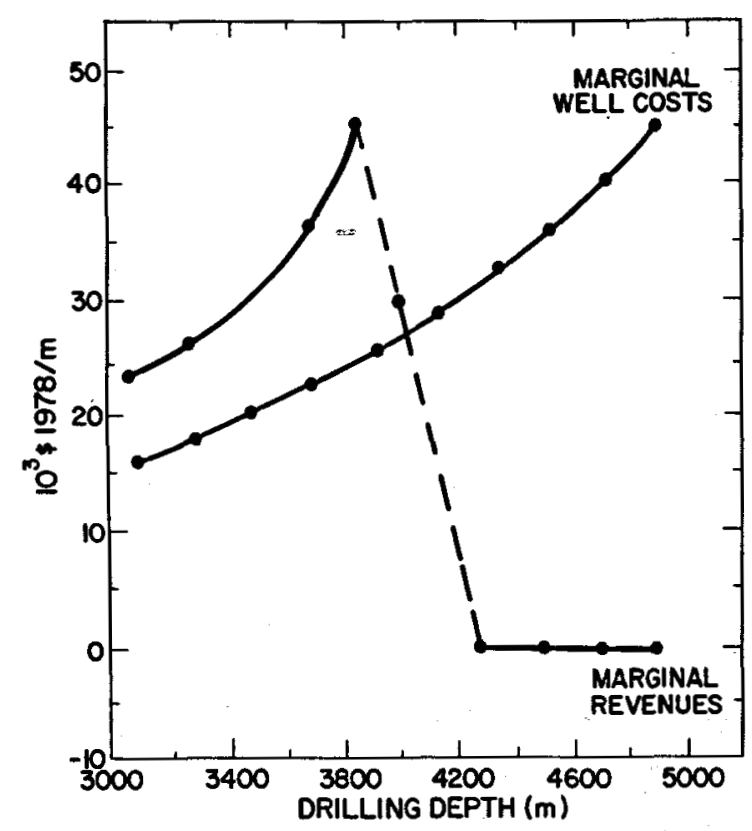

Figure 4-4. Marginal well costs and marginal revenues associated with drilling in the first decision period of the reference case. 
Table 4-4

DRILLING COSTS FOR VARIOUS DRILLING DEPTHS

IN THE FIRST DECISION PERIOD OF THE REFERENCE CASE

\begin{tabular}{ccc}
$\begin{array}{c}\text { Drilling } \\
\text { Depth } \\
(\mathrm{m})\end{array}$ & $\begin{array}{c}\text { Total We 11 Costs } \\
\text { (\$ Million) }\end{array}$ & $\begin{array}{c}\text { Marginal Wel1 costs } \\
\text { (\$ Thousand) }\end{array}$ \\
\hline 3000 & 23.8 & 16.7 \\
3200 & 27.1 & 18.6 \\
3400 & 30.9 & 20.8 \\
3600 & 35.0 & 23.2 \\
3800 & 39.7 & 25.8 \\
4000 & 44.8 & 29.4 \\
4200 & 50.7 & 32.0 \\
4400 & 57.1 & 35.6 \\
4600 & 64.2 & 39.5 \\
4800 & 72.1 & 43.8 \\
5000 & 80.9 &
\end{tabular}

Table 4-5

REVENUES FOR VARIOUS DR ILLING DEPTHS IN THE

FIRST DECISION PERIOD OF THE REFERENCE CASE

\begin{tabular}{ccc}
$\begin{array}{c}\text { Drilling } \\
\text { Depth } \\
(\mathrm{m})\end{array}$ & $\begin{array}{c}\text { Present Value of Revenues } \\
(\$ \text { Million) }\end{array}$ & $\begin{array}{c}\text { Marginal Revenues } \\
(\$ \text { Thousand })\end{array}$ \\
\cline { 1 - 2 } 3000 & 18.3 & 23.9 \\
3200 & 23.1 & 26.4 \\
3400 & 28.4 & 27.8 \\
3600 & 33.9 & 37.2 \\
3800 & 41.4 & 45.9 \\
4000 & 50.6 & 23.5 \\
4200 & 55.3 & 0 \\
4400 & 55.3 & 0 \\
4600 & 55.3 & 0 \\
4800 & 55.3 & 0 \\
5000 & 55.3 &
\end{tabular}


Section 5

ANALYSIS OF THE OPTIMAL PLANT DESIGN TEMPERATURE

This section examines the effects of variations in plant design temperature on the estimated levelized busbar cost for HDR-produced electricity. As suggested in Section 4, the reference case conditions will be the point of departure for many of these analyses. Recall that discussions in Sections 2 and 3 noted that the choice of a $T_{d}$ is a management decision involving economic trade-offs. Consequently, this section will examine the issue of an optimal $T_{d}$ under a variety of circumstances, including the effect of different geothermal gradients on optimal design temperatures.

\section{OPTIMAL PLANT DESIGN TEMPERATURE FOR THE REFERENCE CASE}

The optimal design temperature $\left(T_{d}\right)$ for the surface plant of an HDR system is of great interest to those who are involved in the evaluation and development of the HDR geothermal concept. As Section 3 suggests, higher surface plant design temperatures have three distinct impacts on project costs and revenues. First, higher plant design temperatures would require deeper wells to obtain geothermal fluids with initial temperatures equal to the design temperature. This would increase the cost of drilling and redrilling each reservoir system. Second, higher plant design temperatures would reduce the number of reservoir systems and piping costs needed to allow the surface power plant to attain a given output capacity. This is the case because the higher design temperature allows the plant to derive more energy per unit of fluid, and this, in turn, reduces the total flow requirements of the HDR system. Finally, the cost of the surface plant declines as its design temperature increases. The question then is at what design temperature will the cost increase associated with increased depths just balance the cost reduction associated with fewer reservoir systems and lower surface plant costs? The analysis is conducted by means of a parametric variation in the design tentperature of the reference case. $T_{d}$ varies from 140 to $180^{\circ} \mathrm{C}$ in $5^{\circ} \mathrm{C}$ increments. 
All other model inputs were held at reference case values, and $p=45 \mathrm{mills} / \mathrm{kWh}$. For each value of $T_{d}$, the present value of revenues net of all costs [ referred to as the present value of net benefits (PVNB)] is calculated, and these values for each $T_{d}$ are given in Figure 5-1. Recall that the model solves for the optimal management strategy given the value of the input variables. Thus, these results are the present values of net benefits of an optimally managed system given the specified plant design temperature. They suggest that, for reference case assumptions, the optimal plant design temperature is in the neighborhood of $157^{\circ} \mathrm{C}$.

The data plotted along the curve in Figure 5-1 are based on identical management requirements for flow rates. In all cases a flow rate management obtains that requires the maximum flow of $75 \mathrm{~kg} / \mathrm{s}$ through the reservoir system throughout the lifetime of the facility.

The solutions differed considerably, however, in the drilling strategies that were pursued: initial depths and redrilling choices under optimal management varied substantially with the different $\mathrm{pl}$ ant design temperatures. These variations are depicted graphically in Figure 5-2. As expected, initial drilling depths increase as the design temperature increases from 140 to $155^{\circ} \mathrm{C}$. Over this range for $T_{d}$, redrilling occurs at the beginning of the second, third, and fifth

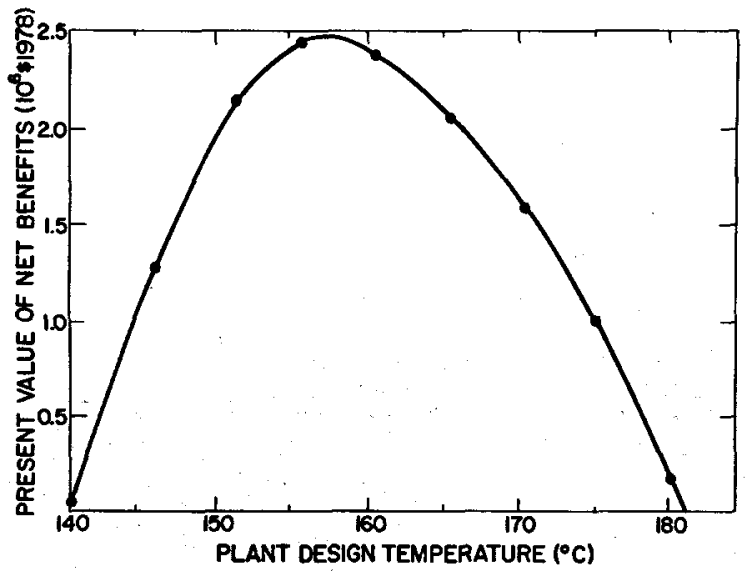

Figure 5-1. Present value of net benefits for alternative plant design temperatures in the reference case, $\nabla T=40^{\circ} \mathrm{C} / \mathrm{km}$ and $\mathrm{f}_{\mathrm{d}}=75 \mathrm{~kg} / \mathrm{s}$.

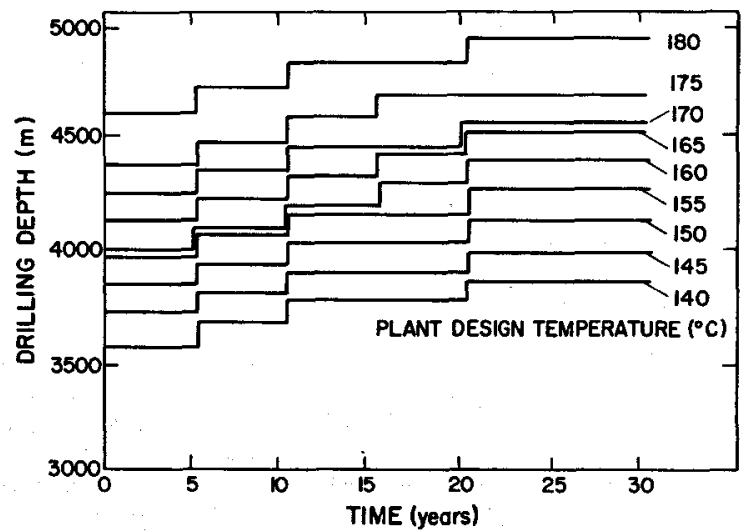

Figure 5-2. . Optimal drilling strategies for alternative plant design temperatures. 
decisian periods. At a design temperature of $160^{\circ} \mathrm{C}$, however, an alternative drilling strategy becomes optimal. The initial drilling depth is the same as for a design temperature of $155^{\circ} \mathrm{C}(4000 \mathrm{~m})$, and additional redrilling at the beginning of the fourth period is undertaken. This redrilling pattern continues, along with increasing initial drilling depths for design temperatures of 165 and $175^{\circ} \mathrm{C}$.

At design temperatures of 170 and $180^{\circ} \mathrm{C}$, the redrilling strategy that avoids redrilling in the fourth period is optimal. This solution pattern suggests that there is a slight trade-off between deeper initial drilling depth and redrilling in the fourth period of operation and al so that relatively small changes in plant design temperature can change the optimal solution from one redrilling pattern to the other.

Figures 5-3 and 5-4 characterize the way in wich costs associated with higher plant design temperatures combine to yield an optimal design temperature. These

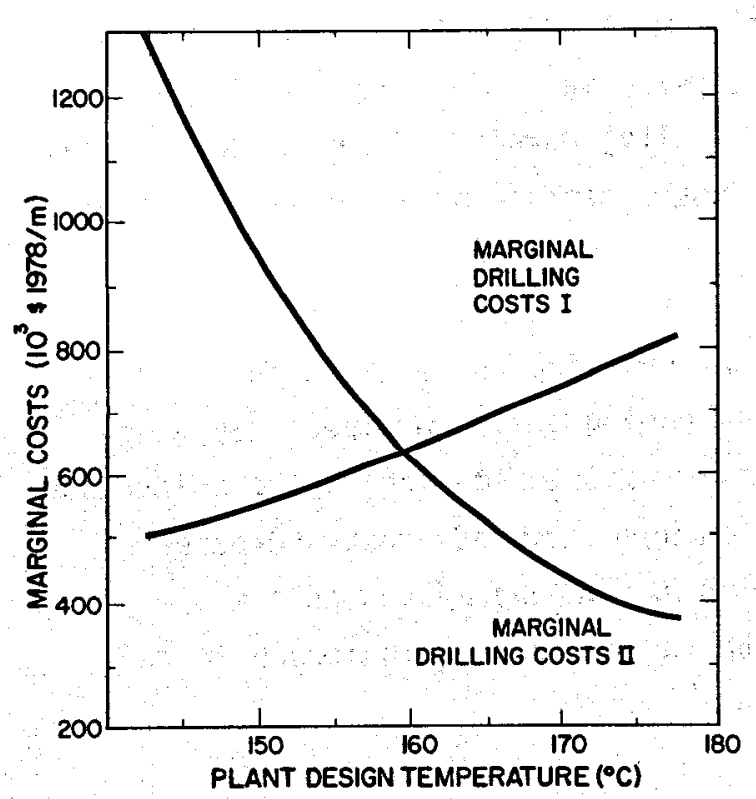

Figure 5-3. Marginal costs associated with varying the plant design temperature. Marginal plant costs were constant for all design temperatures at $-\$ 145,000 / \mathrm{m}$.

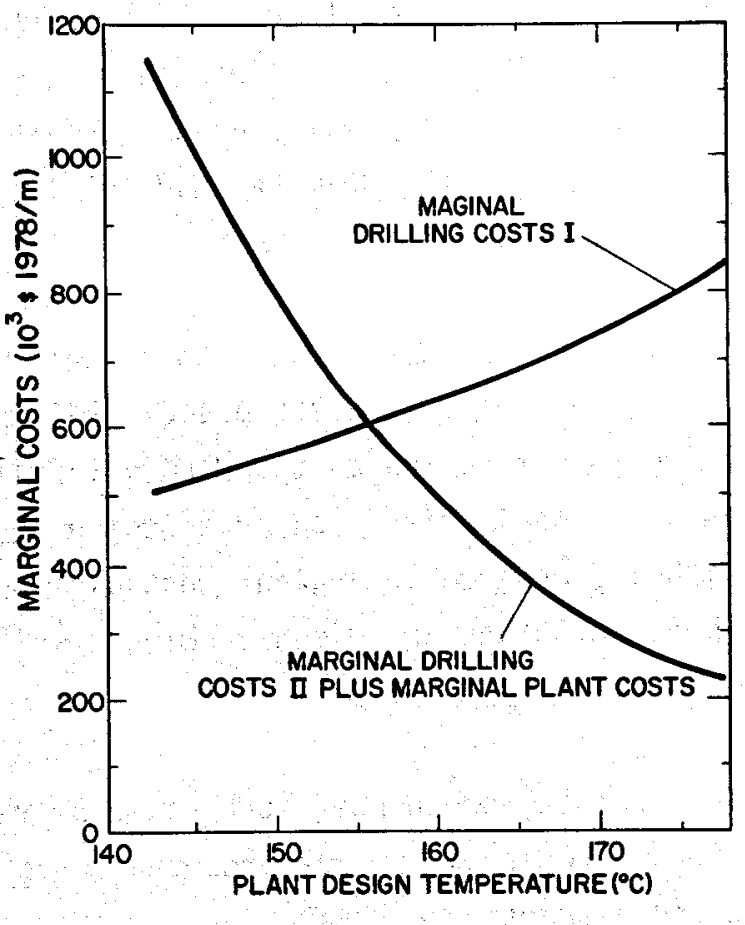

Figure 5-4. Determination of the optimal plant design temperature in the reference case. 
figures are based upon a partial analysis in that not all parts of the system were allowed to respond to the changes in the design temperatures that are postulated. Even this partial analysis, however, serves to provide some measure of the relative magnitudes and patterns of changes in costs that result from changes in design temperatures.

Figure 5-3 shows increasing marginal drilling costs resulting from the increased depths of initial drilling that attend higher design temperatures. This marginal cost function was derived by calculating first-period drilling costs as plant design temperature $\left(T_{d}\right)$ varied, and wile the number of pairs of wells held at in the reference case level. This function, denoted Marginal Drilling Costs I, shows increasing marginal costs with increasing $T_{d}$. These costs do not include cost impacts associated with redrilling in future periods. Such a calculation would most likely shift the curve upward somentiat.

The second marginal drilling cost function, Marginal Drilling Costs II, describes the change in drilling costs associated with the impact of design temperature on the flow rate. In other words, drilling depth is held constant while the marginal cost associated with reduced numbers of well systems and piping requirements is calculated. This function shows decreasing marginal costs with increases in $T_{d}$. As in Marginal Drilling costs $I$, other system variables such as flow rates and redrilling strategies are held fixed. Finally, Marginal Plant Costs are held constant at $-\$ 145,000 / \mathrm{m}$ because total $\mathrm{pl}$ ant costs decline at a constant rate as $T_{d}$ increases.

By combining Marginal Plant Costs and Marginal Drilling Costs II, a function relating decreases in costs associated with increasing $T_{d}$ is obtained. By overlying this function on the Marginal Drilling Costs $I$, which includes the increase in costs as $T_{d}$ rises, an intersection results where marginal cost increases with $T_{d}$, and equal marginal cost declines with $T_{d}$ for the system as a whole. These relations are given in Figure 5-4, with the optimal $T_{d}$ indicated to be $\sim 157^{\circ} \mathrm{C}$.

This result, of course, is based upon reference case conditions and the assumptions of cost and perfomance that have been incorporated into the model. Given these assumptions, however, the result enhances the attractiveness of the HDR concept because it suggests that for a system designed around an optimal $T_{d}$, the required drilling will be to temperatures and depths obtainable with current 
drilling technology and within the experience of many drilling engineers.

Higher optimal design temperatures, perhaps in the neighborhood of $250^{\circ} \mathrm{C}$, would increase the difficulties and costs of drilling and/or redrilling.

OPTIMAL PLANT DESIGN TEMPERATURES FOR DIFFERENT GRADIENTS

The optimal $T_{d}$ described above is appropriate for reference case conditions. A particularly critical parameter included in these conditions is the geothermal temperature gradient $\nabla T$, which is $40^{\circ} \mathrm{C} / \mathrm{km}$ in the reference case. Table 5-1 shows optimal plant design temperatures $T_{d}^{*}$ for al ternative values of the geothermal gradient. A reduction in $\nabla \mathrm{T}$ from 40 to $30^{\circ} \mathrm{C} / \mathrm{km}$ results in an $12^{\circ} \mathrm{C}$ decrease in $T_{d}^{*}$. An increase in $\nabla T$ from 40 to $50^{\circ} \mathrm{C} / \mathrm{km}$ results in a $10^{\circ} \mathrm{C}$ increase in $\mathrm{T}_{d}^{*}$. Thus, $\nabla T$ has a significant influence on $T_{d}^{*}$.

The management strategies called for under the optimal values for $T_{d}$ given in Table 5-1 are al so consistent with what one might expect. Figure 5-5 shows that, al though initial drilling depths are decreasing with increases in the geothemal gradients, the redrilling strategy parallels that for the optimal $T_{d}$ in the reference case $\left(\nabla T=40^{\circ} \mathrm{C} / \mathrm{km}, T_{d}=157^{\circ} \mathrm{C}\right)$. Also well-flow rates for the reservoir systems are maintained at the maximum level of $75 \mathrm{~kg} / \mathrm{s}$. The one exception is the case where $\nabla T=60^{\circ} \mathrm{C} / \mathrm{km}$. Here initial drilling depth increases relative to $\nabla \mathrm{T}=50^{\circ} \mathrm{C} / \mathrm{km}$, reflecting the rather large increase in the optimal design temperature that occurs with $\nabla T=60^{\circ} \mathrm{C} / \mathrm{km}$.

Finally, it is interesting to observe the impacts on $T_{d}$ of changes in the size of the HDR reservoir, which is measured by the number of fractures in each

Table 5-1

OPTIMAL DESIGN TEMPERATURES ASSOCIATED WITH ALTERNATIVE VALUES FOR VT

$\begin{array}{cr}\frac{\nabla T\left({ }^{\circ} \mathrm{C} / \mathrm{km}\right)}{30} & \frac{T_{d}\left({ }^{\circ} \mathrm{C}\right)}{145.0} \\ 40 & 157.0 \\ 50 & 167.5 \\ 60 & 235.0\end{array}$


reservoir's multiple-fracture system where each fracture has an assumed radius of $300 \mathrm{~m}$. Somewhat surprisingly, T* does not vary with reservoir size, at least not in the range considered here. As shown in Figure 5-6, however, drilling strategies do change with changes in reservoir size. Larger reservoirs imply lower rates of temperature drawdown, which reduces initial drilling depth and the need for redrilling. Thus, the design and management of the reservoir system is impacted by reservoir size, but the design of the surface plant is seemingly unaffected. Other considerations, certainly $\nabla T$, dominate the determination of $T_{d}^{*}$

In summary, an optimal $\mathrm{T}_{\mathrm{d}}$ was shown to be well below $200^{\circ} \mathrm{C}$ for gradient areas as high as $50^{\circ} \mathrm{C} / \mathrm{km}$. T $T_{d}^{*}$ rises above $200^{\circ} \mathrm{C}$ for $\nabla \mathrm{T}=60^{\circ} \mathrm{C} / \mathrm{km}$, however. Changes in $T_{d}$ were shown to substantially affect initial drilling and redrilling strategies, whereas well-flow rates remained unchanged with $T_{d}$. Changes in reservoir size in the range considered here did not effect the optimal design temperature of the surface plant.

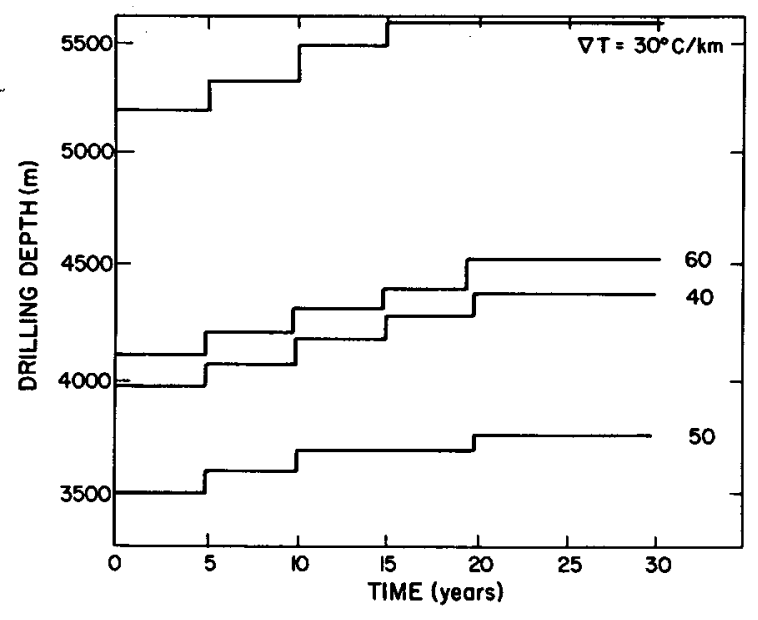

Figure 5-5. Time path of drilling and redrilling activity for varying geothermal gradients with optimal plant design temperatures used.

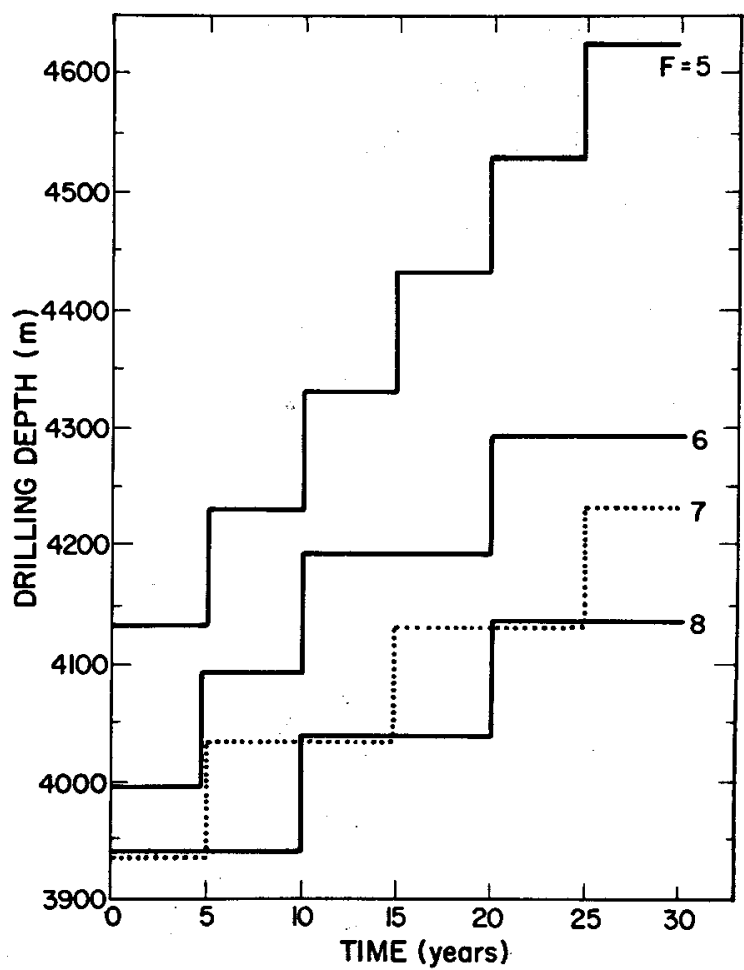

Figure 5-6. Optimal drilling strategies as a function of the number of fractures per reservoir with optimal plant design temperatures used. 
Section 6

ANALYSIS OF RESOURCE, RESERVOIR, AND

PLANT ENGINEERING PARAMETERS

This section is devoted to the examination of some of the important noneconomic parameters of the model. First, the effects of variations in the geothermal gradient and the capacity factor on the percentage change in the levelized busbar price are examined. Next, the percentage changes in $\mathrm{p}^{*}$ are related to changes in the number of fractures; that is, reservoir system performance is considered. Then the structure of optimal system management characteristics is examined when higher and lower design well-flow rates are introduced into the model. The final discussion is of the results for a simultaneous variation in reservoir size (number of fractures) and the design well-flow rates.

\section{VARIATION IN THE GEOTHERMAL GRADIENT}

As demonstrated in the preceding section, the geothermal temperature gradient is an important parameter for determining the potential magnitude of economically recoverable HDR resources in the U.S. There is, at least conceptually, some minimum temperature gradient below which HDR-produced electricity may be prohibitively expensive. The object of this section is not to determine this minimum gradient, but simply to demonstrate the relationship between changes in the level ized busbar cost of FDR-produced electricity and changes in the geothermal gradient relative to reference case assumptions $\left(\nabla T=40^{\circ} \mathrm{C} / \mathrm{km}\right)$. Referring to Table $6-1$, a reduction in $\nabla \mathrm{T}$ from 40 to $30^{\circ} \mathrm{C} / \mathrm{km}$ results in a $76.4 \%$ increase in $\mathrm{p}^{\star}$. Increases in $\nabla \mathrm{T}$ to 50 and $60^{\circ} \mathrm{C} / \mathrm{km}$ lowers $\mathrm{p}^{*}$ by $27.2 \%$ and $39.8 \%$, respectively.

The reservoir system's well-flow rate remains at $75 \mathrm{~kg} / \mathrm{s}$ for all values of $\nabla T$ considered here. However, there were some notable differences in drilling strategies as $\nabla T$ changes. These are shown in Figure 6-1. Of course, the principle reason that higher gradients result in lower $p^{*}$ is because less drilling depth is required to attain a given reservoir temperature. Initial drilling depths for the $H D R$ system with gradients of $60,50,40$, and $30^{\circ} \mathrm{C} / \mathrm{km}$ are $2870,3360,4000$, 
Table 6-1

PERCENTAGE CHANGES IN $p^{*}$ ASSOCIATED WITH

ALTERNATIVE VALUES FOR $\nabla T$

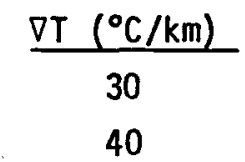

50

60
\% Change in $\mathrm{p}^{\star}$ From

$p^{\star}=43.2 \mathrm{mills} / \mathrm{kWh}$

76.4

0.0

$-27.2$

$-39.8$

and $5200 \mathrm{~m}$, respectively. The systems with the higher gradients optimize by drilling more deeply initially, thereby avoiding redrilling at the beginning of the third and the fifth decision period (Figure 6-1). The system with the $30^{\circ} \mathrm{C} / \mathrm{km}$ gradient is redrilled in all but the next to the last period; and the $40^{\circ} \mathrm{C} / \mathrm{km}$ gradient system of the reference case is redrilled in all but the last period.

Different drilling strategies aside, there is another reason why $\mathrm{p}^{*} \mathrm{dec}$ lines with larger gradients. As described in Sections 3 and 4, the financial leverage incorporated into the model varies directly with the ratio of surface costs to drilling costs. In the case of a $60^{\circ} \mathrm{C} / \mathrm{km}$ gradient, the ratio of $\$ 55.4$ million (the present value of surface costs) to $\$ 26.8$ million (the present value of drilling costs) yields the approximate debt/equity ratio of 2.07. An increase in the gradient from 40 to $60^{\circ} \mathrm{C} / \mathrm{km}$ thus approximately doubles the debt/equity ratio. As gradients rise, the debt/equity ratio rises, and larger proportions of less expensive (after-tax) financing is used for the HDR enterprise.

\section{VARIATIONS IN CAPACITY FACTOR}

Values for $\mathrm{p}^{*}$ are determined for reductions of the capacity factor from the reference case value of $85 \%$. As the capacity factor is reduced to 80,75 , and $70 \%, \mathrm{p}^{*}$ rises by $6.0,12.9$, and $20.7 \%$, respectively. In assessing the impacts of capacity factor reductions on $\mathrm{p}^{\star}$, we did not account for likely decreases in temperature drawdown that should accompany lower capacity factors. Thus, the values for $\mathrm{p}^{\star}$ given in Table 6-2 most likely overestimate increases in $\mathrm{p}^{\text {* }}$ that would be associated with lower capacity factors. 
VARYING RESERVOIR SYSTEM PERFORMANCE

In the model described in Section 3, reservoir system performance is determined by the ratio of the flow rate $\left(\dot{m}_{t}\right)$ to the effective heat transfer surface area $\left(S^{2}=F R^{2}\right)$. This ratio fixes the rate of temperature drawdown to a particular curve as demonstrated in Figure 6-2. By varying the number of fractures in a reservoir, we can vary the effective radius of the system, and thereby vary reservoir performance.

Table 6-3 gives percentage changes in $\mathrm{p}^{*}$ as the number of fractures is varied from that of the reference case ( 6 fractures). These data demonstrate the effect that reservoir performance (or reservoir size) may have on the levelized busbar price. A decrease from 6 to 3 fractures increases $p^{*}$ by $27.3 \%$. Conversely, as reservoir size increases, $\mathrm{p}^{*}$ declines reflecting the decreasing rate of temperature drawdown that attends larger reservoirs.

Data in Figures 6-3 and 6-4 show the changes in time paths for operating wellflow rates and for drilling and redrilling as the number of fractures changes. These data show the first set of results for optimal drilling strategies, which are accompanied by variations in well-flow rates. With three fractures, much deeper wells are drilled than are drilled initially in the reference case $(4500$ rather than $4000 \mathrm{~m}$ ). Despite the deeper wells, the well-flow rates in the first three decision periods are reduced to $63.8 \mathrm{~kg} / \mathrm{s}(85 \%$ of the design well-flow rate) to minimize temperature drawdown (Figure 6-4). Redrilling occurs in every decision period (Figure 6-3), and at the beginning of the third decision period, the well-flow rate is increased to $75 \mathrm{~kg} / \mathrm{s}$. In other words, redrilling has reached a depth sufficient to allow maximum we11-flow rates without driving reservoir temperatures much below plant design temperature by the end of the decision period. As the number of fractures per reservoir system increases, optimal reservoir management is varied to take advantage of the improved reservoir performance. In general, initial drilling depth declines, $\dot{m}_{t}$ increases, and redrilling occurs less often.

When the number of fractures in a reservoir reaches ten, however, an interesting change in pattern occurs. With this relatively large reservoir size, a well-flow rate of $75 \mathrm{~kg} / \mathrm{s}$ is used during the first five years of operation and $63.8 \mathrm{~kg} / \mathrm{s}$ is used for years 6 to 25. Because, the lower flow rate is used over the intermediate 20 years (Figure 6-4), the necessity for redrilling is avoided (Figure $6-3$ ). In the final period (years 25-30, Figure 6-4), there is no incentive to keep temperatures higher beyond 30 years, and the well-flow rate is set at the design rate of $75 \mathrm{~kg} / \mathrm{s}$. 
Table 6-2

PERCENTAGE CHANGES IN $p^{*}$ AS THE

CAPACITY FACTOR VARIES FROM $85 \%$

\begin{tabular}{|c|c|c|}
\hline Capacity Factor & $\begin{array}{l}\% \text { Change in } \\
\text { Capacity Factor }\end{array}$ & $\begin{array}{l}\% \text { Change in } p^{*} \\
\text { from } 43.2 \mathrm{mills} / \mathrm{kWh}\end{array}$ \\
\hline $\begin{array}{l}\text { 85\% (Reference } \\
\text { case value) }\end{array}$ & 0 & 0 \\
\hline 80 & -5.9 & 6.0 \\
\hline 75 & -11.8 & 12.9 \\
\hline 70 & -17.6 & 20.7 \\
\hline
\end{tabular}
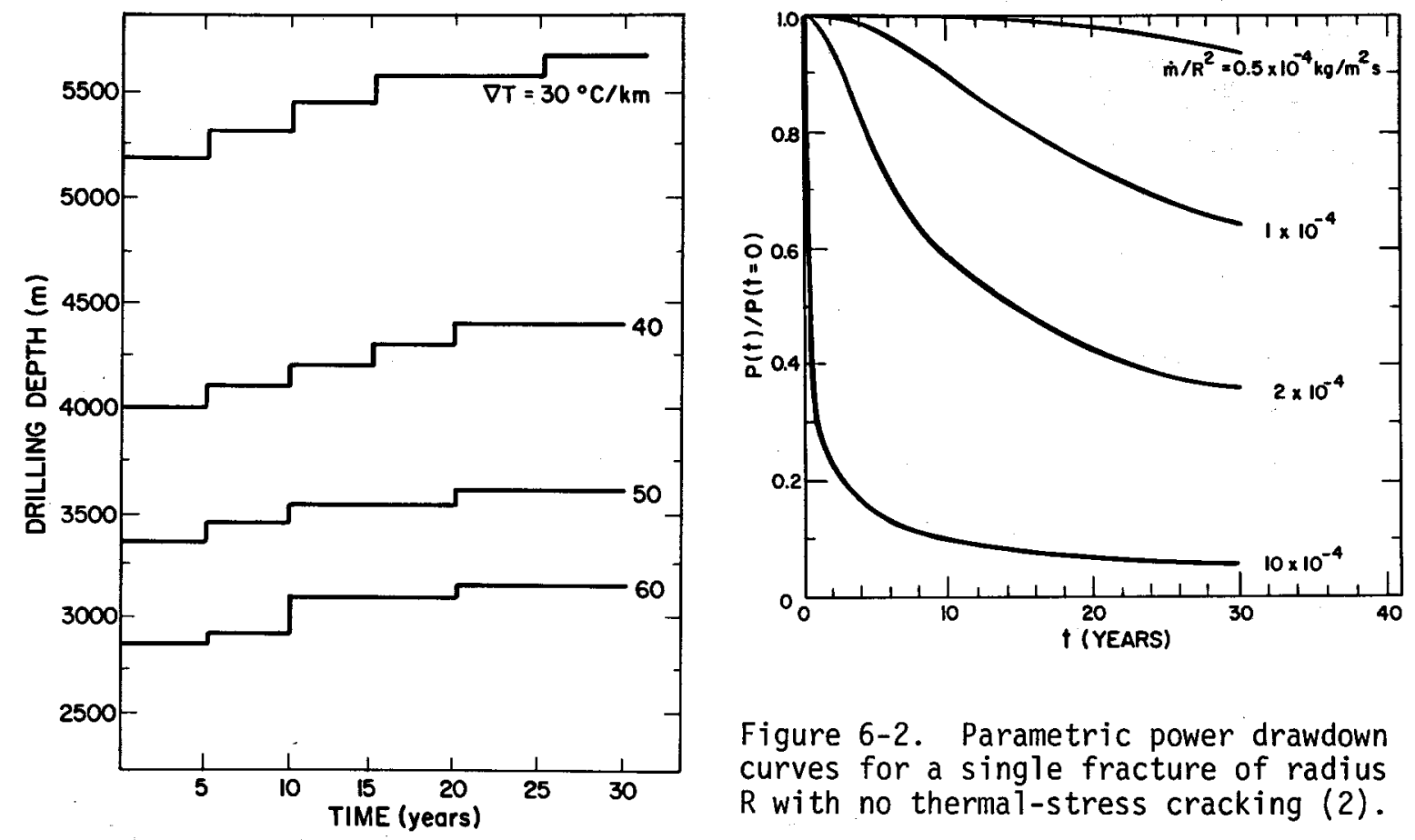

Figure 6-2. Parametric power drawdown curves for a single fracture of radius $R$ with no thermal-stress cracking (2).

Figure 6-1. Optimal drilling strategies for variation of the geothermal gradient in the reference case. 
Table 6-3

PERCENTAGE CHANGE FROM $\mathrm{p}^{\star}=43.2 \mathrm{mi} 1 \mathrm{ls} / \mathrm{kWh}$ WITH ALTERNATIVE NUMBERS OF FRACTURES

\section{Number of \\ Fractures}

3

4

5

6

7

8
\% Change in

27.2

9.0

5.5

0

$-1.7$

$-4.5$

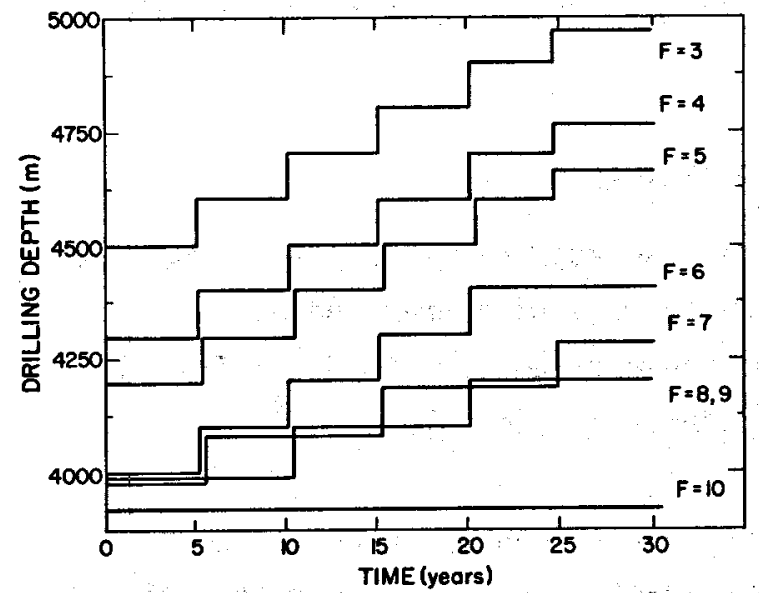

Figure 6-3. Optimal drilling strategies for variations in the number of fractures in the reference case.

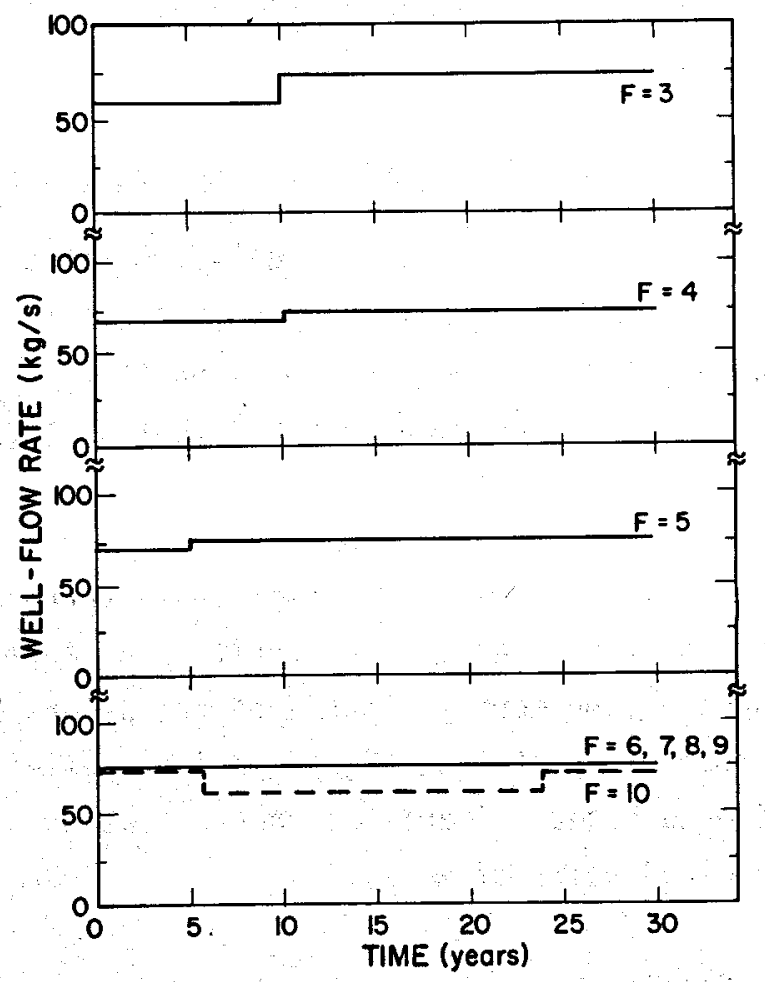

Figure 6-4. Optimal periodic well-flow rates with variations in the number of fractures for the reference case. 
VARYING THE RESERVOIR SYSTEM FLOW RATE

Now we consider the impacts from varying the flow rate while reservoir size remains fixed. Percentage changes in $p^{\star}$ that are associated with varying the maximum flow rate between 50 and $125 \mathrm{~kg} / \mathrm{s}$ are shown in Table $6-4$. At $\dot{m}_{d}=50$ $\mathrm{kg} / \mathrm{s}, \mathrm{p}^{*}$ increases by $17.3 \%$. With well-flow rates of 100 and $125 \mathrm{~kg} / \mathrm{s}, \mathrm{p}^{\star}$ falls by $7.9 \%$ and $14.7 \%$, respectively.

Figure 6-5 gives the drilling strategies associated with the various selected values of $\dot{m}_{d}$. For each $\dot{m}_{d}$, the optional solution requires that the well-flow rate $\left(\dot{m}_{t}\right)$ be set at the maximum, design rate $\dot{m}_{d}$. One might have expected the selection of an $\dot{m}_{t}$ below $\dot{m}_{d}$ so as to reduce temperature drawdown and allow shallower initial drilling depths, and lower drilling costs. However, the increase in the design well-flow rate impl ies a reduction in the number of pairs of wells required by the surface plant. The costs associated with additional drilling depths needed to keep fluid temperatures in the neighborhood of $T_{d}$ with the higher $\dot{m}_{t}$ seem to be offset by the cost savings from requiring fewer pairs of wells.

\section{SIMULTANEOUS VARIATION IN $\dot{m}_{d}$ AND RESERVOIR PERFORMANCE}

Thus far, our analyses of well-flow rates and reservoir sizes as they affect temperature drawdown have been only partial because we varied them individually. Now we will consider combinations of both of these parameters to determine the temperature drawdowns that differ from the reference case values.

Data in Table 6-5 present the relationship between percentage changes in $\mathrm{p}^{*}$ (relative to $p^{\star}=43.2 \mathrm{mills}$ ) and alternative fracture-design flow rate combinations. As expected, for a given value of $\dot{m}_{d}$, a larger number of fractures reduces $p^{*}$, primarily because of reductions in temperature drawdown. For a given number of fractures, higher maximum well-flow rates reduce $\mathrm{p}^{*}$ in the range considered here, primarily because of associated savings in well costs from fewer required pairs of wells.

In Section 2 we stated that temperature drawdown could be critical in terms of any potential cormercial feasibility for HDR-produced electricity, and now we have quantified this from the data and discussions of this section. That is, for large HDR reservoirs (surface areas approximated by our 8-fracture case, see Table $6-5$ ) the relevant $p^{\star}$ will vary from $-12.3 \%$ to $+10.8 \%$ from the reference 
case busbar cost of $43.2 \mathrm{mills} / \mathrm{kWh}$ depending on the design well-flow rate. For the five fracture case, the percentage change in $p^{*}$ varies from -2.3 to $+23.7 \%$ over the same range of design well-flow rates. As the extreme, the combinations of design well-flow rates and reservoir performance can result in a difference of over $15 \mathrm{mills} / \mathrm{kWh}$ in the levelized busbar cost of HDR-produced electricity.

Table 6-4

PERCENTAGE CHANGES IN $p^{*}$ WITH ALTERNATIVE DESIGN WELL-FLOW RATES

\begin{tabular}{cc}
$\begin{array}{c}\text { Design Well-Flow Rate } \\
\left(\mathrm{m}_{\mathrm{d}} \text { in } \mathrm{kg} / \mathrm{s}\right)\end{array}$ & $\frac{\begin{array}{c}\text { Change in } \mathrm{p}^{*} \text { From } \\
43.2 \mathrm{mills} / \mathrm{kWh}\end{array}}{}$ \\
\hline 50 & $17.3 \%$ \\
75 & 0 \\
100 & -7.9 \\
125 & -14.7
\end{tabular}

Table 6-5

PERCENTAGE CHANGE IN $\mathrm{p}^{*}$ FROM $43.2 \mathrm{mills} / \mathrm{k}$ Wh FOR ALTERNATIVE COMBINATIONS OF $m_{d}$ AND NUMBER OF FRACTURES

\begin{tabular}{|c|}
\hline $\begin{array}{l}\text { Design well-Flow } \\
\text { Rate (im in kg/s) }\end{array}$ \\
\hline 50 \\
\hline 75 \\
\hline 100 \\
\hline
\end{tabular}

\begin{tabular}{rrrr}
\multicolumn{4}{c}{ Number of Fractures } \\
5 & \multicolumn{1}{c}{6} & \multicolumn{1}{c}{7} & \multicolumn{1}{c}{8} \\
\hline 23.7 & 17.3 & 16.3 & 10.8 \\
5.5 & 0.0 & -1.7 & -4.5 \\
-2.3 & -7.9 & -10.2 & -12.3
\end{tabular}

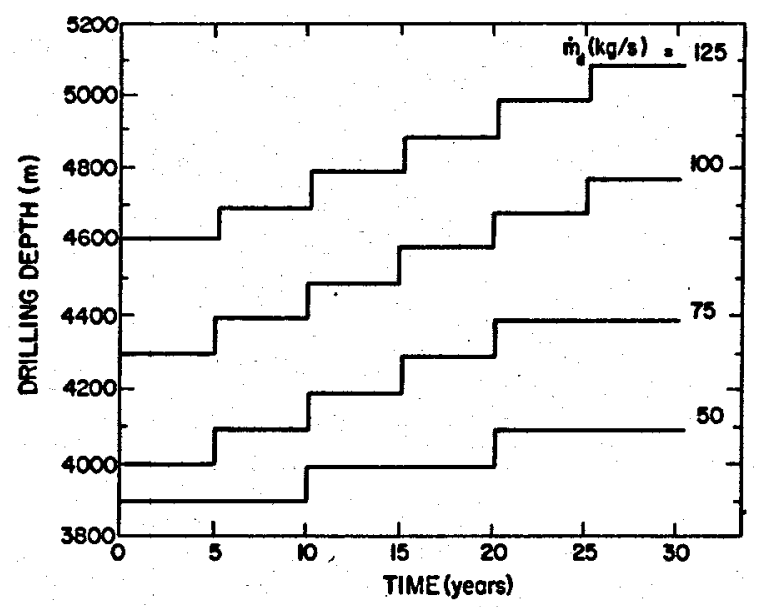

Figure 6-5. Optimal drilling strategies for variations in the design well-flow rate in the reference case. 
Section 7

ANALYSIS OF ECONOMIC PARAMTERS

In this section we examine the effects of variations in the major economic parameters of the model. First we present results related to changes in drilling costs and then those related to increased 0\&M costs and reductions in surface plant capacity. Finally, we consider the impacts of varying real rates of return and of varying the planning horizon (system lifetime).

\section{VARIATIONS IN DRILLING COSTS}

All drilling costs are subject to considerable uncertainty because of the unusual rock formations that may characterize the more attractive HDR sites. This uncertainty is clearly important because of the large proportion of costs associated with drilling. To analyze the impacts of these varying drilling costs on levelized busbar costs $p^{\star}$, we use a percentage change in the reference case drilling costs. For example, the cost of drilling a pair of wells to a depth of three kilometers in the reference case is $\$ 2.22$ million. Our analyses then focus on the optimal structure for an HDR facility when drilling costs for a depth of three kilometers is $\$ 1.332$ million (60\% of reference case costs), $\$ 3.552$ million $\left(160 \%\right.$ of reference case costs), etc. Percentage changes in $p^{*}$ that result from various drilling costs are given in Table $7-1$. Variations of $\pm 20 \%$ from the reference case drilling costs change $p^{\star}$ by $14 \%$, and variations in these costs of $\pm 40 \%$ result in changes in $p^{*}$ of $\sim 28 \%$.

Milora and Tester's drilling cost equation used in the reference case (26) was derived by an upward adjustment of the relationship between drilling costs and the drilling depths for the oil and gas industry. The adjustment was an increase in the intercept of an exponential cost function in the cost-depth plane and was 200-300\%. Many experts are optimistic about the prospects of achieving drilling costs for HDR reservoirs far below these estimates as more experience is gained and new materials and techniques are developed. However, others argue that costs may be higher, and until more experience is acquired, there is no way of conclusively resolving the issue of differing estimates of "true" drilling costs. Therefore, variations in drilling costs, within the range of -60 to $+160 \%$ 
Table 7-1

PERCENTAGE CHANGE IN $p^{\star}$ ASSOCIATED WITH

ALTERNATIVE DRILLING COSTS

\begin{tabular}{l} 
Drilling Costs as a \% \\
of Reference Case \\
\hline
\end{tabular}

60

80

100 (Reference Case)

120

140

160
$\%$ Change in $p^{\star}$ From

$43.2 \mathrm{mills} / \mathrm{kWh}$

$-14.1$

0.0

13.9

27.9

41.7

of reference case costs may well be within the realm of possibility, and all else equal, the estimated busbar cost for HDR-produced electricity is quite sensitive to variations of drilling costs in this range.

The drilling strategies used with alternative drilling costs are shown in figure 7-1. With a $40 \%$ decline in drilling costs, an optimal drilling strategy would involve deeper initial drilling (relative to the reference case) and redrilling in all but the last period. With a $40 \%$ increase in drilling costs, optimal management requires drilling to an initial depth of $4000 \mathrm{~m}$ (as in the reference case) and redrilling in only the second, third, and fifth decision periods. (In the reference case, redrilling takes place in periods 2 through 5.)

An interesting result associated with increases in drilling costs is that the flow rate chosen for the system in each decision period is the maximum $75 \mathrm{~kg} / \mathrm{s}$. A $40 \%$ increase in drilling costs does not result in a reduction in well-flow rates. The cost savings associated with postponing (now more expensive) redrilling do not appear to compensate for the loss in revenues associated with lower well-flow rates, even under these greatly increased drilling costs. As suggested in Section 6, however, a different result might obtain under assumptions of higher design well-flow rates and fewer fractures.

THE EFFECT OF VARIATIONS IN PLANT CAPACITY AND O\&M COSTS ON $p^{*}$

In the reference case, a 50-MW(e) capacity was specified for the HDR plant. Here we wish to examine the impact of changes in installed capacity on optimal management strategies while all other parameters are maintained at reference case levels. 


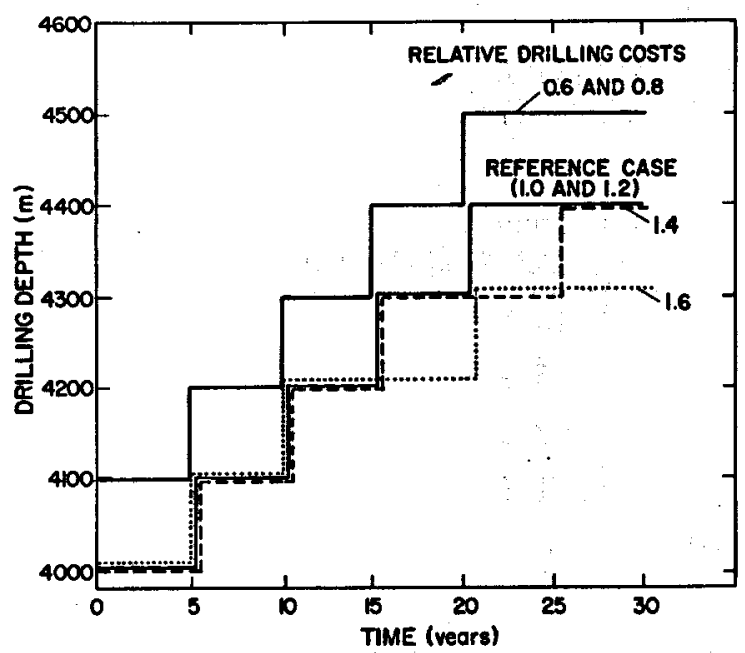

Figure 7-1. Optimal drilling strategies for variation in the drilling cost algorithm in the reference case.

In what follows, analyses are limited to decreases below $50 \mathrm{MW}(\mathrm{e})$. Higher installed capacities are not considered because our plant cost data are characterized by constant returns to scale in the range of 50 to $100 \mathrm{MW}(\mathrm{e})$. On the other hand, decreases in capacity below 50 MW(e) involve less than proportional declines in plant costs. The algorithm used to compute costs (in 1978 \$) for the electric generating plant for capacity $\leq 50 \mathrm{MW}(\mathrm{e})$ is as follows. (Also see Section 3).

$P 1$ ant costs $=\left[\$ 976,910-\$ 2146\left(T_{d}\right)\right] 1000 \cdot Q\left(\frac{50}{Q}\right)^{0.3}$,

where $Q<50$ MW(e).

Referring to Table $7-2$, a decline in $Q$ from 50 to $40,30,20$, and $10 \operatorname{MW}(e)$ results in an increase in $p^{*}$ of $1.5,3.6,6.9$ and $13.6 \%$, respectively. of perhaps more relevance here, the absolute change in $p^{*}$ is just less than 6 mills as the scale declines from 50 to $10 \mathrm{MW}(\mathrm{e})$; that is, $\mathrm{p}^{*}$ rises from 43.2 to $49.1 \mathrm{mills} /$ kWh. Management strategies associated with plant capacities below 50 MW(e) do not differ substantially from those for the reference case solution. In all cases, initial drilling is to a depth of $4000 \mathrm{~m}$, and well-flow rates are maintained at the maximum rate of $75 \mathrm{~kg} / \mathrm{s}$. The only departure from the reference case redrilling strategy occurs with the smallest installed capacity of 10 (MWe). In this case, redrilling occurs in the sixth rather than the fifth decision period. 
Table 7-2

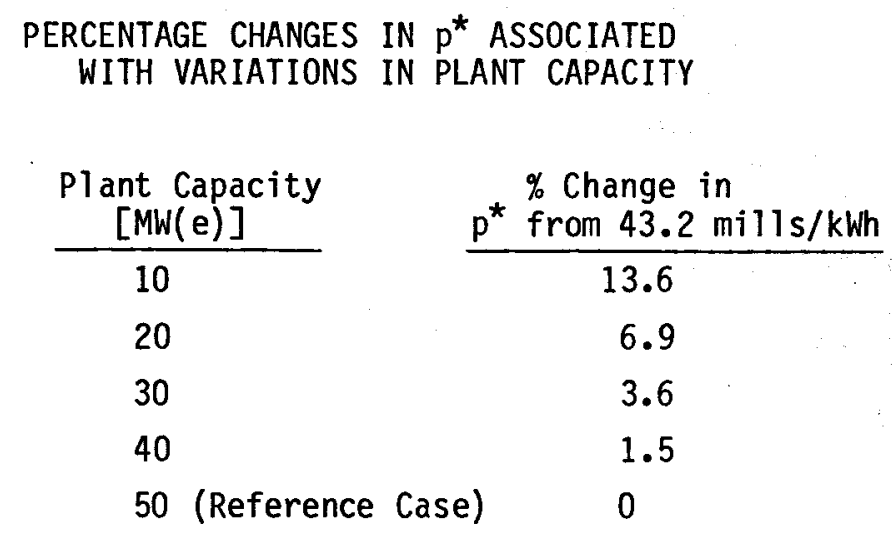

As expected, changes in 0\&M charges result in identical changes in $\mathrm{p}^{\star}$; that is, every mill added to 0\&M costs results in a one mill increase in the levelized busbar costs. Operation-design strategies are unaffected by changes in 0\&M costs.

VARIATIONS IN REAL RATES OF RETURN

Now we consider separately two sets of parameters that are closely related: real rates of return (used in discounting) and planning horizons. In the reference case, we use a 30-year planning horizon, debt financing at $i=9 \%$ for all nondrilling capital costs, and equity financing at $r=12 \%$ for all drilling- related costs. Maintaining a 30-year planning horizon, as well as other reference case assumptions, we can consider the impacts of varying $r$ and $i$, or for convenience $r / i$ combinations.

Table 7-3 presents the percentage changes in levelized busbar costs $\mathrm{p}^{*}$, relative to the reference case costs $p^{*}=43.2 \mathrm{mills} / \mathrm{kWh}$, that are associated with alternative $r / i$ combinations of $r$ and $i$. Of the many combinations of $r$ and $i$ which might be considered, the set of combinations given in Table 7-3 is arbitrarily chosen and intended to simply provide the reader with a feel for the sensitivity of busbar costs to a range of values for $r$ and $i$. As discussed above, changes in $r / i$ combinations in the ranges used here should be viewed as reflecting changes in conditions related to risk and uncertainty relative to the HDR enterprise. As demonstrated in Table 7-3, busbar costs are quite sensitive to changes in $r / i$ combinations. At $r=6 \%, i=3 \%$, the busbar costs is $35 \%$ lower than the reference case. Relative to the reference case, as $r / i$ rises to $21 \% / 12 \%$, $\mathrm{p}^{*}$ increases by almost $67 \%$. 
Table 7-3

PERCENTAGE CHANGE IN $\mathrm{p}^{\star}$ WITH

ALTERNATIVE VALUES FOR $r$ AND $i$

\begin{tabular}{cc}
$\begin{array}{c}\text { Value for } r / i \\
(\% / \%)\end{array}$ & $\begin{array}{c}\% \text { Change in } \mathrm{p}^{*} \text { From } \\
43.2 \mathrm{mi} 11 \mathrm{~s} / \mathrm{kWh})\end{array}$ \\
\hline $6 / 3$ & -35.0 \\
$9 / 6$ & -18.5 \\
$12 / 9$ (Reference Case) & 0 \\
$15 / 10$ & 21.0 \\
$18 / 11$ & 43.1 \\
$21 / 12$ & 66.6
\end{tabular}

of particular interest is the impact of higher $r / i$ combinations on the HDR facility's optimal drilling strategy. In Figure 7-2 optimal drilling depths over time for the $r / i$ combinations greater than reference case values are compared with those for the reference case. Given the higher relative value of current (period 1) production associated with higher real discount rates, initial drilling is deeper than that for the reference case for all higher $r / i$ combinations. With initial drilling to $4100 \mathrm{~m}$ (compared to $4000 \mathrm{~m}$ for the reference case), temperature related efficiencies for the power plant are 100\% during period 1 compared to $97.5 \%$ in the reference case. The greater relative value of production in

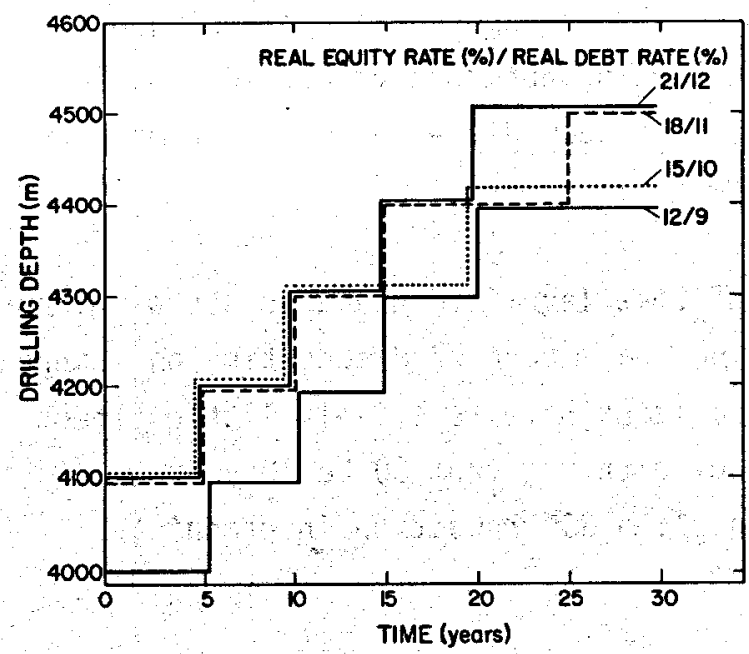

Figure 7-2. Optimal drilling strategies for variations in the real discount rates in the reference case. 
early decision periods is also indicated by the redrilling that occurs in period 4 for $18 \% / 11 \%$ but not for $15 \% / 10 \%$. Redrilling occurs in periods 2 through 5 for $21 \% / 12 \%$, but in only three of these periods for lower $r / i$ combinations. In all cases, the well-flow rate is maintained at the maximum $75 \mathrm{~kg} / \mathrm{s}$. In terms of combinations of $r / i$ lower than reference case values, the drilling strategy and flow-rate policy for $r / i=6 \% / 3 \%$ are identical to the reference case. For $r / i=$ $9 \% / 6 \%$, however, initial drilling is to 4100 meters with redrilling in periods 2 and 3 only; the well flow-rate is $75 \mathrm{~kg} / \mathrm{s}$ in all periods except period 3 wherein the rate is $63.8 \mathrm{~kg} / \mathrm{s}$. This discontinuity in management strategies reflects, in the main, changes in relevant plant and drilling costs as reflected by debt and equity rates. Thus, as one might expect, real discount rates at combinations higher and lower than those in the reference case are shown to have substantial potential effects on levelized busbar costs as well as on management strategies. The nature of risk and uncertainty associated with HDR-produced electricity, relative to future competitive sources of electricity, may then be a critical determinant of potential economic feasibility of HDR technology.

\section{CHANGING THE PRODUCTION LIFETIME OF THE FACILITY}

In the reference case and all other runs of the model, a planning lifetime for the HDR surface plant and well system was assumed to be 30 years. This lifetime was used because experience and current practice suggest that 30 years may be reasonable for the useful economic lifetime of steam-electric facilities. Because HDR power systems differ from conventional systems in several important respects, the economic lifetime, and consequently the appropriate planning horizon, might also be different in practice. Planning horizons of 20,40 , and 50 years are considered to determine the effects of such differences on optimal management strategies and $\mathrm{p}^{*}$.

The various planning horizons affect the relative levelized busbar costs as given in Table 7-4. These data suggest that, given the impact of discounting on future revenues and costs, the extended planning horizons have relatively little effect on $\mathrm{p}^{\star}$. Even reducing the $\mathrm{planning} \mathrm{horizon} \mathrm{by} \mathrm{a} \mathrm{third,} \mathrm{from} 30$ to 20 years, has a much less than proportional impact on $\mathrm{p}^{*}$; a $33 \%$ reduction in planning lifetime increases $p^{*}$ by only $6 \%$. 
Table 7-4

THE EFFECT OF PLANNING HORIZON

VARIATIONS ON $\mathrm{p}^{*}$

\begin{tabular}{ccc}
$\begin{array}{c}\text { Planned Horizon } \\
\text { (years) }\end{array}$ & $\begin{array}{c}\% \text { Change in } \mathrm{p}^{*} \text { From } \\
43.2 \mathrm{mills} / \mathrm{kWh} \text { ) }\end{array}$ \\
\cline { 2 - 3 } 20 & 6 \\
30 (Reference Case) & 0 \\
40 & -2.1 \\
50 & -2.8
\end{tabular}

The effect of planning horizon variations on optimal management strategies for drilling is presented in Figure 7-3. These relationships do not reflect any notable departure from the reference case strategy for drilling, except that redrilling occurs at the beginning of the last period in each case. The well-flow rates used by the systems under varying planning horizons were also the same as for the reference case: $75 \mathrm{~kg} / \mathrm{s}$ over all the decision periods.

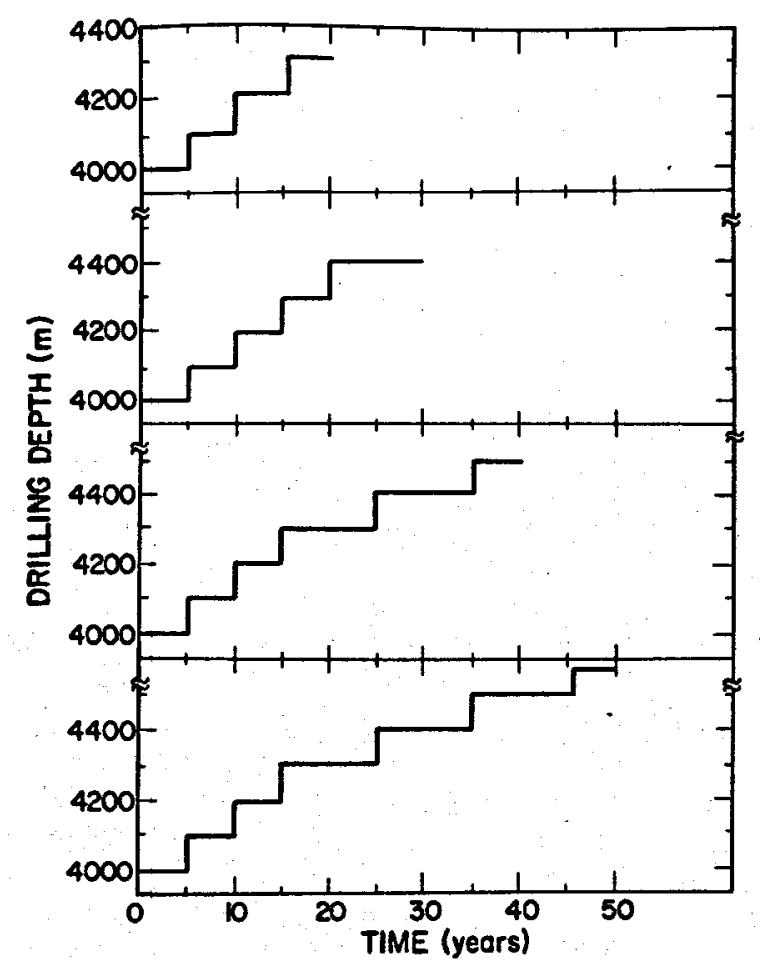

Figure 7-3. Drilling strategies for different facility lifetimes. 
Section 8

SUMMARY AND CONCLUSIONS

Given the large number of reservoir and economic parameters that have been subjected to sensitivity analyses in the preceding sections, we should now reconsider these earlier, necessarily fragmented, results and relate them to the major objectives of this study. We consider the implications of this work and the appropriateness of our analytical model for assessing the process of HDRproduced electricity. We attempt to identify the physical and economic parameters, which sensitivity analyses suggest are important, to help direct the future research, as well as the conditions for HDR-produced electricity to be commercially feasible. We also comment on the interdisciplinary-related benefits that have resulted from this work.

\section{METHOD FOR EVALUATING THE USE OF HDR TECHNOLOGY FOR ELECTRICITY PRODUCTION}

We reasoned in Section 3 that as we are unable to determine beforehand the optimal design and management of an HDR system, more conventional methods for estimating levelized busbar costs for electric generating systems are not applicable. These methods require prior specification of the timing and magnitude of costs and output for the system under scrutiny. For a technology such as HDR, there is no operating experience to suggest what the optimal timing and magnitudes might be. Moreover, HDR offers especially rich opportunities for management discretion.

In HDR systems, periodic costs and power output are endogenously determined by drilling, redrilling, and well-flow rate strategies. For example, power output is determined by reservoir temperatures in each period, and these temperatures will, in turn, be determined by system management. By asserting a particular HDR design and management strategy to make a commercial assessment without thorough examination of the economic trade-offs introduces systematic biases in evaluating this new technology. Thus, we have pursued a methodology that incorporates these trade-offs into the analyses. 
An optimization model based on this methodology allows us to estimate the levelized busbar cost within the context of optimal management. The significance of this approach for HDR is suggested by the following alternative management framework. The power plant will always be operated at its practical optimum, (at plant design temperature) and no redrilling of the reservoir system is considered. Under such conditions, the HDR wells would be drilled just deep enough, given heat transfer surface area, to insure that fluid temperature does not fall below plant design temperature over the lifetime of the system. Such management of an HDR system would result in a levelized busbar price of about $64.0 \mathrm{mills} / \mathrm{kWh}$, which is $21 \mathrm{mills} / \mathrm{kWh}$ higher than $\mathrm{p}^{*}$ in the reference case. Optimum managenent does indeed make a difference.

Al though this comparison may be contrived, the alternative management approach suggested above ensures maximum thermal efficiency, maintains constant output over the lifetime of the facility, and limits the operators' involvement with the drilling industry. These considerations do have substantial appeal and indicate that the example should not be dismissed out-of-hand as "unrealistic." Further- . more, the asserted strategy is identical to the optimum management strategy if the HDR reservoir does not experience temperature decline over the plant lifetime.

Throughout this report, we have emphasized the importance of management strategies in affecting minimum costs. We have shown the drilling strategies, especially initial drilling depth, are very important to HDR economics. Also, the levelized busbar cost of HDR electric systems are quite sensitive to changes in a wide range of parameters, including geothermal temperature gradients (Table 6-1), reservoir size (Table 6-3), well-flow rates (Table 6-4), plant capacity (Table $7-2)$, and real rates of return (Table $7-3$ ).

Our arguments are intended to present the rationale for the need to use optimization techniques in evaluating HDR-produced electricity, particularly at this early technological stage. We do not argue that this dynamic programing algorithm is the only, or necessarily the best, optimization technique. Despite two years of almost continual effort to refine the model, a number of problems remain, such as the size of discrete intervals used for several functional relationships and the size of the model per se. If, in future efforts, a quasiconcave representation of the $\left(T_{d}-\bar{T}_{t}\right) / T_{d}$ relationship to power output

(Figure 3-1) can be justified, greater efficiency could be obtained with the use of linear programming-types of optimization 'models. 


\section{SUMMARY OF SENSITIVITY ANALYSES}

A summary of results from sensitivity analyses is given in Tables 8-1 and 8-2. Referring to Table 8-1, levelized busbar costs for the HDR facility are relative$1 y$ insensitive to variations in installed capacity and system lifetime in the ranges considered here. Changes in busbar costs are roughly proportioned to changes in capacity factors as expected.

Busbar costs are shown to be particularly sensitive to variations in geothermal temperature gradients, drilling costs, and real rates of return. As we move to lower gradients, from 40 to $30^{\circ} \mathrm{C} / \mathrm{km}$, dramatic increases in $\mathrm{p}^{\star}$ result, and a $25 \%$ reduction in the gradient gives rise to a $76.4 \%$ increase in the levelized busbar costs. Higher gradients result in levelized busbar costs that decline at a decreasing rate. Therefore, operating in high gradient areas, at least in early stages of commercial applications, is important.

Given the uncertainty surrounding drilling costs, the sensitivity of levelized busbar costs to changes in drilling costs necessitates immediate research to refine such costs if future assessment studies are to be upgraded. LASL has contracted for such a study of HDR drilling costs, and the results should be available by mid-1979.

Lower $r / i$ combinations result in substantial declines in busbar costs and high combinations, relative to the reference case, imply large increases in $p^{*}$. In the extreme, the range of $r / i$ combinations employed here embrace a difference of almost 44 mills in the levelized busbar cost.

For reservoir performance, the sensitivity of $\mathrm{p}^{*}$ to alternative considerations of design well-flow rate and number of fractures is demonstrated in Table 8-2. These data prove the dependence of HDR system feasibility on reservoir design. Limited reservoir size (3-4 fractures) and small flow rates $(50-75 \mathrm{~kg} / \mathrm{s})$ result in substantially higher levelized busbar costs. We attribute this to a combination of effects related to rapid temperature drawdown and the large number of well-pairs required by the plant. Over a limited range, larger flow rates, resulting in fewer required well-pairs, reduce levelized busbar costs for these "small" reservoirs. If only two fractures are used in this model, with $\dot{m}_{d}=$ $125 \mathrm{~kg} / \mathrm{s}$, temperature drawdown in the first five years of operation is $80 \%$ of initial temperature, and the system is not profitable under any set of reasonable conditions. Larger reservoir size, in conjunction with higher well-flow rates 
Table 8-1

SUMMARY OF SENSITIVITY ANALYSES

Parameter

$\%$ Change in

Estimated Levelized

Busbar Cost $43.2 \mathrm{mi} 11 \mathrm{~s} / \mathrm{kWh}$ )

Geothermal Temperature Gradient $\left({ }^{\circ} \mathrm{C} / \mathrm{km}\right)$ :

30

$40^{\mathrm{a}}$

50

60
76.4

0.0

$-27.2$

$-39.8$

Installed Capacity $[M W(e)]$ :

10
20
30
40
$\geq 50 a$

$+13.6$

6.9

3.6

1.5

0.0

System Lifetime $(y r)$ :

20

$30^{\mathrm{a}}$

40

50

Capacity Factor (\%):

$85^{a}$

80

75

70
6.0

0.0

$-2.1$

$-2.8$

Drilling Costs (\% of Reference Case):

60
80
$100 a$
120
140
160

$-28.0$

$-14.1$

0.0

13.9

27.9

41.7

Real Equity Rate/Real Debt Rate $(\% / \%)$ :

$6 / 3$

$9 / 6$

$12 / 9 a$

$15 / 10$

$18 / 11$

$21 / 12$
0.0

6.0

12.9

20.7

a Reference Case

$-35.0$

$-18.5$

0.0

21.0

43.1

66.6 
Table 8-2

SENSITIVITY ANALYSES FOR RESERVOIR PERFORMANCE

(\% Change in $\mathrm{p}^{\star}$ From $43.2 \mathrm{mill} \mathrm{s} / \mathrm{kWh}$ )

Number of

Fractures

3
4
5
6
7
8
9
10

\begin{tabular}{|c|c|c|c|c|c|}
\hline 50 & $\begin{array}{c}\text { Design } \\
75 \\
\end{array}$ & $\begin{array}{c}\text { We } 11-F l \text { ow } \\
100\end{array}$ & $\begin{array}{r}\text { Rate } \\
125 \\
\end{array}$ & $\begin{array}{r}(\mathrm{kg} / \mathrm{s}) \\
150\end{array}$ & 175 \\
\hline 35.8 & 27.2 & 19.0 & 7.4 & 10.5 & 10.9 \\
\hline 24.3 & 9.0 & 2.1 & -4.5 & -3.2 & -12.1 \\
\hline 23.7 & 5.5 & -2.3 & -5.7 & -12.9 & -13.1 \\
\hline 17.3 & 0.0 & -7.9 & -14.7 & -13.1 & -20.5 \\
\hline 16.3 & -1.7 & -10.2 & -18.3 & -21.0 & -18.1 \\
\hline 10.8 & -4.5 & -12.3 & -18.2 & -21.9 & -26.3 \\
\hline 12.3 & -5.4 & -14.9 & -18.2 & -21.8 & -24.0 \\
\hline 14.9 & -8.4 & -13.5 & -19.4 & -21.6 & -26.6 \\
\hline
\end{tabular}

(relative to reference case conditions), results in substantially reduced levelized busbar costs $(30-35 \mathrm{mill} / \mathrm{kWh})$. This suggests that a proven multiple-fracture concept involving 8 to 12 or more $300-m$-radius fractures or an equivalent surface area system would result in a significant increase in the prospects for commercially feasible electricity production from HDR resources.

POTENTIAL FOR COMMERCIAL FEASIBILITY

In concluding the analytical portion of this study, it is interesting to speculate as to the structure of an HDR system if it is to produce electricity at a competitive price. An immediate problem is that of positing what a "competitive" price might be in various gradient regions of the U.S. at some future date when HDR-produced electricity would be established (32-35). Al though numerous problems underlie comparisons of estimated busbar costs from differing sources ( $\underline{36})$, for our limited speculative purposes, we arbitrarily posit a future competitive busbar cost of $30 \mathrm{mill} / \mathrm{s} / \mathrm{kWh}$. This cost is an est imated average of 1985 costs for nuclear-coal mixes from a Federal Energy Administration report (37).

Using $30 \mathrm{mill} / \mathrm{s} / \mathrm{kWh}$ (in 1978 \$) as a reference for a competitive future busbar cost, we now inquire as to the range of parameter values for the HDR system that would result in a value for $\mathrm{p}^{*}$ that is no greater than $30 \mathrm{mills} / \mathrm{kWh}$. Given the partial nature of our sensitivity analyses, only one parameter is varied while 
all others are held at reference case values. Thus, $\mathrm{p}^{*} \leq 30 \mathrm{mills} / \mathrm{kWh}$ might obtain with many different combinations of these parameter values. In any case, $p^{*} \leq 30 \mathrm{mills} / \mathrm{kWh}$ obtains in the following cases:

- geothermal temperature gradients at $50^{\circ} \mathrm{C} / \mathrm{km}$ and higher;

- a reduction in drilling costs of $30-40 \%$ of those used in the reference case;

- a larger number of fractures (8 to 10) combined with higher well-flow rates $(150-175 \mathrm{~kg} / \mathrm{s})$; and

- real debt and equity rates on the order of $3 \%$ and $6 \%$ respectively.

As noted above, any of these four conditions would result in $p^{*}$ of 30 mills/ $k$ Wh with all other parameters at reference case values. Numerous combinations of these other parameters, such as longer planning horizons, higher capacity factors, and greater installed capacity, might yield the same results.

A set of minimum conditions for a commercially competitive HDR facility, assuming a proven technology, would include: $T>50^{\circ} \mathrm{C} / \mathrm{km}, 30-40 \%$ lower drilling costs, larger reservoirs in combination with larger well-flow rates, or lower debt and equity rates. Alternatively, if the relevant competitive price is greater than $30 \mathrm{mills} / \mathrm{kWh}$, the minimum conditions for commercial feasibility cited above become less stringent.

\section{INTERDISCIPLINARY RESEARCH}

In concluding this report it seems most appropriate to comment on one aspect of our efforts that cannot be included with the numerical results. This aspect concerns the close working relationships and intellectual interchange that have evolved over the last two years between LASL and UMM economists and reservoir and chemical engineers and geoscientists at LASL.

Interdisciplinary research is often an overworked term, and in many cases may involve little more than two or more discipl inary groups that work separately on the same problem. This was certainly not the case here. Throughout the seemingly endless process of model formulation and refinement, as well as analyses of results, the project's economists and engineers have worked together (sometimes heatedly) in evaluating strengths and weaknesses of alternative choices for parameter values, functional representations for reservoir and/or economic processes, etc. There is little in either the model or resulting analyses that has not been 
the subject of joint, intensive scrutiny and discussion by economists and engineers.

The merits of this process must be judged in terms of the quality of the analytical process developed. It has been refreshing, however, to observe the evolution of the interchange between members of these professional groups: economists with growing interest about perceived trade-offs in design temperatures and concepts related to such things as thermal-stress cracking; and engineers expressing concern for potential gains from short-run deviations from design parameters.

It is somewhat unusual for economists to be so involved in assessment studies for activities at such an early stage of technological development. We hope that the results of this work demonstrate the value of such early involvement, particularly as they relate to the directions for future R\&D efforts that are most critical to the potential economic feasibility of HDR-produced electricity. 


\section{Section 9}

\section{REFERENCES}

1. R. G. Cummings, R. K. Hageman, G. E. Morris, and J. W. Tester. "Economic Analysis of the Hot Dry Rock Geothermal Energy Resource." Presented at the 53rd Annual Conference of the Western Economic Association. Hawaiian Islands, June 20-26, 1978.

2. R. G. Cummings, G. E. Morris, J. W. Tester, and R. L. Bivins. "Electricity From Hot Dry Rock Geothermal Energy: Technical and Economics Issues." Los Al amos, New Mexico: Los Al amos Scientific Laboratory, January 1979. LA-7603-MS.

3. "Energy Alternatives: A Comparative Analysis." Norman, Oklahoma: University of Oklahoma, Science and Public Policy Program, May 1975.

4. Energy Research and Development Administration. "Geothermal Energy Research, Development and Demonstration Program: Definition Report." Washington, D. C.: Government Printing Office, October 1975.

5. M. C. Smith, R. L. Aamodt, R. M. Potter, and D. W. Brown. "Man-Made Geothermal Reservoirs." In Proceedings, Second United Nations Symposium on the Development and Use of Geothermal Resources. Washington, D. C.: Geothermal printing office, 1976, pp. 1781-1787.

6. J. W. Tester and M. C. Smith. "Energy Extraction Characteristics of Hot Dry Rock Geothermal Systems." Presented at Twelfth Intersociety Energy Conversion Engineering Conference. Washington, D. C.: August 1977.

7. J. W. Tester, C. E. Holley, Jr., and L. A. BI atz. "Solution Chemistry and Scal ing in Hot Dry Rock Geothermal Systems." In Proceedings of the 83rd National Meeting AIChE. Houston, Texas: March 21-25, 1977.

8. A. G. Blair, J. W. Tester, and J. J. Mortensen. "LASL Hot Dry Rock Geathermal Project, July 1, 1975-June 30, 1976." LOS Alamos, New Mexico: Los Alamos Scientific Laboratory, October 1976. LA-6525-PR.

9. LASL HDR Program Staff. "Hot Dry Rock Geothermal Energy Development Program, Annual REport, Fiscal Year 1978." Los Alamos, New Mexico: Los Al amos Scientific Laboratory, Apri1 1979. LA-7807-HDR.

10. J. W. Tester and J. N. Albright, Eds. "Hot Dry Rock Energy Extraction Field Test: First 75 days of Operation of a Prototype Reservoir at Fenton Hi11." Los Alamos, New Mexico: Los Al amos Scientific Laboratory, April 1979. LA-7771-MS.

11. LASL HDR Project Staff. "Hot Dry Rock Geothermal Project-Annual Report 1977." Los Al amos, New Mexico: Los Alamos Scientific Laboratory, Apri1 1978. LA-7109-PR. 
12. R. M. Potter. Unpublished Results. Los Alamos, New Mexico: Los Alamos Scientific Laboratory, March 1978.

13. J. K. Costain, L. Grover, III, and A. K. Sinha. "Evaluation and Targeting of Geothermal Energy Reservoirs in the South-Eastern United States, Progress Report, Nov. 1, 1976-March 31, 1977." Blacksburg, Virginia: Virginia Polytechnical Institute, 1977. VPI-SU-5103-3.

14. W. H. Diment, "Temperatures and Heat Contents Based on Conductive Transport of Heat." In "Assessment of Geothermal Resources of the United States-1975," U.S. Geological Survey Circular 726, Reston, Virginia: 1975.

15. R. L. Smith and H. R. Shaw. "Igneous-Related Geothermal Systems." In "Assessment of Geothermal Resources of the United States-1975," U.S. Geological Survey Circular 726, Reston, Virginia: 1975.

16. D. E. White and D. L. Williams, Eds. "Assessment of Geothermal Resources of the United States-1975," U.S. Geological Survey Circular 726, Arlington, Virginia: 1975.

17. P. Kruger and C. Otte. Geothermal Energy. California: Stanford University Press, 1973.

18. T. R. McGetchin. "Hot Dry Rock Geothermal Energy: Status Exploration and Assessment." Hot Dry Rock Assessment Panel. Washington, D. C.: in press. ERDA-77-92.

19. F. H. Harlow and W. E. Pracht. "A Theoretical Study of Geothermal Energy Extraction." Journal of Geophysical Research, Vol. 77 (35), February 1976, pp. 7038-48.

20. H. D. Murphy. "Thermal Stress Cracking and the Enhancement of Heat Extraction from Fractured Geothermal Reservoirs." Los Al amos, New Mexico: Los Al amos Scientific Laboratory, April 1978. LA-UR-78-917.

21. S. Nemat-Nasser, L. M. Keer, and K. S. Parihar. "Unstable Growth of Thermally Induced Interacting Cracks in Brittle Solids." Evanston, Illinois: Northwestern University Earthquake Research and Engineering Laboratory, September 1977. 77-9-2.

22. S. Nemat-Nasser. "Minimum Spacing of Thermally Induced Cracks in Brittle Sol ids." Evanston, Illinois: Northwestern University Technological Institute, to be published 1978 .

23. S. Nemat-Nasser. "Thermal Cracks and Their Effects on the Heat Extraction Process." Evanston, Illinois: Northwestern University Technological Institute, to be published 1978.

24. A. C. Gringarten. "Theory of Heat Extraction From Fractured Hot Dry Rock." Journal of Geophysical Research, Vol 80 (8), 1975, p. 1120.

25. C. B. Raleigh. "Multiple Hydraul ic Fracturing for the Recovery of Geothermal Energy (Abstract). EOS Trans. AGU; Vol 55 (4), 1974, p. 4026. 
26. S. J. Milora and J. W. Tester. Geothermal Energy as a Source of Electric Power. Cambridge, Massachusetts: The Massachusetts Institute of Technology Press, 1976.

27. J. H. Eskesen. "Cost and Performance Comparison of Flash Binary and Steam Turbine Cycles for the Imperial Valley." In Proceedings of the Twelfth Intersociety Energy Conversion Engineering Conference, Vol 1, 1977, p. 842.

28. J. H. Altseimer. "Technical and Cost Analysis of Rock Melting Systems for Producing Geothermal Wells." Los Alamos, New Mexico: Los Al amos Scientific Laboratory, November 1976. LA-6555-MS.

29. Independent Petroleum Association of America. "Report of the Cost Study Committee." San Francisco, California: May 20, 1978.

30. "EPRI Technical Assessment Guide." Palo Alto, California: Technical Assessment Group of the Electric Power Research Institute Planning Staff, Special Report, June 1978. PS-866-SR.

31. R. D. McFarland and H. D. Murphy, "Extracting Energy From Hydraul icallyFractured Geothermal Reservoirs." In Proceedings of the Eleventh Intersociety Energy Conversion Engineering Conference, State Line, Nevada, September 1976.

32. "Utilities Weigh Economics of Nuclear Versus Coal." In Electrical World, January 1, 1976, pp. 21-23.

33. Energy Research and Development Administration. "National Plan for Energy Research Development, and Demonstration." Washington, D.C. Government Printing office 1976.

34. W. D. Nordhaus. "The Allocation of Energy Resources." Brookings Paper on Economic Activity No. 3, 1973.

35. U. S. Department of Interior, Energy Perspectives. Washington D. C.: Government Printing Office, June 1976.

36. Public Service Company of New Mexico. "New San Juan Unit Goes on Line." Electric Lines. January 1977.

37. Federal Energy Administration. 1976 National Energy Outlook. Washington, D. C.: Government Printing Office, February 1976.

38. R. D. McFarland. "Geothermal Reservoir Models--Crack Plane Model." Los Alamos, New Mexico: Los Alamos Scientific Laboratory, Apri1 1975. LA-5947-MS.

39. R. Wunder and H. D. Murphy. "Thermal Drawdown and Recovery of Singly and Multiply Fractured Hot Dry Rock Reservoirs." Los Alamos, New Mexico: Los Alamos Scientific Laboratory, Apri1 1978. LA-7219-MS. 
Appendix A

DESCRIPTION OF ASSUMED RESERVOIR PERFORMANCE

The changes that may occur in the reservoir fluid temperature, as well as the rate of power production over the 20-50 year lifetime of an HDR power plant, can be crucial in developing an optimal strategy for reservoir management. The most desirable approach is to maintain a constant output temperature while maximizing the mass flow rate of fluid through the reservoir. This will not be possible because any finite-sized system will have a finite rate of drawdown. The energy drawdown rate for an HDR reservoir with low formation permeability will depend on $(\underline{6}, \underline{31}, \underline{38})$ :

- accessible fracture surface area, $A$;

- mass flow rate, $m$;

- distribution of fluid across the fractured surface; and

- thermal properties of the rock (density, heat capacity, conductivity).

A simplified approach to estimating reservoir performance would assume that a certain fraction $n$ of the recoverable power, corresponding to a uniform flow across the face of a single ideal pl ane fracture, could be extracted. By solving the transient problem of one-dimensional heat conduction from the rock into the fracture face, the recoverable power $P(t)$, in $J / s$ for uniform flow, can be expressed as $(6,31,39)$.

$$
P(t)=n \dot{m} C_{w}\left(T-T_{\text {min }}\right) \text { erf }\left[\sqrt{\frac{(\lambda \rho C) r}{t}} \frac{\pi R^{2}}{\dot{m} C_{w}}\right] \text {, }
$$

where:

$$
\begin{aligned}
& A=\pi R^{2}=\text { area of one face of the fracture, } \mathrm{m}^{2}, \\
& C_{W} \\
& C_{r}
\end{aligned}
$$




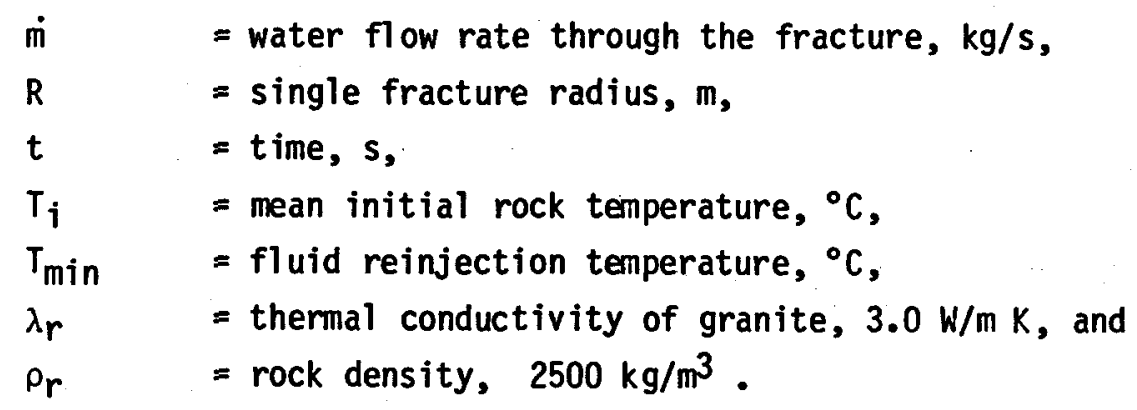

McFarland and Murphy (31) compare $P(t)$ to estimated values that account for nonuniform flow across the accessible fracture area. Fluid buoyancy and convection effects within the ideal fracture, as well as transient conduction of heat through the surrounding rock, are treated in a numerical solution of the four coupled, two-dimensional, nonlinear partial differential equations describing continuity, fluid momentum, and rock and fluid energy balances. Depending on the location and separation of fluid injection and recovery points within the fracture and the internal fracture permeability (gap width versus radius, see figures $A-1$ and $A-2$ ), the recoverable fraction of power $a$ may vary from 0.4 to 0.9 depending on the degree of buoyant circulation through the fracture. A computersimulated flow contour presented in Figure $A-3$ compares flow in a relatively high impedance fracture with buoyancy effects active.

Equation $A-1$ shows that $P(t)$ depends directly on the error function of $K\left(R^{2} / \dot{m} \sqrt{t}\right)$, for constant rock and fluid properties where $K \pi=\sqrt{\left(\lambda \rho C / C_{w}{ }^{2}\right) r}$. Consequently, reasonably accurate predictions of reservoir lifetime can be made for specified ideal fracture sizes and flow rates. Figure A-4 presents parametric results for the power ratio $P(t) / P,(t=0)$ versus time $t$ using different values of $\dot{m} / R^{2}$ to generate a family of curves for a granitic single-fracture reservoir. 


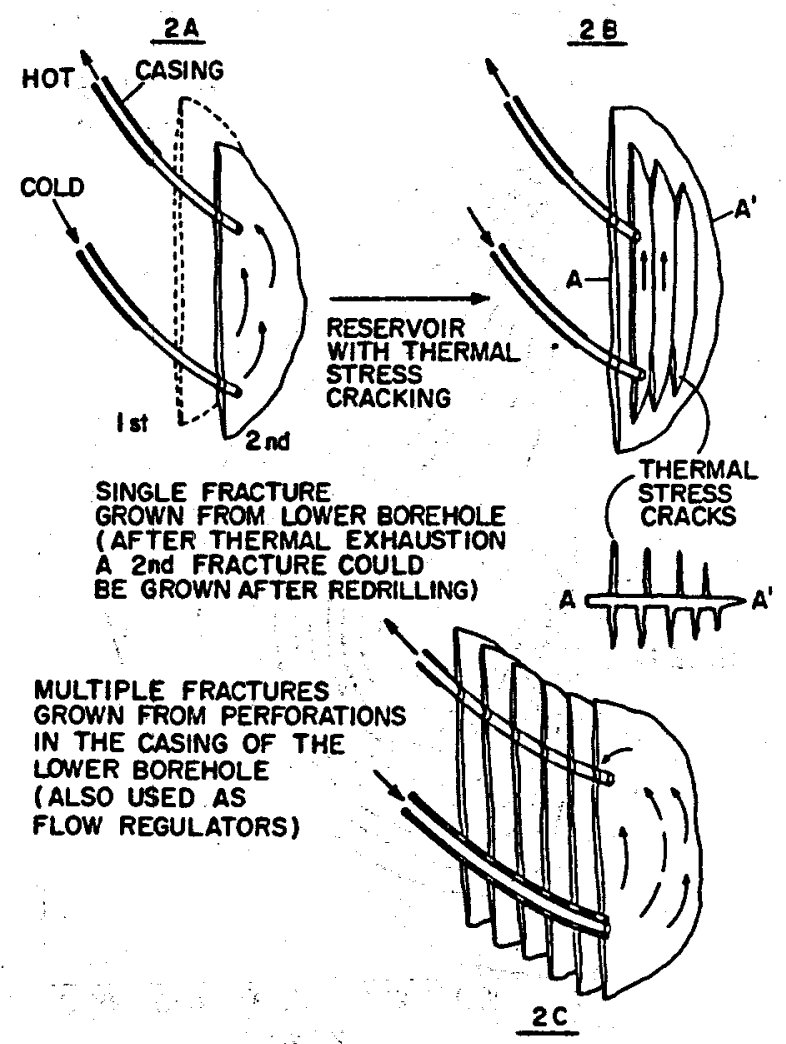

Figure A-1. Single- and multiplefracture concepts applicable to lowpermeability formations. Symmetrical views of hydraulic fracture half-planes are shown.

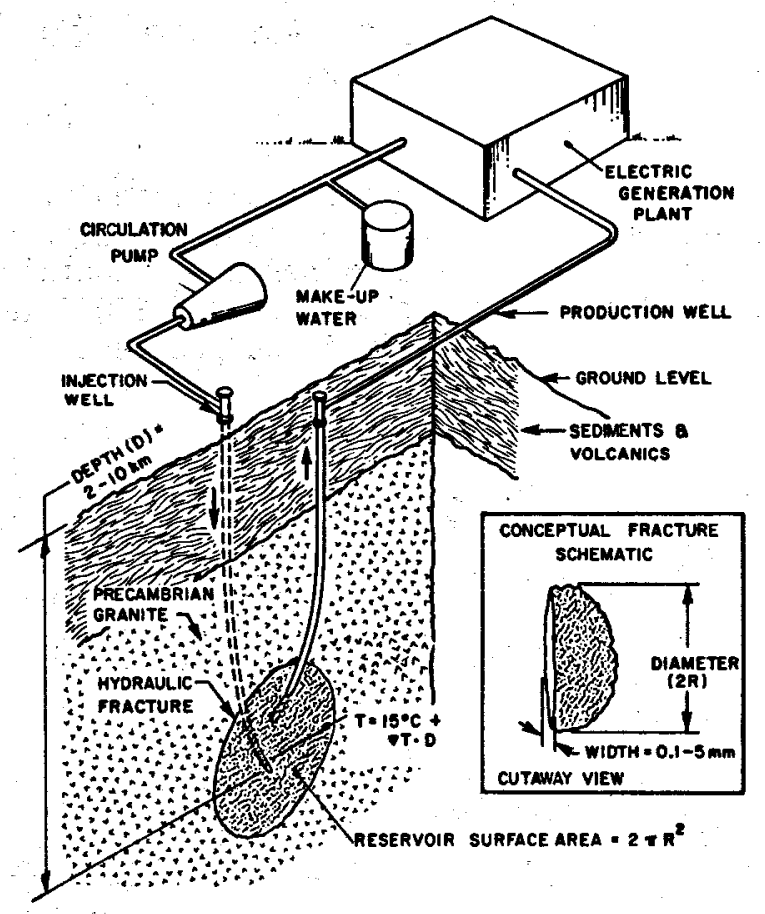

Figure A-2. Schematic representation of a conceptual hot dry rock system in lowpermeability rock. 


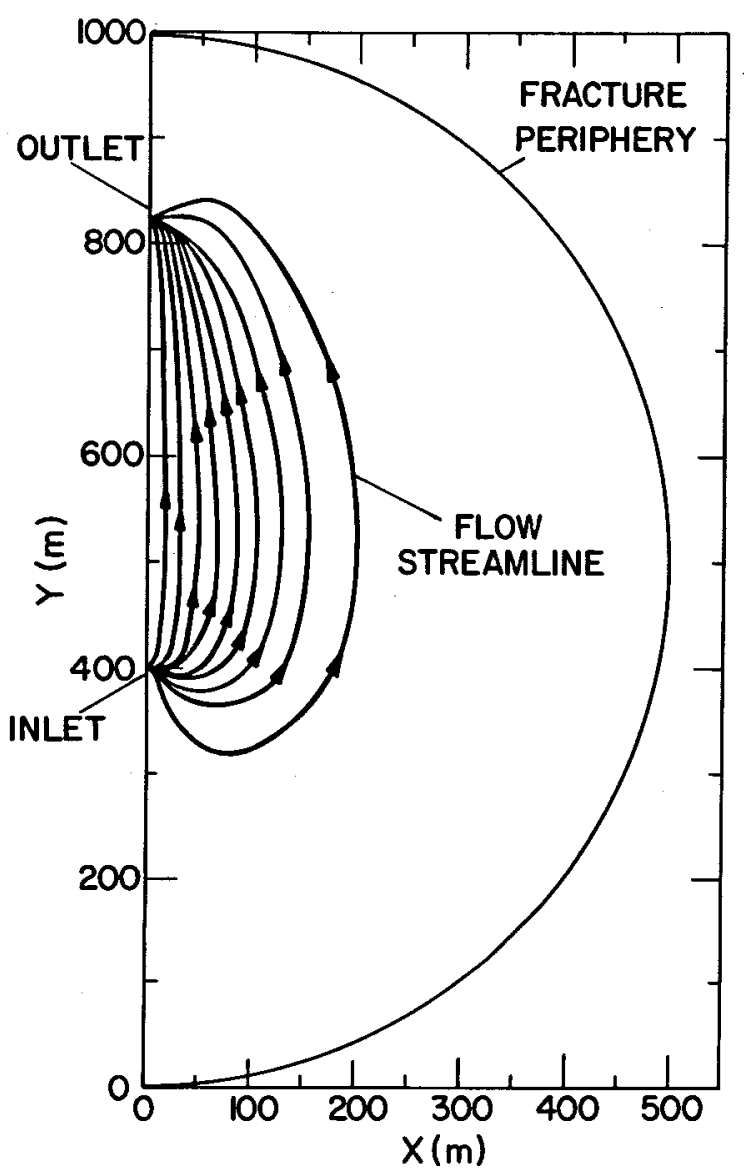

(a)

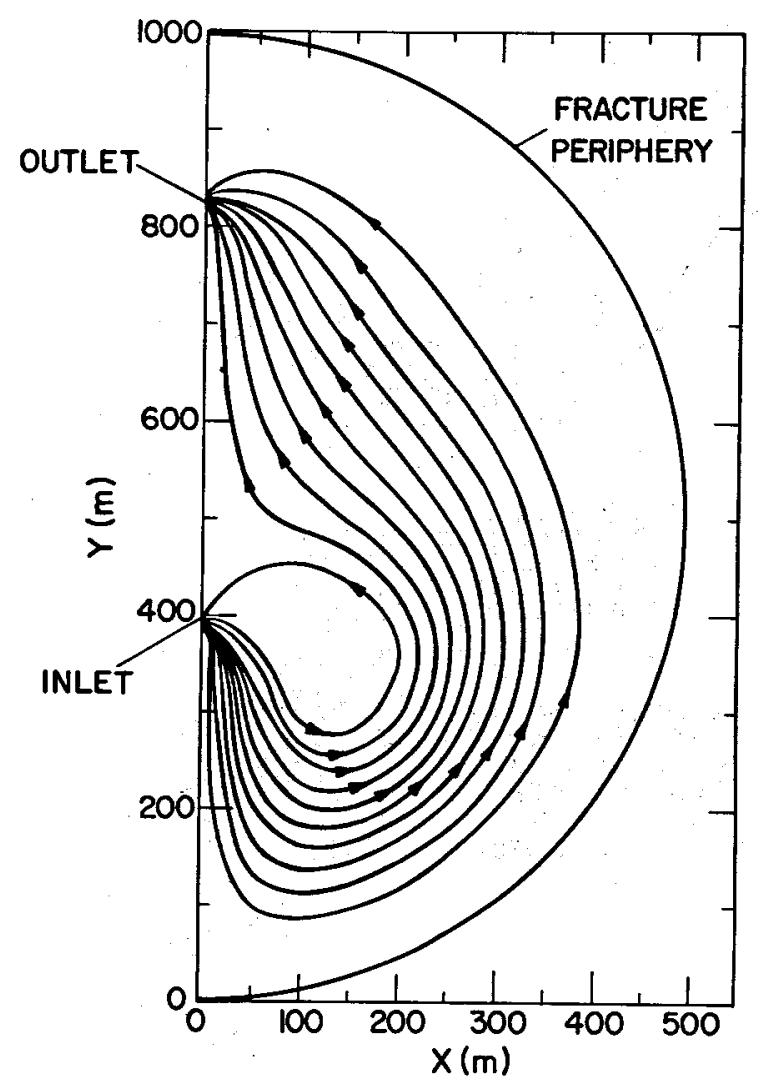

(b)

Figure A-3. Flow contours simulated by the McFarland-Murphy model (31) of heat transfer in an idealized plane circular crack of $500-\mathrm{m}$ radius and elliptical cross section. Streamlines shown contain $210 \%$ of the total $144 \mathrm{~kg} / \mathrm{s}$ flow. An initial mean rock temperature of $250^{\circ} \mathrm{C}$ was used with a gradient of $50^{\circ} \mathrm{C} / \mathrm{km}$.

(a) With buoyancy affects suppressed. (b) With buoyancy affects active. 


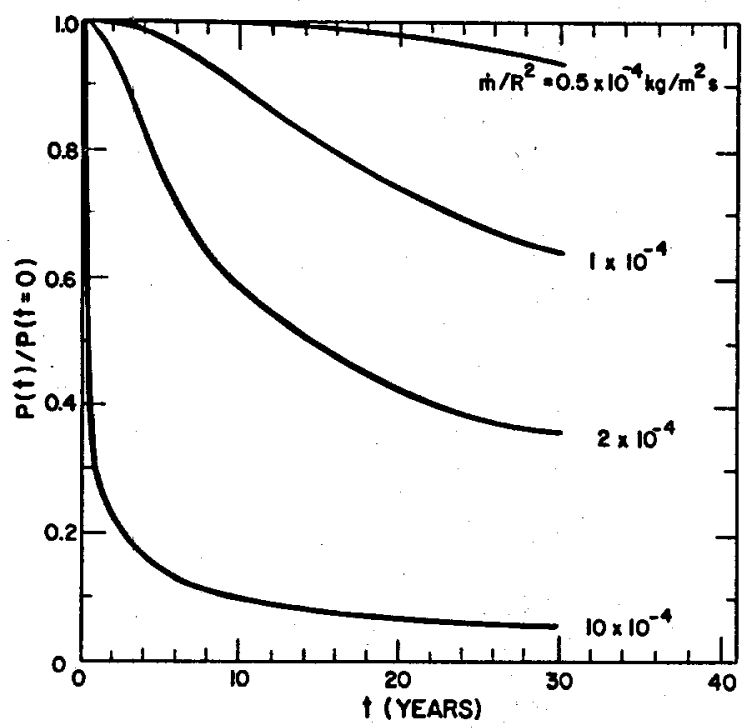

Figure A-4. Parametric power drawdown curves for a single fracture of radius $R$ with no thermal-stress cracking. 


\section{Append ix B}

METHODOLOGY FOR CALCULATING TEMPERATURE DRAWDOWN

Reservoir engineers at LASL have estimated the rate of periodic temperature drawdown in the reservoir as $\left(1-\operatorname{erf}_{t}\right)$, where the relationship in erf is a function of the periodic choice of well-flow rate $m_{t}$ and the established reservoir effective radius $S$. The effective radius depends upon the number of fractures $F$ created in the reservoir and the radius $R$ of each fracture, assuming that all fractures are identical $(\underline{6}, \underline{24}, \underline{39})$. Because total surface area over all fractures is $F \pi R^{2}$, the effective radius may be estimated by

$$
S=R \sqrt{F}
$$

In this analysis, we assumed that the horizontal spacing between adjacent fractures is sufficient to avoid themal interference over the useful lifetime of that portion of the reservoir $(\underline{6}, \underline{39})$.

The temperature of the geothermal fluid entering the plant at the end of period $t$ (that is, the beginning of period $t+1$ ) is approximated as follows.

$$
T_{t+1}=T_{t} \operatorname{erf}\left(\dot{m}_{t}, S\right) ; 0<\operatorname{erf}<1
$$

The erf calculation, an error function, specifies the percentage of temperature remaining in a system of size $S$ after a period of use, where "use" is reflected by the rate at which water is flowed through the fractures, cooling the rock's surface area. The value that enters into the error function is given below as derived-from Eq. (A-1) using the physical properties of granite and water.

$$
\operatorname{erf}\left(\frac{s^{2}}{\dot{m}_{t}} \cdot \frac{2048}{\sqrt{\tau}}\right)
$$

where $\tau$ is the time in seconds that has elapsed since drilling last occurred. When Eq. B-3 multiplies initial temperature, it effectively lowers reservoir 
temperature over time until redrilling occurs. If redrilling takes place in period $t$, all temperature losses are reinstated, so the value given by erf at the start of period $t$ is 1 .

The value of erf after each period of reservoir use clearly depends upon the reservoir size relative to the well-flow rate $s^{2} / \dot{m}_{t}$. As size of the reservoir is increased (either by creation of more cracks, cracks with larger radii, or both) relative to flow, the value of erf increases, or the rate of temperature drawdown decreases, so higher temperatures in the reservoir obtain. Likewise, if the well-flow rate is decreased relative to reservoir surface area, erf yields a larger value (Table B-1). Notice that various combinations of well-flow rates and surface areas (as specified by fracture radius and the number of fractures per reservoir) will result in the same erf value. Flowing water through the system at a rate of $100 \mathrm{~kg} / \mathrm{s}$, where the system is comprised of four fractures each with a radius of $500 \mathrm{~m}$, will result in the same rate of temperature drawdown as when the flow rate is $75 \mathrm{~kg} / \mathrm{s}$ and the reservoir has one crack with an 866-m radius (in either case, $s^{2} / m_{t}=10,000$ ).

Table B-1

EXAMPLES OF TEMPERATURE DRAWDOWN FOR $160^{\circ} \mathrm{C}$ RESOURCE $(\mathrm{m}=75 \mathrm{~kg} / \mathrm{s})$

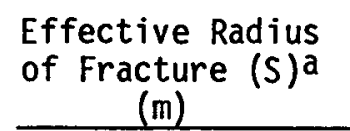

(m)

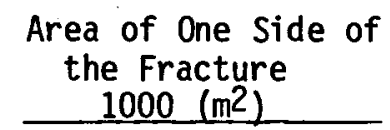

31.4

125.6

282.6

502.4

785.0

1130.4

1538.6

2009.6

2543.4

3140

1000

700

800

900

acalculated as $R \sqrt{F} ; R=300 \mathrm{~m}$ and $F$ is the number of fractures.

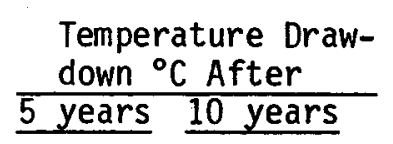

144

152

$114 \quad 152$

$116 \quad 128.7$

$91.2 \quad 110$

$68 \quad 91.9$

$48 \quad 74.9$

$22.4 \quad 45.8$

$8 \quad 26.2$

$1.6 \quad 14.3$

$0 \quad 4$ 
APPENDIX C

DEFINITION OF TERMS

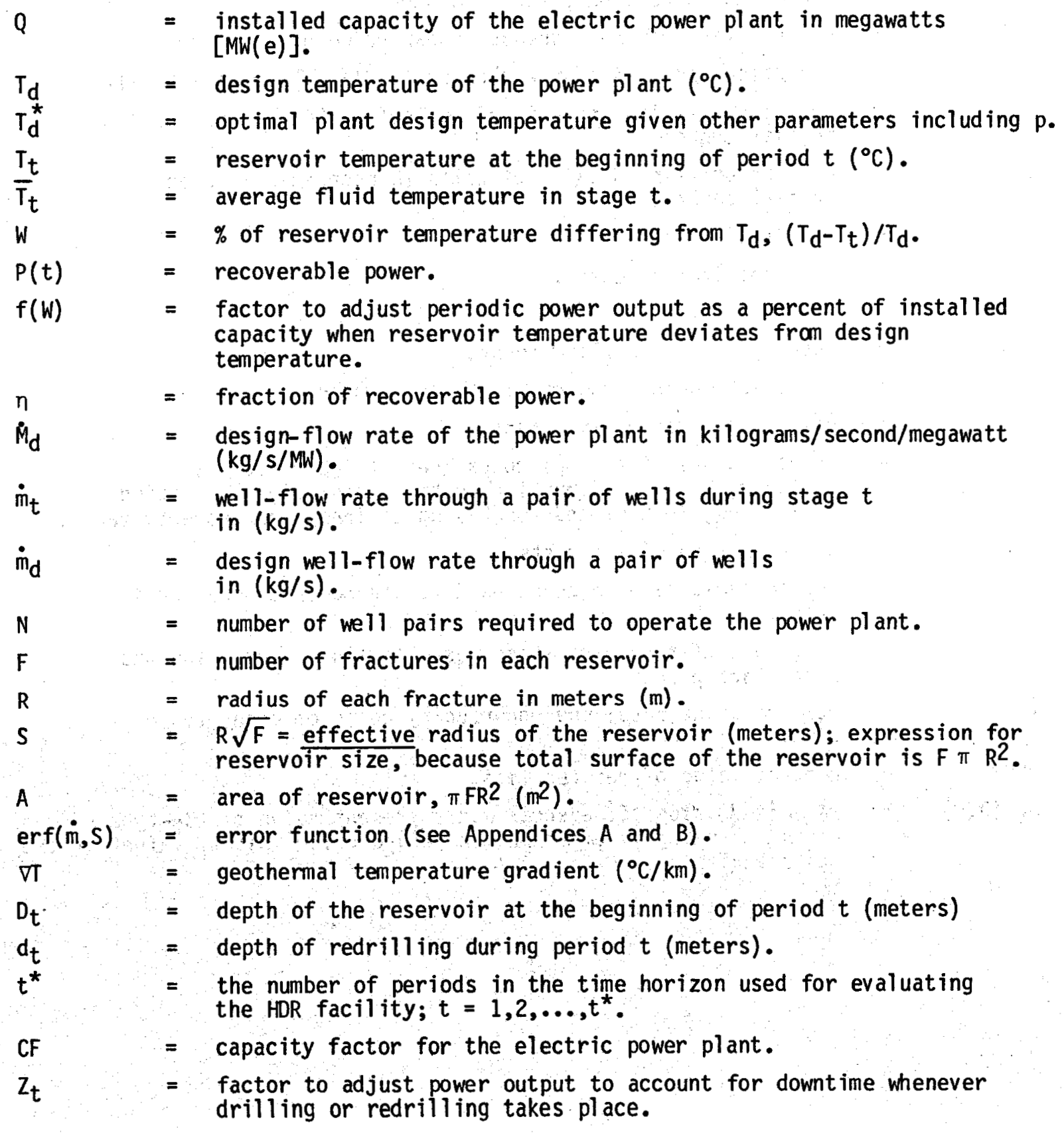




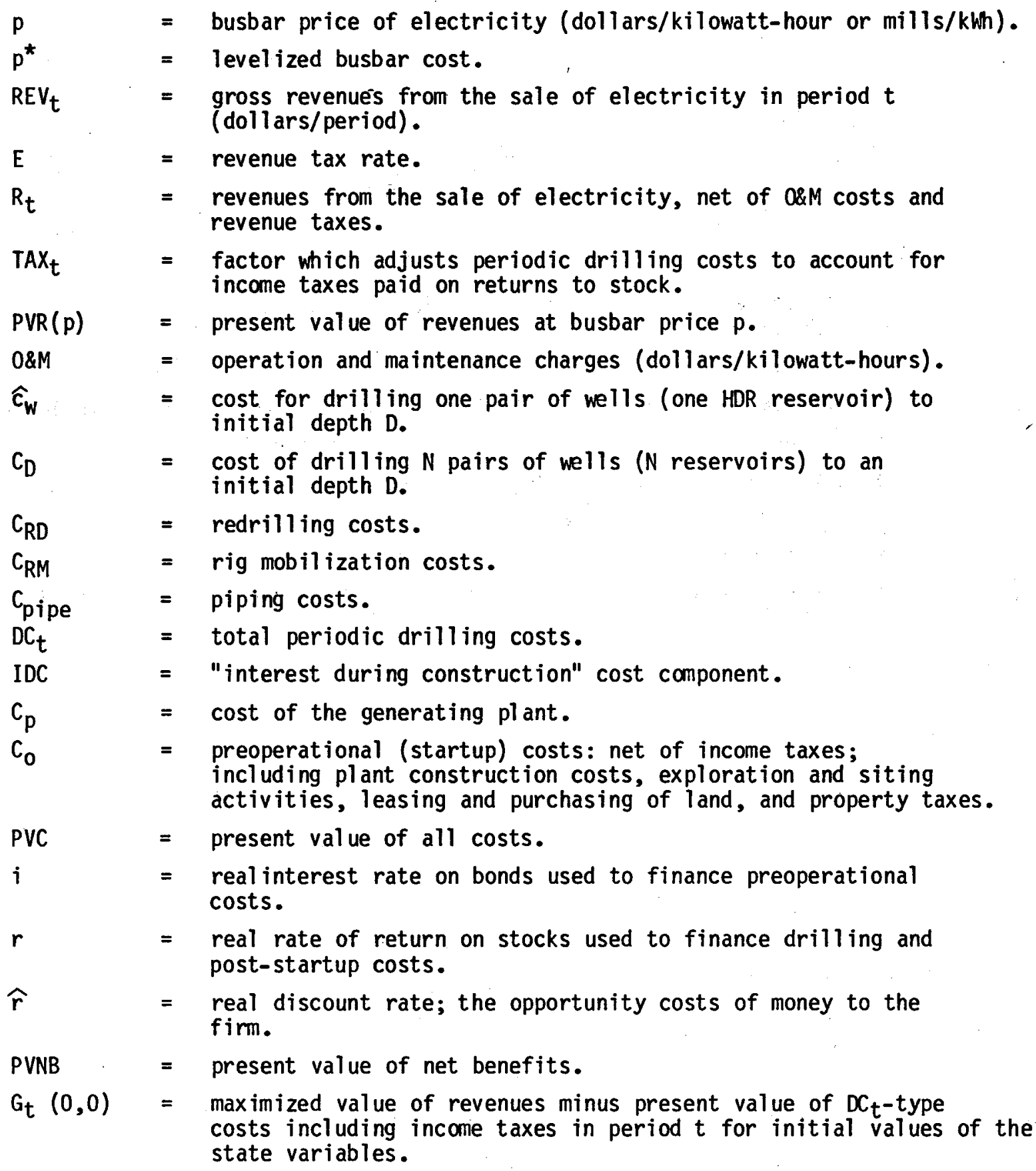

